\title{
Hard Work Beats Talent, Unless Talent Works Hard: Exploring the Relationship Between Self-Efficacy and Sales Performance
}

\author{
Mohammad Sakif Amin \\ West Virginia University, ma0096@mix.wvu.edu
}

Follow this and additional works at: https://researchrepository.wvu.edu/etd

Part of the Marketing Commons

\footnotetext{
Recommended Citation

Amin, Mohammad Sakif, "Hard Work Beats Talent, Unless Talent Works Hard: Exploring the Relationship Between Self-Efficacy and Sales Performance" (2020). Graduate Theses, Dissertations, and Problem Reports. 7585.

https://researchrepository.wvu.edu/etd/7585

This Dissertation is protected by copyright and/or related rights. It has been brought to you by the The Research Repository @ WVU with permission from the rights-holder(s). You are free to use this Dissertation in any way that is permitted by the copyright and related rights legislation that applies to your use. For other uses you must obtain permission from the rights-holder(s) directly, unless additional rights are indicated by a Creative Commons license in the record and/ or on the work itself. This Dissertation has been accepted for inclusion in WVU Graduate Theses, Dissertations, and Problem Reports collection by an authorized administrator of The Research Repository @ WVU. For more information, please contact researchrepository@mail.wvu.edu.
} 


\title{
Hard Work Beats Talent, Unless Talent Works Hard: Exploring the Relationship Between Self-Efficacy and Sales Performance
}

\author{
Mohammad Sakif Amin \\ Dissertation submitted to the John Chambers College of Business and Economics at \\ West Virginia University \\ in partial fulfillment of the requirements for the degree of \\ Doctor of Philosophy in \\ Marketing \\ Jody L. Crosno, PhD, Chair \\ Paula Fitzgerald, PhD \\ Wyatt A. Schrock, PhD \\ Xinchun Wang, PhD \\ Department of Marketing \\ Morgantown, West Virginia \\ 2020
}

Keywords: Salesperson, self-efficacy, opportunism, stress, self-control, sales performance Copyright: 2020 Mohammad Sakif Amin 


\title{
ABSTRACT \\ Hard Work Beats Talent, Unless Talent Works Hard: Exploring the Relationship Between Self-Efficacy and Sales Performance
}

\author{
Mohammad Sakif Amin
}

\begin{abstract}
Current research in sales suggests that salesperson self-efficacy, which is a person's belief about his/her ability to achieve a desired level of performance in a given task, affects sales performance positively. The logic behind this positive effect is that people who exhibit a high level of selfefficacy have increased motivation and thus exert increased efforts towards completing a task. Research in psychology, however, suggests that there can be a downside to self-efficacy. Drawing on perceptual control and ego depletion theories, this dissertation explores two possible dark side effects of self-efficacy in a sales context: (1) decreased salesperson effort engendered by complacency and (2) increased salesperson opportunism due to lower self-control.

Furthermore, this research examines role stress as a potential moderator of the relationship between self-efficacy and sales outcomes. Two studies are designed to examine the hypothesized relationships: (1) a cross-sectional survey of sales representatives in the U.S. and (2) a 2 (Selfefficacy: High v. Low) x 2 (Role Stress: High v. Low) between subjects experiment. The primary contribution of this research is identifying the processes through which self-efficacy has deleterious effects on salesperson performance.
\end{abstract}




\section{DEDICATION}

This dissertation is dedicated to my son, Uzayr Yaseen Amin, the center of my life and the greatest source of my inspiration. 


\section{ACKNOWLEDGMENTS}

I could not have completed my dissertation without the support and encouragement of several people. I am sincerely grateful to them.

First, I would like to thank my dissertation chair, Dr. Jody Crosno for her tremendous support, encouragement, and kindness. Without her feedback and mentorship, it would have been impossible for me to complete my Ph.D. She taught me how to think critically and how to be a good evaluator of my own work. Dr. Crosno and her husband Jereme are the two kindest people, who not only gave me scholarly support but also mental support when I needed it. I feel incredibly blessed to have her as my dissertation chair.

I am also very thankful to my committee members: Dr. Paula Fitzgerald, Dr. Wyatt Schrock, and Dr. Xinchun Wang. I could not have asked for a more supportive committee. Their valuable insight and regular feedback made this research possible. I want to give special thanks to Dr. Schrock for mentoring me in the first two years of my Ph.D. journey and introducing me to the world of sales research. I joined the Ph.D. program without a cohort and Dr. Schrock was a godsend who took me under his wings and helped me publish. He also helped me be a better person by teaching me how to be humble, compassionate, and conscientious.

I would like to thank all the faculty members and the fellow Ph.D. students in the Department of Marketing at West Virginia University. They have been incredibly caring and friendly.

Finally, I would like to thank my parents, Shireen Akhter and Aminul Islam; my wife, Nusrat Nabi; my brothers Shafkat and Shyiq; and my sister, Shabnaz for believing in me. I am grateful for their unconditional support. 


\section{TABLE OF CONTENTS}

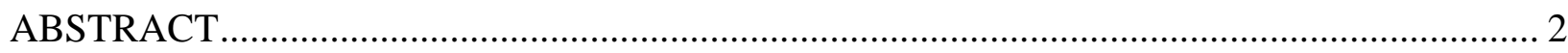

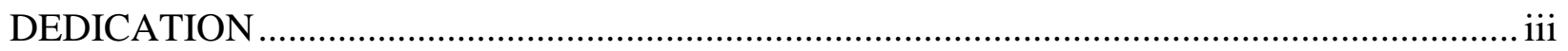

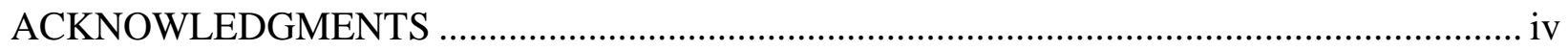

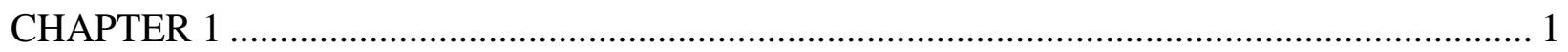

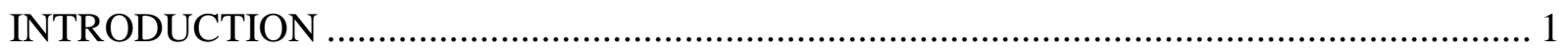

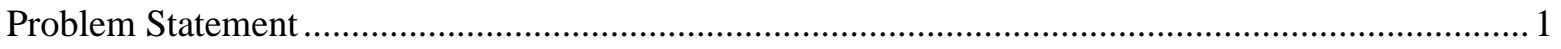

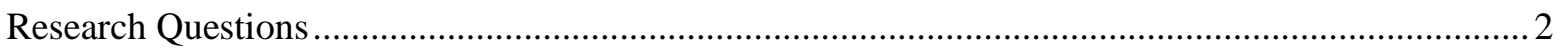

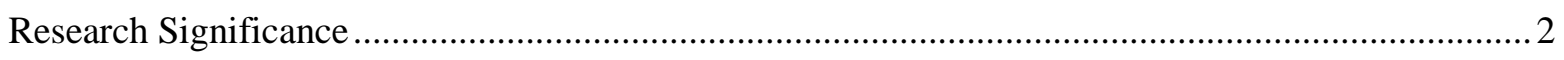

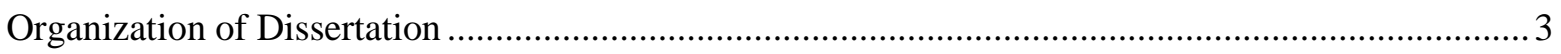

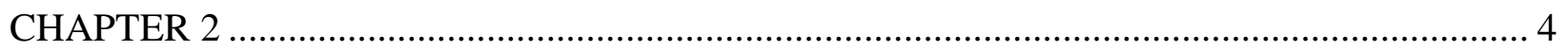

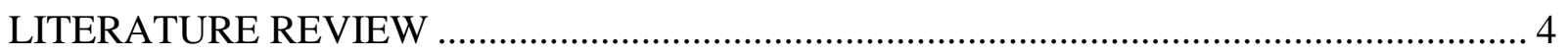

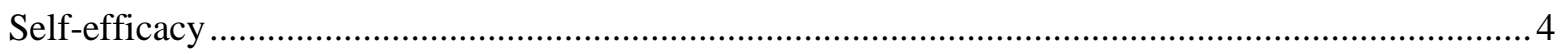

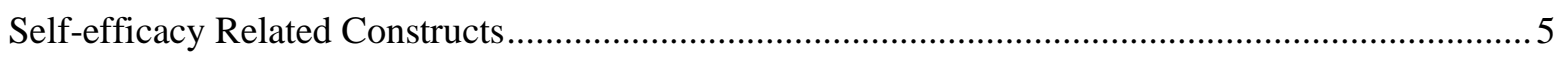

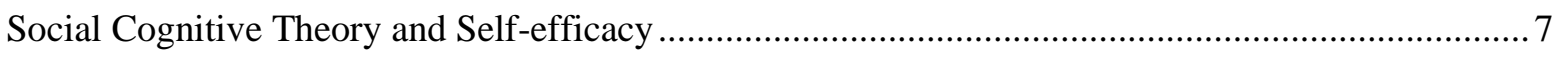

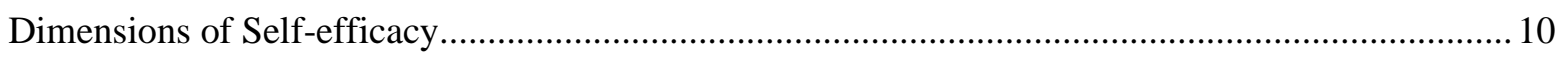

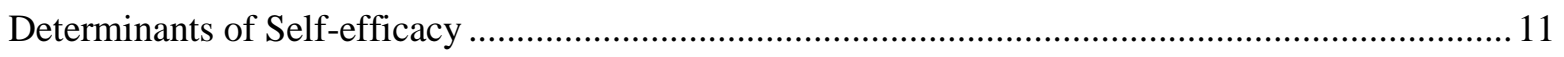

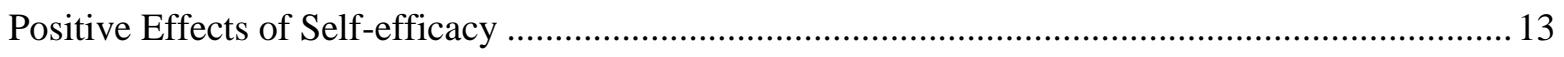

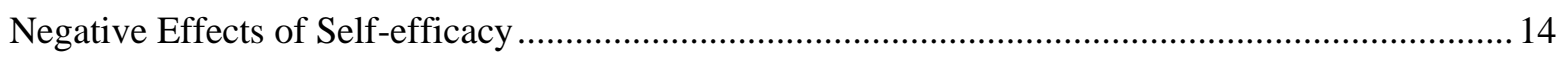

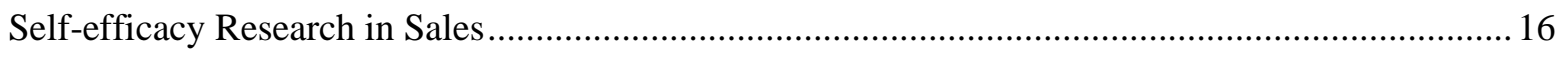

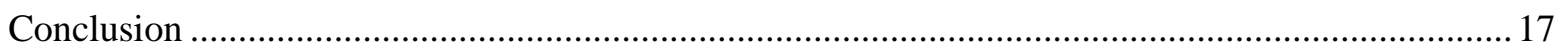

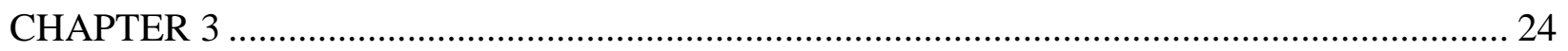

CONCEPTUAL MODEL AND HYPOTHESES .............................................................. 24

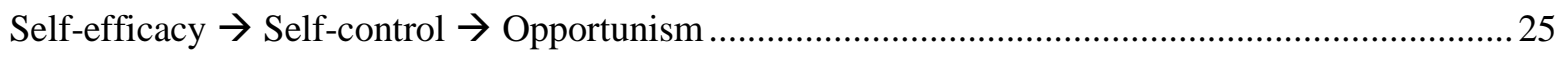

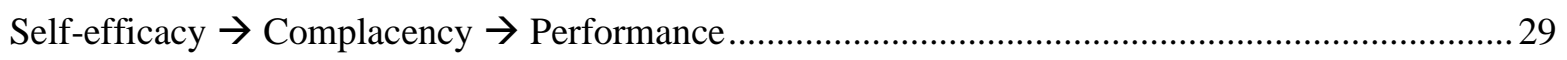

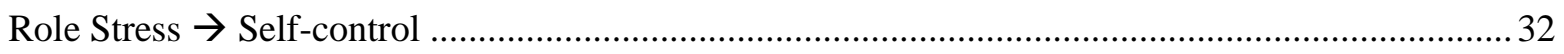

Moderating Role of Salesperson Role Stress .......................................................................... 34

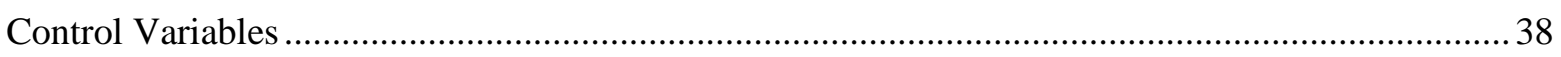

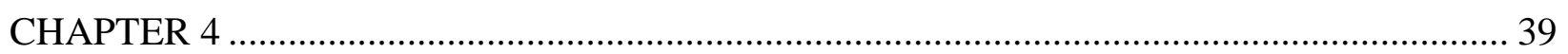

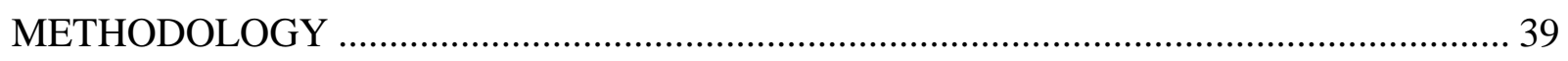

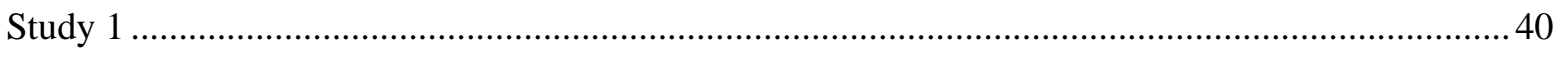

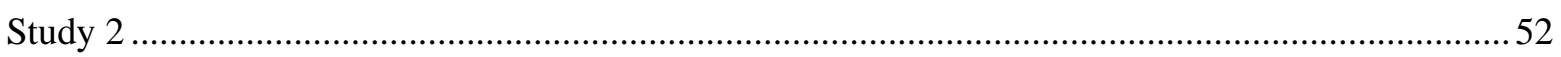




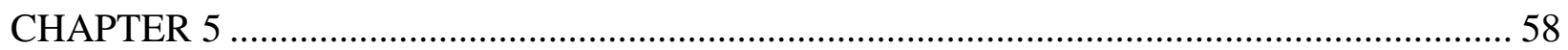

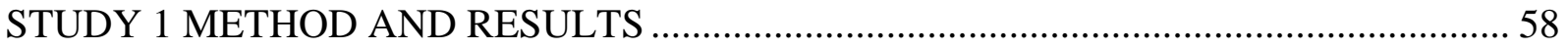

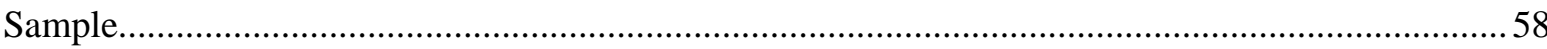

Measurement Purification and Validation …………………………………………………....59

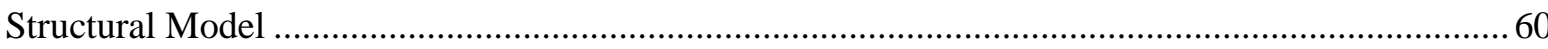

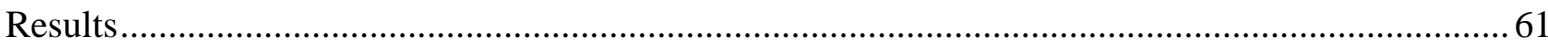

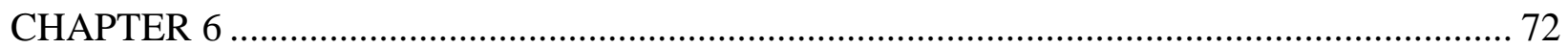

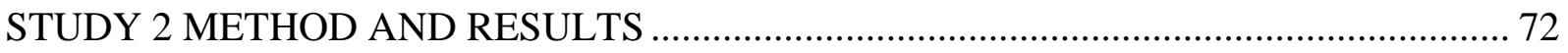

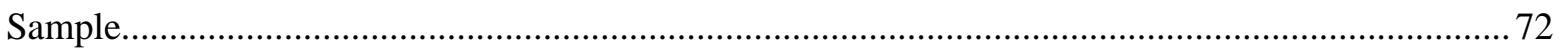

Measurement Purification and Validation ................................................................................ 72

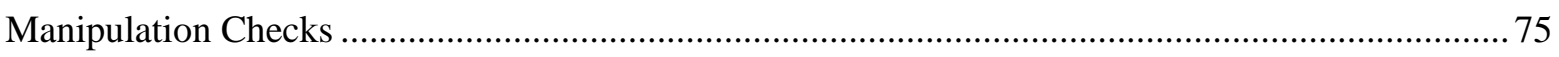

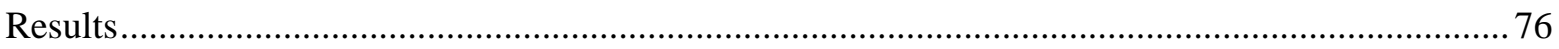

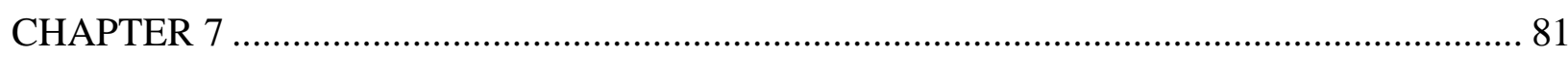

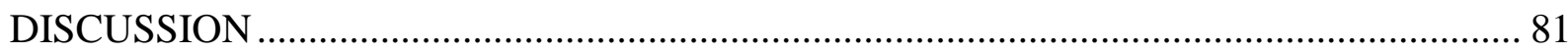

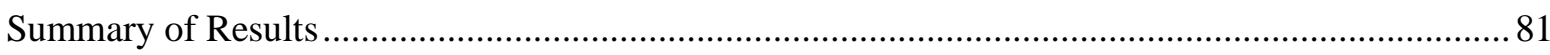

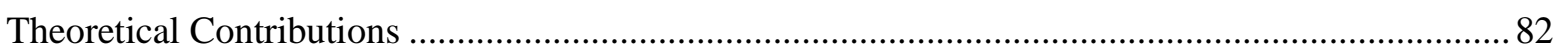

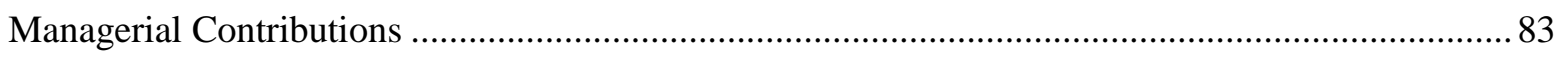

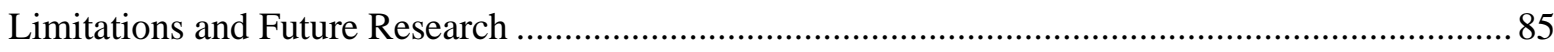

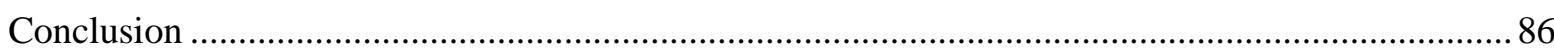

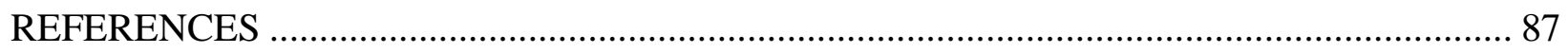

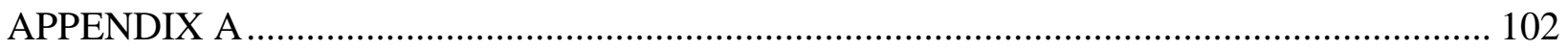

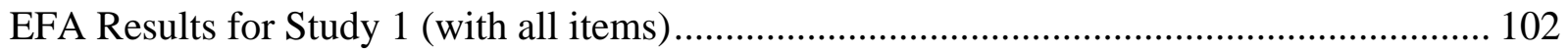

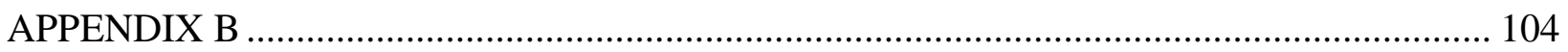

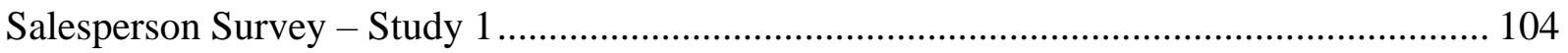

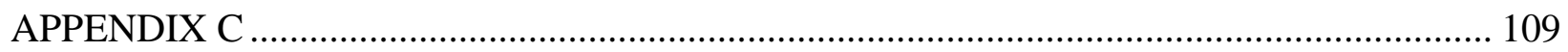

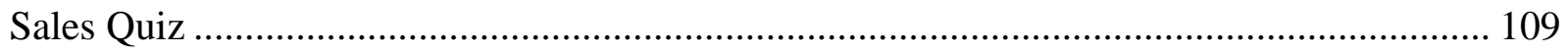

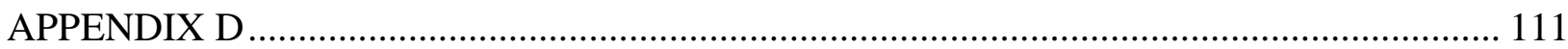

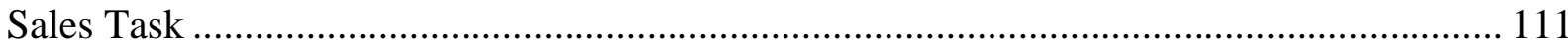

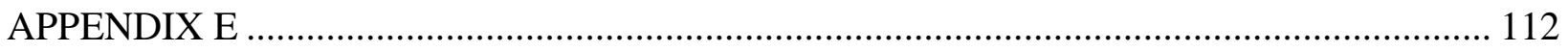

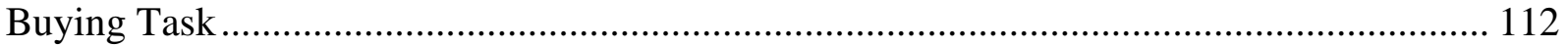

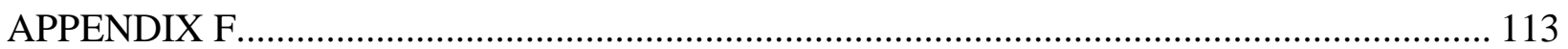

Salesperson Survey - Study 2 ……………………………………………………... 113

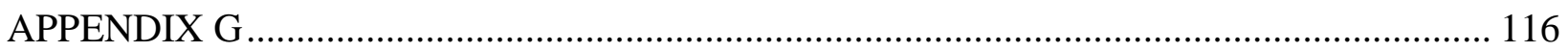

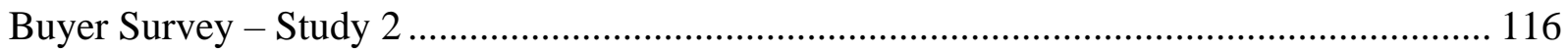




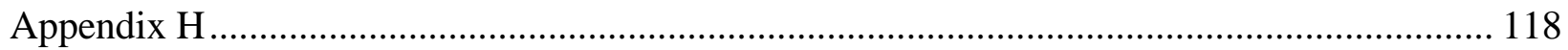

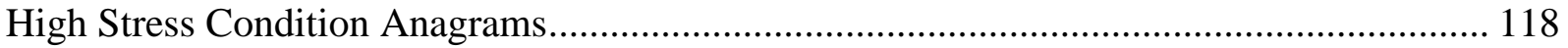

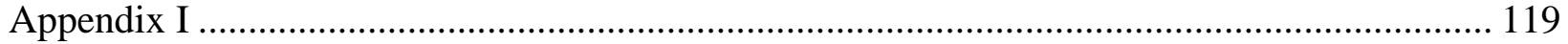

Low Stress Condition Anagrams ............................................................................... 119

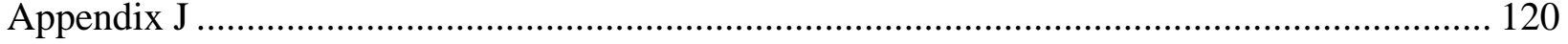

Example of Buyer-Seller Conversation in Chatplat.......................................................... 120

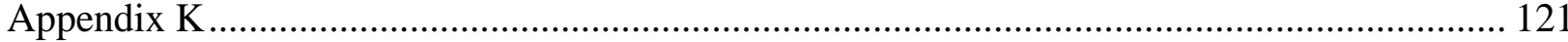

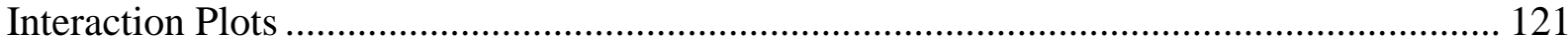

\section{LIST OF TABLES}

Table 1: Selected Research Articles in Psychology Demonstrating Potential Negative Effects of Self-efficacy ....................................................... 18

Table 2: Selected Sales Research Articles on Self-efficacy ........................ 20

Table 3: Definitions and Established Measures of Key Constructs..................... 43

Table 4: Study 1 CFA Results for the Constructs (with all items) ................... 63

Table 5: Study 1 Descriptive Statistics and Correlations for Variables (with trimmed items) ...................................................................... 70

Table 6: Study 1 Structural Equation Results ..................................... 71

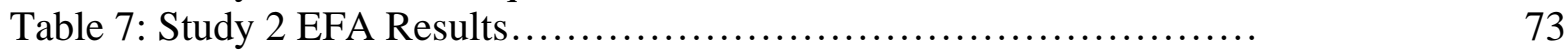

Table 8: Study 2 Variance Explained from the Exploratory Factor Analysis (with trimmed items) .............................................................. 74

Table 9: Study 2 CFA Results for Discriminant Validity Test ..................... 75

Table 10: Study 2 Descriptive Statistics and Correlations.....................................

Table 11: Summary of the Results .............................................. 80

\section{LIST OF FIGURES}

Figure 1: Hypothesized Model................................................ 25

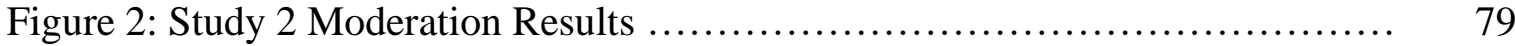




\section{CHAPTER 1}

\section{INTRODUCTION}

"What gets us into trouble is not what we don't know.

It's what we know for sure that just ain't so." Mark Twain

Problem Statement

Salesperson performance has been an important topic for marketing researchers and practitioners for a long time (Bolander et al. 2015). According to the Bureau of Labor Statistics (2018), there are close to 12 million sales jobs in the United States, and sales and sales-related occupations are expected to grow 3\% from 2016 to 2026, resulting in about 500,000 new jobs. Realizing the substantial contribution of salespeople for organizational success, numerous studies investigating factors affecting sales performance found self-efficacy, which is the belief a person has about his/her ability to achieve a desired level of performance in a given task (Wang and Netemeyer 2002), to be a significant predictor of performance (e.g., Ahearne et al. 2005; Brown et al. 1998; Frayne and Geringer 2000).

The logic behind this is that people who exhibit a high level of self-efficacy have increased motivation and thus exert increased effort towards completing a task (Sujan, Weitz, and Kumar 1994). Further, previous sales research suggests that highly efficacious salespeople are more likely to retain training materials and transfer those skills to the field (Wilson et al. 2002). Therefore, it is not surprising that companies seek to select and retain salespeople who are highly efficacious.

Research in psychology, however, has hinted that there may be a dark side to selfefficacy (e.g., Bandura and Locke 2003, Stirin Tzur et al. 2016; Vancouver et al. 2002). For example, Vancouver et al. (2002) found that self-efficacy is correlated positively with confidence 
but correlated negatively with performance. In an experimental study, Stone (1994) reported that in a cognitively complex task, high perceived self-efficacy induces overconfidence and decreased effort. Given these findings, the primary objective of this research is to examine the potential dark side of self-efficacy in a sales context.

\section{Research Questions}

Drawing on perceptual control and ego depletion theories, this dissertation explores two possible dark side effects of self-efficacy in a sales context: (1) decreased salesperson effort engendered by complacency and (2) increased salesperson opportunism due to lower selfcontrol. Furthermore, this research examines role stress as a potential moderator of the relationship between self-efficacy and sales outcomes. The specific research questions are:

1. Does self-efficacy lead to opportunism? If so, does self-control mediate this relationship?

2. Does self-efficacy hinder performance? If so, does complacency mediate this relationship?

3. Does role stress moderate the relationship between self-efficacy and sales outcomes?

\section{Research Significance}

The current research makes three key contributions to the understanding of self-efficacy in a sales context. First, to the best of our knowledge, past sales research has not examined the potential deleterious effects of self-efficacy on sales performance. Addressing this gap, the primary contribution is suggesting that a high level of salesperson self-efficacy may hinder sales performance. Perceptual control theory (Powers 1973) argues that highly efficacious people may become complacent (Stone 1994). Hence, they invest fewer resources (i.e., effort) toward the task than people with low self-efficacy (Stirin Tzur et al. 2016). Therefore, we argue that 
salesperson complacency is one reason behind this negative effect. This possible dark side of self-efficacy, has, thus far, managed to escape empirical investigation in the sales literature.

Our second contribution lies in examining a previously unexplained mechanism that clarifies how self-efficacy can lead to opportunism. Salespeople with high self-efficacy, because of their increased utilization of cognitive resources, may have limited capacity to engage in selfcontrol. Drawing on the concept of resource depletion (Baumeister 2002), we argue that this reduced self-control may engender salesperson opportunism.

Finally, we introduce the concept of "good stress" and "bad stress." We expect that the relationship between self-efficacy and opportunism and the relationship between self-efficacy and performance may change under different levels of role stress. Specifically, roles stress may prevent complacency (which we refer to as good stress) and yield higher performance, yet it may hinder self-control (which we refer to as bad stress) and yield higher opportunism. Finding support for these predictions would contribute to literature by identifying the processes through which self-efficacy may deleteriously affect salesperson performance.

\section{Organization of Dissertation}

The remainder of this dissertation is organized as follows. We begin with the literature review of self-efficacy in Chapter 2. In the literature review, we define self-efficacy and differentiate it from similar constructs, such as self-esteem, self-confidence, and competence. In this chapter, we also discuss social cognitive theory and perceptual control theory while highlighting self-efficacy research in sales and psychology. In Chapter 3, drawing on social cognitive theory, perceptual control theory, and ego depletion theory, we develop the conceptual model and hypotheses. Next, in Chapter 4, we present the methodology of two studies designed to empirically test our hypotheses. Study 1 is a cross-sectional survey of sales representatives in 
the U.S., and Study 2 is a 2 (Self-efficacy: High v. Low) x 2 (Role Stress: High v. Low) between subjects experimental study. In Chapters 5 and 6, we present the results of Study 1 and Study 2, respectively, and in Chapter 7, we conclude with a discussion of the managerial contributions and theoretical implications.

\section{CHAPTER 2}

\section{LITERATURE REVIEW}

The goal of this chapter is to review self-efficacy research. While research in marketing supports the positive influences of self-efficacy (e.g., Dixon and Schertzer 2005; Fu et al. 2010), research in psychology has found some possible negative effects of self-efficacy (e.g., Stone 1994; Vancouver et al. 2002). Together, these two research streams will provide a foundation for the conceptual model developed in Chapter 3.

The literature review is organized as follows. First, the concept of self-efficacy will be defined and differentiated from similar constructs, such as self-esteem, competence, and selfconfidence. Next, two theories that shed insight on the effects of self-efficacy-social cognitive theory and perceptual control theory_-will be discussed. In reviewing these theories, the dimensions of self-efficacy, as well its consequences will be explicated. To conclude, selfefficacy research in the sales area will be summarized, highlighting research gaps that this research intends to fill.

\section{Self-efficacy}

Self-efficacy refers to "people's judgments of their capabilities to organize and execute courses of action required to attain designated types of performances” (Bandura 1986, p. 391). Stated differently, self-efficacy reflects one's belief in his/her capability to perform a task successfully (Lunenburg 2011). Self-efficacy affects a person's effort, persistence, and choice of 
activities (Schunk 1991). It also regulates human behavior through "cognitive, motivational, affective, and decisional processes" (Vieira et al. 2018, p. 152). Self-efficacy's regulation of human behavior can be self-aiding or self-debilitating (Bandura and Jourden 1991). People with a strong sense of efficacy focus their attention on solutions to problems and exert increased efforts, whereas, people with self-doubt about their capabilities focus their attention inwardly and become self-occupied with concerns when their efforts prove unsuccessful (Bandura 1989). For instance, if an employee does not believe that he/she has the behavioral, cognitive, and/or motivational resources to perform a task successfully, that employee will most likely exert less effort and as a result, will not do well on the task (Porter et al. 2003). Self-efficacy is often used interchangeably with similar, but different constructs, such as self-esteem, self-confidence, and competence. In the next few sections, self-efficacy will be compared to and differentiated from these similar constructs.

\section{Self-efficacy Related Constructs}

The concept of self-efficacy and self-esteem are often used interchangeably, even though they refer to different things. Self-efficacy is concerned with one's belief or judgement about his/her capabilities, whereas self-esteem is concerned with one's judgement of self-worth (Bandura 1997). For instance, a person may judge himself/herself very inefficacious in a specific task (e.g., dancing) without losing self-esteem, because that person knows he/she does not have that skill set and hence, this will not create a negative feeling of perceived self-worth. Furthermore, self-esteem is stable, more along the lines of a trait; while, self-efficacy is a dynamic construct; research shows that it changes as new information and/or experiences are gained (Porter et al. 2003). Finally, self-esteem is said to be a global construct, representing a one's self-worth in various situations. In contrast, self-efficacy is task or context specific 
(Bandura 1997). For example, a student may take pride and have of high self-efficacy in mathematics but undervalue himself/herself in a social context.

Self-confidence, a widely recognized variable in sports psychology literature, is also similar, but different from perceived self-efficacy (Bandura 1997). Self-confidence refers to “one's belief that he or she can successfully execute a desired behavior" (Feltz 2007, p. 278). Self-confidence reflects the strength of belief but does not specify the level of perceived competence or the level of perceived capability (Bandura 1997; Feltz 2007). In contrast, selfefficacy includes the belief of one's capability as well as his/her the strength of that belief (Bandura 1997; Feltz 2007). Research suggests that self-confidence influences one's situation specific self-efficacy (McCormick 2001). For instance, Chemer's (1993) integrative theory of leadership posits that a confident leader can have high self-efficacy, which in turn affects his/her behavioral intentions. However, social cognitive theory suggests that self-confidence is a "catchword" in sports rather than a construct grounded in theory (Bandura 1997, p. 382). Self-efficacy may also appear similar to competence, which is defined as "feeling effective in one's ongoing interactions with the social environment and experiencing opportunities to exercise and express one's capacities" (Deci and Ryan 2002, p. 7). According to self-determination theory (SDT), competence is one of three psychological needs that humans have (with the other two being autonomy and relatedness); and this need for competence makes people seek challenges that help them maintain or build on their skills and capabilities (Deci and Ryan 2002, p. 7). Competence was first introduced by White (1959); he suggested that an important attribute of competence is "effectance" motivation. Effectance motivation refers to the need to make changes to the environment to attain successful outcomes, and it is the reason why individuals are compelled to engage in challenging tasks (Rodgers et al. 2014). Furthermore, 
effectance motivation distinguishes challenging tasks that meet the need for competence from mundane or meaningless tasks that do not meet the need for competence. Therefore, competence is more than just the "ability" to perform a task; it also includes the importance of the task (Rodgers et al. 2014, p. 528).

Unlike competence, which is a need to maintain or enhance skills, self-efficacy refers to the perception about how well one can organize and effectively orchestrate cognitive, social, and behavioral skills to serve a variety of purposes (Bandura 1997). Moreover, self-efficacy is not concerned with the number of skills a person has, but with that person's beliefs regarding what he/she can do with the skills.

Now that self-efficacy has been defined and differentiated from related constructs, two theoretical foundations will be presented. First, social cognitive theory will be reviewed, and second, perceptual control theory will be discussed.

\section{Social Cognitive Theory and Self-efficacy}

Social cognitive theory (SCT) has been widely used in explaining human behavior (Hsu et al. 2007). In SCT, the social part reflects the knowledge individuals acquire by being part of a society or the environment, and the cognitive part recognizes the influence of human thought process on motivation, attitude, and behavior (Stajkovic and Luthans 1998). Employees' knowledge is mostly generated from the environment in which they work, yet employees process available information differently based on their personal characteristics (Porter et al. 2003). SCT posits that human agency operates in a wide network of social structures, and these social structures impose constraints and offer resources for everyday operations and personal development (Bandura 1997). However, these resources and constraints do not create uniform human actions; rather each individual interprets, enforces, and adopts these resources and 
constraints differently (Burns and Dietz 2000). As such, there is a variation in knowledge gained by the individuals from the environment, and this knowledge serves as a guideline for the construction of behaviors (Bandura 1989).

SCT suggests there are three interdependent causes of psychosocial functioning (1) human behavior; (2) "personal factors in the form of cognitive, affective, and biological events"; and (3) external environment (Bandura 1999, p. 6). These three factors influence each other bidirectionally and in a dynamic manner (Bandura and Jourden 1991). It should be noted that, in these triangular and reciprocal relationships (Bandura 1986), all three factors may not exert equal influence on an individual; it varies depending on different activities and different situations (Stajkovic and Luthans 1998). In addition, each individual has a varying level of personal abilities, which is another reason why the interdependent structure mentioned above does not exert equal influence on everyone (Bandura 1997).

SCT explains the nature of this triadic, reciprocal structure through five basic human capabilities. These capabilities are: “(1) symbolizing, (2) forethought, (3) vicarious learning, (4) self-regulation, and (5) self-reflection" (Porter et al. 2003, p. 128). Individuals use these capabilities to regulate and sustain their behavior (Porter et al. 2003). Most importantly, these capabilities help explain variance in employee behaviors within the same organization (Stajkovic and Luthans 1998). The first capability, symbolizing, refers to people's ability to use symbols. Specifically, when individuals process and convert "visual experiences into cognitive models" that guide future actions, individuals are utilizing this capability (Stajkovic and Luthans 1998, p. 129). An example is processing and converting the symbol of a "flag" into patriotic behavior (Stajkovic and Luthans 1998). Symbolizing also helps to communicate complex ideas to others (Lent and Maddux 1997). 
Second, forethought operates as a motivator and a regulator of human behaviors. The ability to envision the future engenders actions that are likely to bring about the desired outcomes. Also, through forethought, individuals plan their course of action and anticipate the potential outcomes from these actions; and with this mind, they set their goals for themselves (Porter et al. 2003).

Third, vicarious learning occurs by observing the behaviors of others. It is the ability to learn without the direct experience. The observations are coded first and then used as a guideline for future actions. Vicarious learning enables employees to gain knowledge without having to learn through trial and error method of performing the task first (Porter et al. 2003). This capability helps reduce making costly mistakes when the tasks are complex and involve potentially hazardous outcomes if not conducted properly.

Fourth, self-regulatory capability explains an individual's ability to motivate and evaluate his/her own self. Self-regulatory capability suggests that individuals have the power to exercise direct control over their actions. Individuals set a personal standard before initiating a behavior. If there is an incongruity between the standard and the behavior, it activates self-evaluation, which again influences subsequent behaviors accordingly (Lent and Maddux 1997).

Lastly, self-reflective capability enables people to analyze their thoughts and experiences (Stajkovic and Luthans 1998). Managers and employees can generate new knowledge about themselves and the environment by reflecting on their experiences. Individuals can generate different types of knowledge through self-reflection, but most central to SCT is people's judgement about their own capabilities to effectively deal with the environment that affects their lives. This type of judgement is known as self-efficacy (Porter et al. 2003). 
Self-efficacy corresponds to how people's beliefs in their capabilities influence their actions to obtain desired outcomes (Stajkovic and Luthans 1998). By influencing the motivation level and the choice of behaviors, self-efficacy also contributes to the acquisition of knowledge on which skills are based (Bandura 1997). Individuals are likely to weigh and evaluate information regarding their perceived capability before initiating the efforts to perform a task. Then perceived self-efficacy determines how much effort will be exerted and for how long the effort will be maintained (Stajkovic and Luthans 1998). If employees or individuals do not believe that they have the necessary cognitive, motivational, and behavioral resources to perform a task successfully, then they will most likely exert inadequate efforts, and as a result, fail (Bandura 1989).

\section{Dimensions of Self-efficacy}

SCT suggests that self-efficacy has three dimensions with regard to performance (Stajkovic and Luthans 1998). The first dimension is magnitude, which is the level of task difficulty an individual believes he/she can accomplish (Shortridge-Baggett 2001). Different levels of difficulty pose different degrees of challenges for the successful completion of a task. The second dimension is the strength, which refers to the level of certainty (strong or weak) of an individual regarding the magnitude of his/her self-efficacy (Porter et al. 2003). Strength asks questions like "How confident am I that I can excel in my work?" and/or "How sure am I that I can be successful?" Lastly, the third dimension is the generality which is the degree to which the expectation generalizes to other situations (Lunenburg 2011). Generality asks questions like, "How sure am I that what I have learned can be applicable to a new task?" The generalizability of self-efficacy can be applied to a specific task (e.g., selling, computer programming) or to a more expanded task (e.g., organizing, managing) (Porter et al. 2003). 
The concept of self-efficacy, as presented in Bandura's (1997) social cognitive theory, is narrow in scope and task-specific (Gardner and Pierce 1998). It is also considered a malleable state, which is much more variable than the personality traits (e.g., big five personality traits, such as extroversion) (Chen et al. 2004). However, some researchers suggest that the taskspecific self-efficacy may transform into global self-efficacy (and become a more trait-like belief), through successes and failures (Choi 2005). This global efficacy belief is referred to as generalized self-efficacy (Choi 2005). Generalized self-efficacy explains individual differences when someone faces a broadly defined task, while specific self-efficacy explains individual differences when someone faces a clearly and narrowly defined task (Choi 2005).

\section{Determinants of Self-efficacy}

Bandura (1986) identified four major determinants of self-efficacy: (1) enactive mastery, (2) vicarious experience, (3) verbal persuasion and (4) physiological and emotional arousal. The first determinant, enactive mastery, is the most influential source of enhancing self-efficacy and it involves the process of learning by succeeding in a challenging task (Wood and Bandura 1989). Successfully accomplishing a task raises mastery expectations, whereas repeated failures lower this expectation, especially when failures occur before a strong sense of efficacy is established. Once a strong sense of efficacy is developed, "the negative impact of occasional failure is likely to be reduced" (Bandura 1977, p. 195). Therefore, the impact of failure on selfefficacy is partly determined by the timing in which failures occur (Shortridge-Baggett 2001). Once a person is convinced that he/she has what it takes to succeed, that person is more likely to persevere during hardship and recover from setbacks.

The second major source of self-efficacy is vicarious experience which is simply learning by observing others (i.e., models) performing a task. Knowledge about one's own capability is 
often derived from the social environment where he/she operates; hence, acquiring knowledge by modeling others who work in the same organization becomes an important source of selfefficacy (Maddux 2016). As stated by Stajkovic and Luthans (1998, p. 71) "the higher the perceived similarity between the model and the observer in terms of personal characteristics that are assumed to be relevant to performance accomplishment, the greater the model's influence on observers' learning." An example of vicarious learning is the training provided to the employees in an organization. During training, the employees observe the trainer as he/she explains and performs a task, and then the trainees (i.e., employees) try to replicate the task. Successfully modeling the trainer's performance persuades the employees that they too can do the job, which enhances their self-efficacy about their capability (Stajkovic and Luthans 1998). Vicarious experience is also related to vicarious learning capability discussed in the previous section. Individuals have different levels of this capability, and therefore, people with high vicarious learning capability can generate more self-efficacy through vicarious experience than people with low vicarious learning capability (Bandura 1977).

The third determinant, verbal persuasion, is another source of enhancing people's belief that they have the capability to achieve success. When an employee is verbally persuaded that he/she possesses the skills to do a certain task by someone the employee trusts and sees as competent, he/she exerts greater efforts, particularly when difficulties arise (Stajkovic and Luthans 1998). The purpose of this persuasion is to enhance a person's belief that he/she has what it takes rather than their actual ability (Stajkovic and Luthans 1998).

The fourth determinant of self-efficacy is physiological and emotional arousal. When judging their own abilities, individuals use information regarding physical and emotional situations. Tension, anxiety, and depression are indicators of emotional deficiency, whereas 
fatigue and pain are indicators of low physical efficacy (Shortridge-Baggett 2001). Since adverse arousal (e.g., stress) can debilitate performance, employees are less likely to expect success when they are agitated and stressed than when they are not (Porter et al. 2003). Different mood states also affect a person's efficacy judgement; hence, self-efficacy can be influenced by stress levels, physical status, and/or (mis)comprehension of bodily states (Bandura 1997). Furthermore, when individuals experience positive physical and/or emotional arousal (e.g., feeling at ease with the task in hand, enthusiasm), they view it as an energizing factor which in turn creates a higher perception of self-efficacy (Stajkovic and Luthans 1998).

\section{Positive Effects of Self-efficacy}

In this section, the positive effects of self-efficacy will be discussed. Self-efficacy influences an individual's motivation and decisions regarding how much effort to put forth while completing a task (Hsu et al. 2007). Research suggests that people with high self-efficacy construct success scenarios in their mind, and that these scenarios work as a guideline for performance (Bandura 1989). Furthermore, individuals who have strong belief in their capabilities view difficult tasks differently; rather than viewing these tasks as obstacles to be avoided, they view these tasks as challenges (Bandura 1997). This type of approach increases interest and involvement in any task. Also, individuals with high self-efficacy tend to attribute failures to lack of effort, which reflects a success orientation (Bandura 1997).

Self-efficacy also affects thought patterns, which in turn affects performance (Bandura 1989). People with high self-efficacy set challenging goals, work hard, and actively look for effective strategies to complete a task successfully (McCormick 2011). This leads to superior work performance (Bandura 1989). In short, self-efficacy influences goals, motivation, efforts, choices and persistence (Gist and Mitchell 1992), which in turn, should enhance performance. 
In line with this reasoning, empirical research by and large reports positive effects of selfefficacy (see Table 1). Bandura and Locke (2003) reviewed nine meta-analyses that examine various outcomes of self-efficacy, including work performance (e.g., Boyer et al. 2000; Sadri and Robertson 1993), psychosocial functioning (e.g., Holden et al. 1990), academic achievement (e.g., Multon et al. 1991), athletic performance (e.g., Moritz et al. 2000), and health-related outcomes (e.g., Holden 1992). Even though moderators affected the strength of the relationships, the relationships between self-efficacy and these outcomes were positive. Similarly, Stakovic and Luthans' (1998) meta-analysis reports a positive correlation $(r=.38)$ between self-efficacy and performance. These meta-analyses collectively provide evidence that self-efficacy in general has a significant, positive impact on performance and performance-related outcomes.

\section{Negative Effects of Self-efficacy}

While extant research predominantly reports positive effects of self-efficacy, research in psychology suggests that there can be a downside. Bandura (1997), for example, argues that selfefficacy may affect motivation negatively. In a high self-efficacious condition, there is an absence of self-doubt; therefore, the individual feels adequately prepared for a challenge (Bandura and Locke 2003). As a result, the individual is less motivated to prepare than if his/her self-efficacy were lower (Bandura and Locke 2003). Simply stated, individuals with high selfefficacy may fail to prepare sufficiently for a task, especially if it is based on a mistaken sense of self-efficacy (Vancouver and Kendall 2006). This lack of preparation could hamper performance and goal achievement. Previous research suggests that in cognitively complex tasks, individuals with a high self-efficacy feel overconfident, which, in turn, induces complacency and less effort (Stone 1994). Further, the resilient orientation of self-efficacy (i.e., the belief that one has what it takes to succeed in the face of failures and setbacks) may also lead to questionable behavior 
(Bandura and Locke 2003). For example, managers who have high perceived self-efficacy may be more likely to engage in questionable behaviors than those with low self-efficacy to maintain their performance levels (and hence, their perceived self-efficacy).

Like social cognitive theory, perceptual control theory (Powers 1973) suggests that there may be a negative effect of self-efficacy on performance. Perceptual control theory focuses on the comparisons between desired goal state (e.g., performance level) and the perceptions of one's current state (Vancouver and Kendall 2006). According to this theory, when a person's selfefficacy is high, he/she is expected to invest fewer resources (e.g., prepare less, study less) because the discrepancy between the desired goal state and the perception of current state is smaller compared to when self-efficacy is relatively low (Vancouver et al. 2002). In contrast, when the perceived discrepancy between the desired state and the current state is high, more effort is required to close this gap, and, hence, the motivation is high (Vancouver et al. 2002). This line of reasoning suggests that high self-efficacy diminishes the difference between the current state and the desired state (i.e., goal), induces complacency, and decreases motivation, which ultimately may hinder performance (Stirin Tzur et al. 2016).

Using the lens of perceptual control theory and a within-subject experimental design, Vancouver et al. (2001) found that there is a negative relationship between high self-efficacy and performance. Stone (1994) showed that individuals with high self-efficacy are overconfident and display lack of motivation to reach their goals. Stirin Tzur et al. (2016, p. 362) reported that "when reward was high, the effect of self-efficacy on performance was positive, whereas when reward was low, the effect of self-efficacy on performance was negative." In a recent study, Vancouver and Purl (2017) found that self-efficacy is related positively to performance when information is not ambiguous. However, self-efficacy is related negatively to performance when 
information is ambiguous. Additional examples of empirical research demonstrating the potential negative effects of self-efficacy are reported in Table 1.

\section{Self-efficacy Research in Sales}

Despite the potential negative effects of self-efficacy, sales research consistently reports positive effects. For example, in all the sales research studies reviewed, self-efficacy is reported to have a positive relationship with performance (see Table 2). Empirical evidence also suggests that self-efficacy can affect performance indirectly through effort (e.g., Fu et al. 2017; Krishnan, Netemeyer, and Boles 2002). High self-efficacious salespeople tend to work harder, smarter, and show higher intentions to sell new products than low self-efficacious salespeople (Fu et al. 2010; Sujan, Weitz, \& Kumar 1994). They also tend to be more customer-oriented (compared to low self-efficacious salespeople), which results in higher customer satisfaction, customer loyalty, and positive word-of-mouth (e.g., Groza and Groza 2018; Vieira et al. 2018). In short, salespeople with high self-efficacy perform better than those with low self-efficacy (Fu et al. 2010).

Highly self-efficacious salespeople may also be more resilient; they are optimistic, capable of handling failure, and internally motivated to perform (e.g., Dixon and Schertzer 2005; Fu et al. 2017). They also show higher adaptability and readiness than low self-efficacious salespeople (Ahearne et al. 2005). Mulki et al. (2008) found that salespeople who have high selfefficacy are less stressed by role overload because self-efficacy has been found to be related negatively to role conflict and role ambiguity, which are two sources of stress. Further, a recent study shows that high self-efficacious salespeople feel that their job is more secure and, therefore, they have lower intentions to quit compared to low self-efficacious salespeople (Sunder et al. 2017). 
Lastly, several studies have reported that salesperson self-efficacy is correlated positively with employee characteristics such as competitiveness, conscientiousness, extraversion, and selfesteem—characteristics that bolster salesperson performance (e.g., Brown et al. 1998;

Panagopoulos and Ogilvie 2015; Yang et al. 2011). In short, sales research demonstrates that high self-efficacy provides numerous benefits to salespeople.

\section{Conclusion}

This dissertation aims to understand the mechanisms through which self-efficacy affects salesperson performance. This chapter provides a theoretical background for this study. The first section of this chapter defines self-efficacy and differentiates it from similar constructs, such as self-esteem, competence, and self-confidence.

Also explained in this chapter are different dimensions and determinants of self-efficacy. In reviewing the literature, we found that while the sales literature consistently reports the positive effects of self-efficacy, psychology literature highlights some potential downsides of self-efficacy. Finally, two theories related to self-efficacy—social cognitive theory and perceptual control theory - are discussed in this chapter. These theories provide a foundation to understanding the conflicting findings in extant research.

In the next chapter, we will present the conceptual model and hypotheses and delve into the mechanisms that may lead to the dark side effects of self-efficacy. 
Table 1: Select Research Articles in Psychology Demonstrating Potential Negative Effects of Self-efficacy

\begin{tabular}{|c|c|c|c|c|}
\hline Study & Author(s) & Theory & Method & Key takeaway/correlations \\
\hline 1 & Vancouver et al. (2002) & Perceptual control theory & $\begin{array}{l}\text { Experiment } \\
\text { (repeated } \\
\text { measures design) }\end{array}$ & $\begin{array}{l}\text { Self-efficacy is positively correlated with } \\
\text { confidence and logical errors, but negatively } \\
\text { correlated with performance. }\end{array}$ \\
\hline 2 & $\begin{array}{l}\text { Vancouver and Purl } \\
\text { (2017) }\end{array}$ & $\begin{array}{l}\text { Perceptual control theory } \\
\text { and social cognitive theory }\end{array}$ & Simulation & $\begin{array}{l}\text { Self-efficacy is positively related to } \\
\text { performance when information is not } \\
\text { ambiguous. However, Self-efficacy is } \\
\text { negatively related to performance when } \\
\text { information is ambiguous. }\end{array}$ \\
\hline 3 & Stone (1994) & Social cognitive theory & Experiment & $\begin{array}{l}\text { In a cognitively complex task, high } \\
\text { perceived self-efficacy induces } \\
\text { overconfidence, but did not increase effort, } \\
\text { attention to strategy and performance. } \\
\text { Furthermore, high self-efficacious persons }\end{array}$ \\
\hline
\end{tabular}


contributed fewer resources toward the task

compared to low self- efficacious persons.

$4 \quad$ Bandura and Jourden

(1991)

5

Stirin Tzur et al. (2016)

Schmidt and DeShon

(2010)
Social cognitive theory

Experiment

Subjects who achieved success easily

developed high level of self-efficacy, but

also developed complacent self-assurance.

This reduced the motivation and effort

needed to achieve high performance.

Experiment When reward is high, the effect of self-

efficacy on performance is positive, whereas

when reward is low, the effect of self-

efficacy on performance is negative.

Social cognitive theory

Experiment

(within-subject)
Self-efficacy is positively related to effort

and performance when performance

ambiguity is low. However, self-efficacy is negatively related to effort and performance when performance ambiguity is high. 
Table 2: Selected Sales Research Articles on Self-efficacy

\begin{tabular}{|c|c|c|c|c|c|}
\hline Study & Author(s) & Theoretical Lens & Focal/Control & Method & Correlations with self-efficacy \\
\hline 1 & $\begin{array}{l}\text { Ahearne et al. } \\
(2005)\end{array}$ & $\begin{array}{l}\text { Social cognitive } \\
\text { theory }\end{array}$ & Focal & Survey & $\begin{array}{l}\text { Leadership empowerment behavior }(+) \text {, employee readiness } \\
(+) \text {, performance }(+) \text {, adaptability }(+) \text {, customer Satisfaction } \\
(+)\end{array}$ \\
\hline 2 & $\begin{array}{l}\text { Barling and } \\
\text { Beattie (1983) }\end{array}$ & $\begin{array}{l}\text { Social cognitive } \\
\text { theory }\end{array}$ & Focal & Survey & Sales performance $(+)$ \\
\hline 3 & $\begin{array}{l}\text { Brown et al. } \\
(1998)\end{array}$ & Goal setting theory & Control & Survey & $\begin{array}{l}\text { Job involvement }(+) \text {, locus of control }(+) \text {, conscientiousness } \\
(+) \text {, performance }(+) \text {, trait competitiveness }(+)\end{array}$ \\
\hline 4 & $\begin{array}{l}\text { Brown, Jones } \\
\text { and Leigh } \\
(2005)\end{array}$ & $\begin{array}{l}\text { No theory } \\
\text { mentioned }\end{array}$ & Focal & Survey & Previous performance $(+)$, goal level $(+)$, performance $(+)$ \\
\hline 5 & $\begin{array}{l}\text { Brown, } \\
\text { Ganesan and } \\
\text { Challagalla } \\
(2001)\end{array}$ & $\begin{array}{l}\text { No theory } \\
\text { mentioned }\end{array}$ & Focal & Survey & Role clarity $(+)$, self-generated feedback $(+)$, performance $(+)$ \\
\hline 6 & $\begin{array}{l}\text { Chelariu and } \\
\text { Stump (2011) }\end{array}$ & Attribution theory & Focal & Survey & Work-family conflict (-), job stress (-), turnover intentions (-) \\
\hline 7 & $\begin{array}{l}\text { Dixon and } \\
\text { Schertzer } \\
(2005)\end{array}$ & Attribution Theory & Focal & Survey & $\begin{array}{l}\text { Optimism }(+) \text {, internal attribution following a failure }(+), \\
\text { intention to increase effort following a failure }(+) \text {, intention to } \\
\text { change strategy following a failure (ns), intention to seek } \\
\text { assistance a failure (ns) }\end{array}$ \\
\hline 8 & $\begin{array}{l}\text { Frayne and } \\
\text { Geringer } \\
(2000)\end{array}$ & $\begin{array}{l}\text { Social cognitive } \\
\text { theory }\end{array}$ & Focal & $\begin{array}{l}\text { Field } \\
\text { experiment }\end{array}$ & $\begin{array}{l}\text { Performance }(+) \text {, policies sold }(+) \text {, calls made }(+) \text {, revenue } \\
\text { generated }(+)\end{array}$ \\
\hline 9 & $\begin{array}{l}\text { Fournier et al. } \\
(2010)\end{array}$ & $\begin{array}{l}\text { Social cognitive } \\
\text { theory }\end{array}$ & Focal & Survey & Person-career fit $(+)$, job satisfaction $(+)$, performance $(+)$ \\
\hline 10 & Fu et al. (2010) & $\begin{array}{l}\text { Theory of planned } \\
\text { behavior }\end{array}$ & Focal & Survey & $\begin{array}{l}\text { Intention to sell new product }(+) \text {, attitude toward selling new } \\
\text { product }(+) \text {, subjective norm toward selling new product }(+) \text {, }\end{array}$ \\
\hline
\end{tabular}


Fu et al. (2017) Theory of planned Focal behavior

Groza and

Groza (2018)

Jaramillo and

Mulki (2008)

$$
\text { (2007) }
$$

Krishnan,

Netemeyer, and

Boles (2002)

Lee and Gillen

(1989)

Mayo and
Mallin (2010)

Conservation of

resource theory

and attribution

theory

18 Mallin and

Mayo (2006)

19

Mathieu,

Ahearne and

taylor (2007)

\section{Conservation of}

Resource Theory

Social cognitive

theory

Menguc et al.

(2017)

Job Demands-
Resources (JD-S)
Model

quota $(+)$, tenure $(+)$, cumulative sales $(+)$, customer newnes

$(-)$

Survey Sales effort (+), intrinsic motivation $(+)$, extrinsic motivation $(\mathrm{ns})$, brand attitude $(+)$, brand commitment $(+)$, experience $(+)$

Survey Regulatory knowledge (+), job satisfaction (+), customer orientation $(+)$, sales performance $(+)$

Survey Job performance $(+)$, effort level $(+)$, effort direction $(+)$, intrinsic motivation $(+)$

Survey Job performance $(+)$, job satisfaction $(+)$, Organizational commitment $(+)$

Survey $\quad$ Effort $(+)$, performance $(+)$, competitiveness $(+)$

Survey Type A behavior (ns), performance quality (ns), performance quantity (ns)

Survey Lack of effort (-), lack of ability (-), internal locus of control

$(+)$

Survey Internal locus of control (+), lack of effort (-), lack of ability (-)

Survey Technology self-efficacy with work experience (-), technology self-efficacy with use of sales technology $(+)$

Survey Employee education (+), employee tenure (ns), job engagement $(+)$, job autonomy $(+)$, customer service performance $(+)$, job satisfaction $(+)$, performance focused climate $(+)$, service failure recovery climate (ns) 


\begin{tabular}{|c|c|c|c|c|c|}
\hline 21 & $\begin{array}{l}\text { Mullins et al. } \\
\text { (2014) }\end{array}$ & $\begin{array}{l}\text { Empathic accuracy } \\
\text { approach, Social } \\
\text { exchange theory, } \\
\text { Assimilation } \\
\text { contrast theory }\end{array}$ & Focal & Survey & $\begin{array}{l}\text { Salesperson relationship quality }(+) \text {, trust }(+) \text {, commitment }(+) \text {, } \\
\text { satisfaction }(+) \text {, customer orientation }(+)\end{array}$ \\
\hline 22 & $\begin{array}{l}\text { Mulki and } \\
\text { Jaramillo } \\
\text { (2011) }\end{array}$ & Evolution Theory & Focal & Survey & $\begin{array}{l}\text { Instrumental leadership }(+) \text {, satisfaction with the supervisor } \\
(+) \text {, helping }(+) \text {, sportsmanship }(+) \text {, courtesy }(+) \text {, turnover } \\
\text { intentions }(-) \text {, workplace isolation }(-)\end{array}$ \\
\hline 23 & $\begin{array}{l}\text { Mulki et al. } \\
(2008)\end{array}$ & $\begin{array}{l}\text { Social cognitive } \\
\text { theory }\end{array}$ & Focal & Survey & $\begin{array}{l}\text { Role conflict (-), role ambiguity }(-), \text { work overload (-), } \\
\text { capability reward (ns), pay satisfaction }(+)\end{array}$ \\
\hline 24 & $\begin{array}{l}\text { Panagopoulos } \\
\text { and Ogilvie } \\
(2015)\end{array}$ & $\begin{array}{l}\text { Social cognitive } \\
\text { theory and self- } \\
\text { regulation theory }\end{array}$ & Focal & Survey & $\begin{array}{l}\text { Self-monitoring }(+) \text {, thought self-leadership (ns), self-esteem } \\
(+) \text {, performance }(+)\end{array}$ \\
\hline 25 & $\begin{array}{l}\text { Rapp et al. } \\
(2015)\end{array}$ & $\begin{array}{l}\text { Self-regulation } \\
\text { theory and } \\
\text { Expectancy theory }\end{array}$ & Focal & Survey & $\begin{array}{l}\text { Coping behavior (ns), cross-selling (ns), showrooming (-), } \\
\text { performance }(+)\end{array}$ \\
\hline 26 & $\begin{array}{l}\text { Schaefer and } \\
\text { Burnett (2014) }\end{array}$ & $\begin{array}{l}\text { No theory } \\
\text { mentioned }\end{array}$ & Focal & Survey & $\begin{array}{l}\text { Sales performance }(+) \text {, customer satisfaction }(+) \text {, customer } \\
\text { orientation }(+)\end{array}$ \\
\hline 27 & $\begin{array}{l}\text { Singh et al. } \\
(2017)\end{array}$ & $\begin{array}{l}\text { Self-regulation } \\
\text { theory and Job } \\
\text { Demands- } \\
\text { Resources (JD-S) } \\
\text { Model }\end{array}$ & Focal & Survey & Thought self-leadership $(+)$, selling skills $(+)$, performance $(+)$ \\
\hline 28 & $\begin{array}{l}\text { Sujan, Weitz, } \\
\text { \& Kumar } \\
\text { (1994) }\end{array}$ & $\begin{array}{l}\text { Learning } \\
\text { orientations }\end{array}$ & Focal & Survey & $\begin{array}{l}\text { Performance }(+), \text { working smart }(+) \text {, working hard }(+), \\
\text { learning orientation }(+)\end{array}$ \\
\hline 29 & $\begin{array}{l}\text { Vieira et al. } \\
\text { (2018) }\end{array}$ & Path Goal Theory & Focal & Survey & $\begin{array}{l}\text { Customer satisfaction }(+) \text {, word of mouth }(+) \text {, Loyalty }(+), \\
\text { Cross-selling }(+)\end{array}$ \\
\hline 30 & $\begin{array}{l}\text { Wang and } \\
\text { Netemeyer } \\
(2002)\end{array}$ & $\begin{array}{l}\text { Social Cognitive } \\
\text { Theory }\end{array}$ & Focal & Survey & $\begin{array}{l}\text { Job autonomy }(+) \text {, learning effort }(+) \text {, trait competitiveness } \\
(+) \text {, customer demandingness }(+) \text {, performance }(+)\end{array}$ \\
\hline
\end{tabular}




\begin{tabular}{|c|c|c|c|c|c|}
\hline 31 & $\begin{array}{l}\text { Yang et al. } \\
\text { (2011) }\end{array}$ & $\begin{array}{l}\text { Distal-proximal } \\
\text { theoretical } \\
\text { framework of } \\
\text { motivation }\end{array}$ & Focal & Survey & Conscientiousness $(+)$, extraversion $(+)$, sales performance $(+)$ \\
\hline
\end{tabular}




\section{CHAPTER 3}

\section{CONCEPTUAL MODEL AND HYPOTHESES}

Social cognitive theory (Bandura 1999) has been criticized for not clearly describing the role self-efficacy plays in affecting human behaviors (e.g., Powers 1991). For instance, Schmidt and DeShon (2010) find that self-efficacy is related negatively to performance, and Vancouver et al. (2002) argue that this finding can be explained by perceptual control theory (Powers 1973), but not by social cognitive theory. Vancouver et al. (2002) also find that motivation weakens when self-efficacy reaches a relatively higher state, and the authors argue that this phenomenon is consistent with perceptual control theory. In a meta-analysis, Sitzmann and Yeo (2013) find that past performance affects self-efficacy positively; however, the effect of self-efficacy on performance is not consistent. In the current research, we combine both social cognitive theory and perceptual control theory to explain the consequences of self-efficacy and apply the concept of resources to shed insight on these conflicting perspectives.

Resources are "objects, personal characteristics, conditions or energies" that individuals value and strive to protect and maintain (Hobfoll 1989, p. 516). Example of such resources are knowledge, social support, and time (Halbesleben 2006; Mayo and Mallin 2010). Applying social cognitive theory, we suggest that salespeople gain resources (e.g., knowledge) via learning; and, this enhances self-efficacy. We also suggest that highly efficacious salespeople utilize more cognitive resources, and this reduces their self-control (because of limited available resources). Applying ego depletion theory, we posit that the loss of self-control leads to opportunism as means of preserving sources. In an alternative path, we suggest that high selfefficacious individuals become complacent because they think they have all the necessary resources to successfully complete a task, and hence, they don't feel motivated to exert 
additional effort. We expect that this feeling of complacency that stems from high self-efficacy will affect performance negatively by reducing salesperson efforts.

To the best of our knowledge, the negative effects of self-efficacy on performance have not been studied in a sales context. Furthermore, the extant literature does not clearly explain the mechanism(s) behind the undesirable effects (i.e., opportunism and decreased effort) of selfefficacy. In the current research, not only do we address these issues, but we also examine the role of salesperson stress as a moderator and examine how it may have both positive and negative effects. Figure 1 represents the conceptual model and the hypothesized relationships that are explicated in the subsequent sections.

\section{Figure 1: Hypothesized Model}

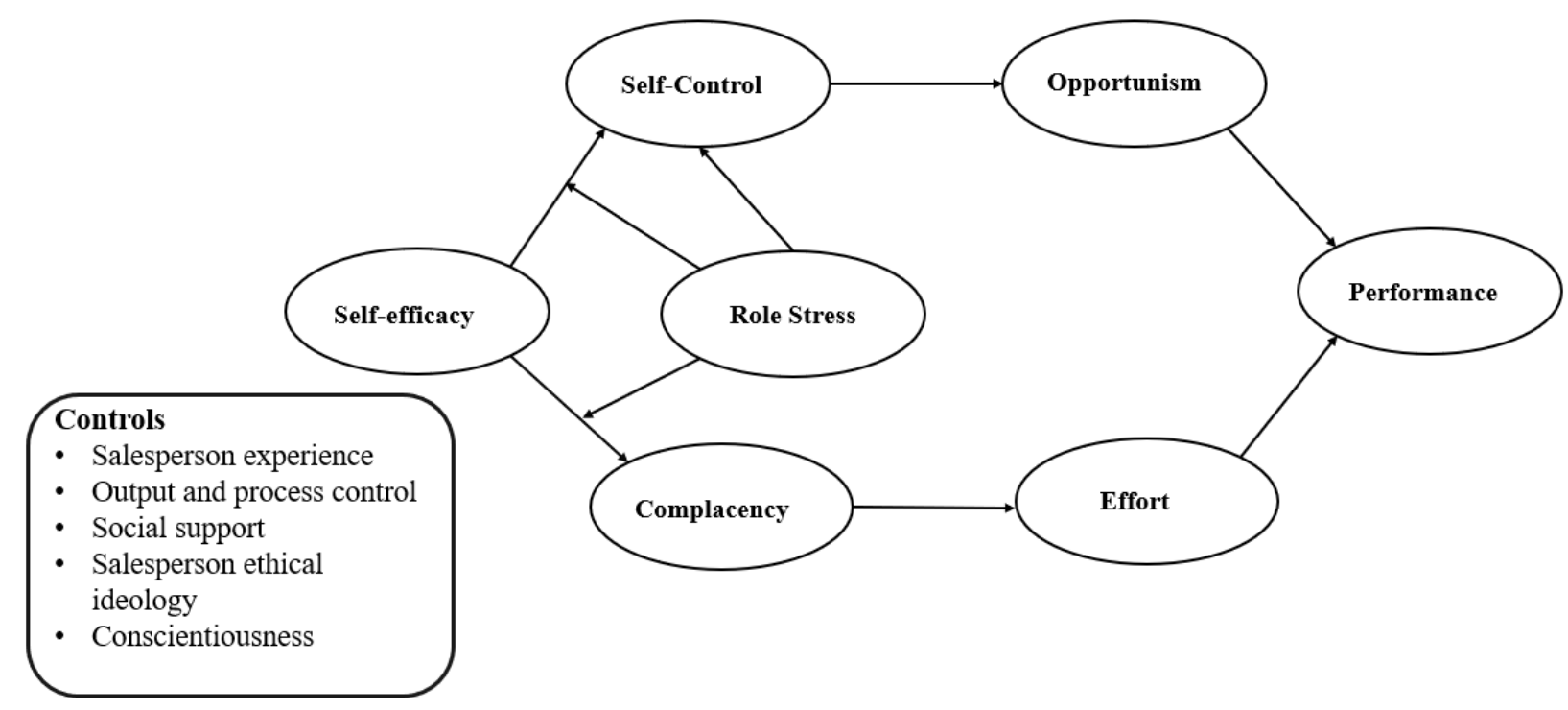

\section{Self-efficacy $\rightarrow$ Self-control $\rightarrow$ Opportunism}

In this section, we explore the consequences of self-efficacy. We argue that developing and maintaining self-efficacy requires resources, which in turn leaves fewer resources available for regulating one's behavior. Depletion of resources (also termed ego depletion) refers to a 
reduction in one's ability to engage in volitional actions, such as controlling the self, initiating actions, and making choices (Baumeister et al. 1998). Ego depletion may arise when the self does not have all the resources it has normally because of prior exertion of resources (Baumeister et al. 2007). An example of prior exertion of a resource could be spending cognitive efforts on a prior task. Once ego depletion sets in, individuals' ability to act in their own interest diminishes (Cholbi 1996). Ego depletion theory posits that self-control, which is a person's ability to refrain from acting upon impulses, declines during continuous efforts, similar to a muscle that becomes tired after repeated use (Baumeister 2002).

Self-control is "the ability of the self to exert control over the self" (Hagger et a. 2010, p. 496). It requires resources, such as energy, strength, or willpower. These resources are limited and can be depleted over time (Hagger et al. 2010). When these resources are depleted from an initial task, it impairs an individual's ability to exert self-control in subsequent tasks (Baumeister 2002). Stated differently, when an individual uses limited resources (e.g., willpower, energy) on a task, he/she has fewer resources available for self-control on subsequent tasks. Baumeister et al. (2007) suggest that there are seven different acts (e.g., paying attention, making choices) that draw resources from the same pool of resources that self-control draws from. Among these different acts, two of them: (1) cognitive processing and (2) choice and volition are critical for self-efficacious individuals.

We argue that high self-efficacious salespeople use more mental resources than those who have low self-efficacy. According to social cognitive theory, self-efficacy belief regulates human functioning through cognitive processes (Benight and Bandura 2004). As such, highly efficacious individuals are constantly utilizing their knowledge in cognitive tasks, such as decision making and information processing. These tasks expend resources that are required for 
self-control. There is also empirical evidence that suggests that making decisions and choices reduce the same resource that is used for self-control (e.g., Twenge et al. 2000). Moreover, selfefficacious individuals believe that they have control over events that affect their lives (Benight and Bandura 2004). Therefore, people who have a firm belief in their efficacy (i.e., high selfefficacious individuals) always want to be in control and through "ingenuity and perseverance, figure out ways to exercise some measure of control” (Mulki et al. 2008, p. 284). This also requires cognitive resources.

Further, individuals with high self-efficacy may be less likely to supplement their expended resources from external sources. A high level of self-efficacy may cause alienation (Mulki and Jaramillo 2011). Stated differently, highly efficacious salespeople may think they don't need social support (e.g., support from coworkers or managers) because they consider themselves very knowledgeable and capable. This reduces the likelihood of seeking support (i.e., additional resources) to replenish the initial resource loss (Wright and Hobfoll 2004). Hence, we assume that losing self-control is more prominent for highly self-efficacious people because of their resource depletion from continuous use of mental resources and failure to gain additional resources through social support.

H1: Salesperson self-efficacy is related negatively to salesperson self-control.

Once a salesperson loses self-control, we expect that he/she is more likely to engage in opportunism, or "self-interest seeking with guile" (Williamson 1981, p. 554). More specifically opportunism is defined as "guileful self-interest seeking behaviors that benefit one party at the expense of its exchange partner" (Crosno and Brown 2015, p. 299). Opportunism includes an element of deceit which makes it different from other forms of self-interest seeking behavior, such as hard bargaining, frequent disagreements, and conflict (John 1984). Violations of formal 
agreements are blatant opportunism, whereas violations of informal agreements are referred to as lawful opportunism (Wathne and Heide 2000). Examples of these type of opportunism are lying, stealing, cheating, evading duties, and withholding information (Williamson 1975). In a selling context, opportunism takes many forms, such as (1) withholding information or effort, (2) distorting results, such as sales goals achieved, (3) misrepresenting intentions to customers, and (4) misrepresenting selling costs (Anderson 1988). Another form of opportunism in a sales context is deliberately withholding knowledge and information to retain one's competitive advantage (Anaza and Nowlin 2017).

Drawing on SCT, Bandura and Locke (2003) argue that the resilient sense of self-efficacy (i.e., the belief that one has what it takes to succeed despite failures and setbacks) that enhances performance can also facilitate adherence to practices of questionable behaviors (i.e., opportunism). But, what is the mechanism behind it? We argue that a highly self-efficacious salespersons may engage in opportunism because of their reduced self-control. A high level of self-control is linked to positive outcomes, such as success at school, better ability to cope with problems, and increased concentration (Gailliot and Baumeister 2007; Hagger et al. 2010). On the other hand, a low level of self-control is linked to negative outcomes, like theft, aggression, and cheating (Gino et al. 2011). A low level of self-control is also linked to dishonesty (Freeman and Muraven 2010) and impairment of critical thinking (Schmeichel, Vohs, and Baumeister 2003).

The awareness of the social acceptability and/or the morality of many opportunistic behaviors draws on one's cognitive resources; and resisting the temptation to behave opportunistically also draws on these cognitive resources (Joosten et al. 2014). Moreover, opportunism (e.g., falsifying reports, shirking) is tempting because it provides short-term gains; 
however, it may endanger a salesperson's relationship with the company and hurt his/her moral identity (Gino et al. 2011). Thus, the decision to engage in opportunism requires a salesperson to weigh two opposing factors: (1) desire to maximize self-interest, and (2) desire to maintain a long-term relationship with the company and a positive moral identity. To resolve this conflict, an individual must exert self-control. As argued previously, highly self-efficacious individuals are more resource depleted; therefore, they have limited willpower or self-regulatory power left at their disposal to weigh these opposing factors. Consequently, we expect that highly selfefficacious salespeople to be more prone to opportunism. ${ }^{1}$

H2: Salesperson self-control is related negatively to salesperson opportunism.

\section{Self-efficacy $\rightarrow$ Complacency $\rightarrow$ Performance}

In the following sections, we will discuss two different perspectives on the effects of selfefficacy on performance. The received view is that high self-efficacious individuals perform well because of their increased effort (e.g., Fu et al. 2017; Jaramillo and Mulki 2008). However, applying perceptual control theory (Powers 1973), we suggest an alternative view; namely, selfefficacy may reduce performance because of complacency.

\section{Received View}

Social cognitive theory (Bandura 1991) suggests that a person's belief in his/her abilities to execute a course of action determines the level of effort put forth. Since salespeople with a high level of self-efficacy have strong beliefs in their abilities and consequently their likelihood of being successful on the job, they exert more effort towards completing a task than salespeople

\footnotetext{
${ }^{1}$ As an alternative perspective, we argue that high self-efficacious salespeople are more knowledgeable (than low self-efficacious salespeople) (Bowell 2013); therefore, they may be more likely to be opportunistic because they know how to cut corners, shirk, etc. (better than those with low self-efficacy) without getting caught.
} 
with low self-efficacy (Sujan, Weitz, and Kumar 1994). Furthermore, it is well-established that salesperson effort leads to higher performance (e.g., Fang et al. 2004; Jaramillo and Mulki 2008). In sales literature, performance is usually defined as the effectiveness of a salesperson in sales related tasks, such as sales quality achieved, handling objections, closing sales, etc. (Wang and Netemeyer 2002). Brown and Peterson (1994), in their meta-analysis, also show that effort is a significant predictor of performance. Therefore, path from self-efficacy to performance through effort is well established.

\section{Alternative View}

While extant research in sales consistently reports a positive relationship between selfefficacy and performance (see Table 1), perceptual control theory in psychology (Powers 1973) suggests that high self-efficacy can induce complacency and decrease motivation, which results in reduced efforts. Perceptual control theory focuses on the comparisons between desired goal state (e.g., performance level) and the perceptions of one's current state (Vancouver and Kendall 2006). According to this theory, when a person's self-efficacy is high, he/she is expected to invest fewer resources (e.g., prepare less, study less) because the discrepancy between the desired goal state and the perception of current state is smaller compared to when self-efficacy is relatively low (Vancouver et al. 2002). In contrast, when the perceived discrepancy between the desired state and the current state is high, more effort is required to close this gap ${ }^{2}$, and, hence, the motivation is higher (Vancouver et al. 2002). This line of reasoning suggests that high self-

\footnotetext{
${ }^{2}$ If the gap is between the current state and the desired state is too large (i.e., not an attainable goal), this may decrease employee motivation. This argument is supported by expectancy theory (Vroom 1964). Expectancy theory suggests that motivation depends on individuals' belief that an outcome will follow certain efforts or action (Vroom 1995). There is also empirical evidence that shows the relationship between goal difficulty and performance is curvilinear and beyond a certain point, an increase in goal difficulty reduces motivation (Baron et al. 2016). Therefore, when a person believes that the goal is unattainable, he/she may not exert effort because the effort will not help achieve the outcome.
} 
efficacy diminishes the perceived difference between the current state and the desired state (i.e., goal), induces complacency, which ultimately may hinder performance (Stirin Tzur et al. 2016).

Complacency is characterized by: (1) overestimation of one's accomplishment or status, (2) too much self-satisfaction, (3) lack of strong desire to improve to an appropriate level of accomplishment, and (4) lack of motivation and effort (Kawall 2006). The lack of desire to improve and/or the lack of motivation stem from individuals' unwillingness to change their existing state (Kawall 2006). In marketing, complacency is defined as "sentiments of misplaced satisfaction and an unwillingness or inability to recognize the need for change" (Ingene et al. 2019). Complacency is often associated with unawareness of deficiencies, ignorance, and lack of self-reflection (Chowdhury and Lang 1996; Kawall 2006). Shipley (1994) suggests that complacency is an internal aversion to change the existing state, and it prevents a person from being effective in his/her work. According to Austin (1991), complacency fosters an unwillingness to recognize that change is needed. Complacency also provides a sense of security, which in turn fosters a feeling of comfort (Oster 2018).

In the current research, we argue that when a salesperson has high self-efficacy, he/she develops feelings of complacency. Bandura (1997) suggests that high self-efficacious individuals have increased confidence in their abilities and they think they are well in control of the situation. Bandura (1977) also suggests that past successful performances heavily influence one's sense of self-efficacy. Since highly efficacious individuals have been successful in the past (which is one of the reasons for their increased self-efficacy) and are very confident in their abilities, they develop a sense of comfort and security which, in turn, creates a lack of motivation to change their existing status. All these conditions (i.e., believing that they will be successful 
because they have been successful, feeling of comfort, and lack of motivation) together create a feeling of complacency.

H3: Salesperson self-efficacy is related positively to salesperson complacency.

As discussed previously, complacent individuals have little motivation to enact change or put forth more effort because they are satisfied with their existing status (Dant and Gleiberman 2011). In a business-to-business context, Friend and Johnson (2017) suggest that when a supplier feels complacent, continuous learning and putting forth the effort to generate creative solutions lose their salience. This line of research suggests that when a salesperson is complacent, he/she has very little motivation to exert effort. Given that successful sales performance requires adequate efforts in sales-related tasks (e.g., Wang and Netemeyer 2002), complacency will diminish performance. Aligning with this perspective, there is empirical evidence that suggests complacency hinders performance (e.g., Berger et al. 2013; Parasuraman et al. 1993). Applying the theory and extrapolating from empirical evidence, we hypothesize the following:

H4: Salesperson complacency is related negatively to salesperson performance, and this relationship is mediated by salesperson (reduced) effort.

\section{Role Stress $\rightarrow$ Self-control}

Role stress is commonly experienced by salespeople (Schwepker and Good 2017). When stressed, a salesperson "perceives personal resources as taxed, resulting in an unknown potential for negative outcomes" (Sager \& Wilson, 1995, p. 59). Role stress corresponds to specific taskrelated role perceptions held by salespeople. It may include role ambiguity, role conflict, and/or role overload (Sager 1994). First, role ambiguity occurs when a salesperson does not have all the information needed to perform the job properly (Walker, Churchill and Ford 1975). Role ambiguity also makes a salesperson confused about his/her job responsibilities (Jaramillo et al. 
2006). Second, role conflict is experienced when a salesperson perceives that the goals set by different parties (e.g., customers, sales team members, managers, etc.) are incompatible (Jaramillo et al. 2006). Finally, role overload "is a perception that role demands are overwhelming relative to available capabilities and resources" (Fournier et al. 2010, p. 10).

Previous research suggests that the efforts requiredvif to cope with the stress make an individual less able to regulate behavior (Oaten and Cheng 2005). Furthermore, when people are under stress, they are required to make difficult choices and decisions (Baumeister 2002).

Coping with stress also involves managing one's feelings of worry, pressure, and frustration and requires using one's thoughts toward solving problems (Baumeister 2002). All these activities deplete resources. These resources (e.g., energy, strength, willpower), according to ego depletion theory, come from a finite source (Baumeister 2002). Ego depletion theory also posits that the act of self-control draws resources from the same source (Muraven et al. 1998). Past research suggests that decision making depletes the same resources that are used for self-control (Vohs et al. 2014; Baumeister 2002). Therefore, when individuals are stressed, they use more resources which makes it difficult for them to engage in self-control. Stated differently, distressed salespeople expend more resources, and as a result, they have fewer resources to engage in selfcontrol and regulate their behavior (Tice et al. 2001).

Dealing with stress may demand acts of restraint, such as regulating attention, suppressing emotions, and overriding negative thoughts (Oaten and Cheng 2005). All these acts that involve altering and/or controlling the self draw from the limited resources that self-control is governed by. There is also empirical evidence suggesting that stress leads to impaired selfcontrol. For example, emotionally distressed people fail in their effort to quit smoking (Brownell et al. 1986); people lose self-control and indulge in compulsive shopping when they are stressed 
(Faber 1992); distress contributes to loss of self-control and alcohol consumption; and induced stress causes people to increase their food consumption (Slochower and Kaplan 1980). Hence, we hypothesize the following:

H5: Salesperson role stress is related negatively to self-control.

\section{Moderating Role of Salesperson Role Stress}

As we have discussed in the previous sections, self-efficacy may lead to opportunism because of reduced self-control and self-efficacy may also hinder performance because of complacency. These negative effects of self-efficacy can be explained by the concept of resources. Highly efficacious individuals lose some self-control because of their increased utilization of cognitive resources; and as noted previously, a lack of self-control may engender opportunism. On the other hand, highly efficacious individuals believe that they have all the necessary resources to be successful, and this perception can create complacency, which in turn, hurts performance. However, when we add stress to the picture, these relationships may change. Conservation of resource theory (Hobfoll 1989) may shed light on these relationships.

Conservation of resource theory (COR) explains how individuals build, protect, and retain resources they value (Hobfoll 1989). COR theory has also identified four types of resources: (1) objects (e.g., house) which can provide status; (2) energy (e.g., time, money), (3) personal characteristics (e.g., self-mastery, psychological hardiness), which helps plan effective strategies to achieve objectives; and (4) conditions (e.g., marriage, seniority), which also helps acquire other resources (Mallin and Mayo 2006). COR theory argues that individuals experience stress when they encounter a situation that may lead to a loss of these resources. Here, we focus on work-related stress which is defined as "the existence of tension and pressures growing out of job requirements, including possible outcomes in terms of feelings or physical symptoms" 
(Chelariu and Stump 2011, p. 1663). Stress can result from a threat to resources, an actual loss of a resource, and/or a failure to gain resources (Chelariu and Stump 2011).

Salespeople experience stress due to their organizational boundary spanning positions (Babin and Boles 1996). As discussed previously, salesperson role stress has three components: role ambiguity, role conflict, and role overload (Johnson and Sohi 2014). First, when a salesperson is uncertain about others' expectations regarding his/her duties, that salesperson may experience role ambiguity (Behrman and Perreault 1984). Role ambiguity creates a lack of direction and clarity (Zablah et al. 2012). For example, a salesperson may be responsible for multiple clients with unique needs. This makes it difficult for sales managers to provide specific directions for assessing and attending to these needs, which results in role ambiguity (Schwepker and Good 2017). Salespersons need to exert a lot of cognitive resources and effort to manage role ambiguity.

Second, role conflict is the extent to which a salesperson experiences incompatibility associated with the role expectations (Johnson and Sohi 2014). For example, the manager, other supervisors, coworkers, and even customers can have different goals, which can make a salesperson feel conflicting about meeting these often incompatible goals. To meet these goals satisfactorily, a salesperson expends high level of cognitive and behavioral efforts, and in the process, can feel overwhelmed (Mulki et al. 2008). This can induce stress (Avlonitis and Panagopoulos 2006). Third, salespeople also face issues with role overload (Cameron Montgomery et al.1996). Sometimes a salesperson can have too many territories or too many clients, which can create a perception that he/she doesn't have the motivation or the ability to perform the job (Singh 1998). A salesperson may also be responsible for serving existing customers, generating new clients, and monitoring competition, which can also contribute to role 
overload (Johnson and Sohi 2014). In short, when employees feel that they have too many tasks to do and they think they don't have enough resources to finish them properly, they feel stressed.

In addition to explaining how stress can be evoked, COR theory includes a list of resources (e.g., intimacy with spouse or partner) that individuals strive to build and protect (Halbesleben 2006). Among these are work-related resources, such as "support from coworkers" and "understanding from the employer," both of which are relevant to the current study. Wright and Hobfoll (2004), in COR theory, suggest that people with high self-efficacy believe that they are very knowledgeable, and hence, they don't think that they need social support (e.g., support from colleagues and/or managers). This can decrease the opportunity for social and emotional interactions with co-workers and supervisors. Fewer interactions can create a perception of isolation, which can contribute to stress (Mulki and Jaramillo 2011).

Using the theoretical lens of ego depletion, when a salesperson is under stress (from role conflict, role ambiguity, and/or role overload, or the lack of social support), he/she spends more resources (i.e., more effort and/or cognitive resources) to manage the stress. As argued previously, salespeople with high level of self-efficacy already use more cognitive resources than salespeople with low levels of self-efficacy. Hence, adding stress leads to ego-depletion and ultimately loss of self-control. We argue that this effect of stress is more prominent for highly self-efficacious salesperson because they are already resource depleted and adding stress exacerbates the situation even more. Furthermore, they are less likely to draw on external resources, as they do not feel they need social support. In the current research, we call this stress the "bad stress."

H6: Role stress will strengthen the negative relationship between salesperson selfefficacy and self-control. 
According to Powers (1991), high self-efficacy may not always be good. Perceptual control theory suggests that when a salesperson has a high level of self-efficacy, he/she becomes complacent and is less motivated to exert effort (Vancouver et al. 2002). However, we believe that when a salesperson is faced with a stressful situation, the positive relationship between selfefficacy and complacency may change. We base this argument on attribution theory (Weiner 1985). Attribution is the process individuals use to understand why an event has occurred; this attribution can be internal (e.g., lack of ability, lack of effort) or external (e.g., luck, task difficulty) (Heider 1958).

It is important to understand the attributions made by salespeople because it affects subsequent effort (Sujan 1986). Dixon and Schertzer (2005) suggest that self-efficacy affects salespersons' attribution perceptions. The authors show that efficacious salespeople are more likely to attribute sales failures to internal factors and work harder following a sales failure. In a similar line of research, Chelariu and Stump (2011), applying attribution theory, suggest that high self-efficacious individuals attribute stress to internal factors. This is because highly efficacious people believe that when they fall short it is due to lack of effort, and not due to external factors (Chelariu and Stump 2011). Furthermore, contrary to the received view that suggests that role stress is related negatively to organizational outcomes (e.g., Kohli 1985; Teas 1983), Nygaard and Dahlstrom (2002) find that role ambiguity and role conflict (two sources of stress) have a nonlinear relationship with competency and effort. In a similar line of research, Singh et al. (1996) fail to support the negative effects of stress on performance. These empirical studies suggest that stress may not always be a bad thing. In the current research, we call this stress the "good stress." Applying the theory and extrapolating from empirical evidence, we argue that in a stressful situation, highly self-efficacious salespeople will be more affected than 
low self-efficacious salespeople, and they will not be as complacent as when there is little to no stress. In other words, role stress may motivate high self-efficacious salespeople to put in more effort. Specifically, we posit:

H7: Role stress will weaken the positive relationship between salesperson self-efficacy and complacency.

\section{Control Variables}

In testing the effects of self-efficacy, five relevant control variables will be included in the model: salesperson experience, salesforce control, social support, salesperson ethical ideology and salesperson conscientiousness. The rationale for each variable is discussed briefly. First, the impact of work experience on performance is well established (e.g., Deadrick and Madigan 1990; Fu 2009). In a meta-analysis, Franke and Park (2006), show that a salesperson's experience is correlated positively with performance. Furthermore, according to learning theory, work experience improves job performance through accumulated skills and knowledge (Weiss 1990). Previous research also suggests that work experience influences salespersons' job attitude and behavior (Ahearne et al. 2010). Hence, work experience is likely to affect salesperson opportunism.

Second, previous studies report that different types of control (i.e., behavior-based and outcome-based) can influence opportunism and performance in different ways (Heide et al. 2007; Crosno and Brown 2015). Research also shows that salesforce control can erode trust and induce opportunistic behavior (Husted and Folger 2004). In a recent meta-analysis, Crosno and Brown (2015) report that control can have both positive and negative outcomes depending on organizational settings (i.e., interorganizational vs. intraorganizational). They also note that 
control affects performance, relationship quality, and employee satisfaction (Crosno and Brown 2015).

Third, extant research suggests that social support (e.g., support from the manager, support from the coworkers) reduces the impact of stress in a work environment (Cooper et al. 2001). A significant relationship has also been reported between lack of social support and job dissatisfaction (Ganster et al. 1986) and depression (Frone, Russell, and Cooper 1995). Fourth, previous research suggests that a salesperson's ethical ideology affects sales performance and customer relationships (e.g., Schwepker and Good 2011; Schwepker and Ingram 1996).

Although not examined empirically previously, salespersons' ethical ideology is also expected to influence their likelihood of behaving opportunistically. Finally, it has been reported that people who are conscientious are organized, hard-working, and achievement oriented, and therefore are likely to perform better (Barrick et al. 1993).

In this chapter, we presented our conceptual mode, developed the hypotheses, and discussed the control variables. In the next chapter, we will present the research methods employed to empirically test the conceptual model and hypotheses.

\section{CHAPTER 4}

\section{METHODOLOGY}

The goal of this chapter is to outline the methods that are employed to empirically test the conceptual model developed in Chapter 3. Two studies are designed to test the conceptual model and hypotheses. Study 1 is a cross-sectional survey of sale representatives in the U.S., and Study 2 is a laboratory experiment. For both studies, the research design, sampling procedures, measurement, data collection, and statistical analyses are discussed. 


\section{Design}

\section{Study 1}

Study 1 is a cross-sectional, self-reported, online survey of sales representatives in the U.S. Although cross-sectional design is often criticized for not being able to establish causality, cross-sectional studies are useful for establishing correlation among measures; and this is a necessary first step for early-stage research (Spector 2019). Furthermore, by adding control variables, cross-sectional studies can rule out alternative explanations (Spector 2019). In short, this study determines if there is a significant relationship between the variables studied. Given its cross-sectional design, this survey does not address temporal sequence of the independent and dependent variables (Schwab 1999).

\section{Procedure}

In order to capture adequate heterogeneity, we included business-to-business (B2B) salespersons from different industries. Like other sales research (e.g., Hartmann and Rutherford 2015), an online market research organization (i.e., Dynata) was used to collect data for our cross-sectional survey. Benefits of using a professional research firm that operates online include access to a large number of specified respondents, cost-efficiency, and timeliness (Hartmann and Rutherford 2015). Moreover, research suggests that data collected through online panel can be as reliable as data collected through traditional ways (Hartmann and Rutherford 2015)

Dynata contacted a panel of prescreened B2B salespeople to invite them to participate in an academic research study. Respondents first read the cover letter, and then completed the survey (see Appendix B). In the cover letter, respondents were notified that they are eligible to complete the survey only if they are currently working as sales representatives. We also had filter questions to ensure that the respondents were currently working as salespeople. Respondents then completed the survey questions of the measurement items (e.g., self-efficacy, stress, 
complacency, self-control, opportunism and performance). In addition, we collected profile information in our survey. Specifically, we captured the following: gender, age, tenure with company, job title, compensation type, industry, B2B vs. B2C (business-to-consumer) sale distinction, and a measure of sales cycle time (how long it takes from initial customer contact to close) (Schrock 2015).

\section{Sample}

Dynata contacted a panel of salespeople from a variety of industries. A multi-industry sample enhances the external validity of the findings (Maignan and Ferrell 2001).

Without a large enough sample, the analysis lacks the statistical power required to reduce the chance of rejecting the false null hypothesis (Shadish, Cook, \& Campbell, 2002). Bagozzi and Yi $(1988,2012)$ suggest that a sample size of 100 is the minimum for analyzing models using structural equation models. However, they also recommend that researchers should aim for above 200 observations to be conservative. Following the suggestions of Bagozzi and Yi (1988, 2012), we set a target of 250 completed questionnaires.

Dynata initially sent out invitations via email to 10,677 potential respondents who have membership accounts with Dynata. Invitations are sent to the panelists to encourage them to log into their accounts to access surveys that are available for their participation in a given time. Overall, 1,056 salespeople entered the online survey. Since the focus of our survey is B2B salespeople, respondents who did not self-identify as B2B salespeople $(n=106)$ in a screening question were filtered out. Furthermore, 668 respondents were bumped out of the survey for failing the attention-check question (i.e., Select "Somewhat Agree" for this question to continue). Once the target of 250 completed questionnaires was met, the survey site became inaccessible to the potential respondents. 
We took several steps to clean the dataset. First, we analyzed frequencies using SPSS to look for missing data. Since, we "forced the response" instead of "request the response" in Qualtrics, there was no missing data. Next, to check for potential multicollinearity problems, we looked at the variance inflation factors (VIFs) (Field 2009). None of the VIFs values were higher than 3.0, which suggests that we don't have a multicollinearity issue (Kutner et al. 2005). Then, we calculated Mahalanobis Distance (MD) to identify multivariate outliers (DeSimone et al. 2015). If the MD for a response is higher than the critical value (at a certain degree of freedom and confidence interval), it suggests that the particular response is an anomaly, and it can significantly bias the findings of a study (Hadi 1992). We deleted 19 responses based on the MD. In addition, we calculated survey completion time (in minutes) for each respondent. Our pretest suggested that it should take approximately 15-20 minutes to complete the survey. We made a judgement call and deleted five responses that had a completion time of five minutes or less. After cleaning the data based on these factors, our final sample size was 226.

\section{Measurement}

Measurement refers to "rules for assigning numbers to objects in such a way as to represent quantities of attributes" (Nunnally 1978, p. 3). The objective of measurements is to adequately and reliably capture the attributes of a construct (i.e., producing an observed score that approximates the true score of an attribute) (Churchill 1979). In this study, all variables are measured by multi-item, reflective scales.

Moreover, all the variables in the model are measured using existing scales or adaptations of existing scales. Table 3 includes definitions and measurement items of all the variables. 
Table 3: Definitions and Established Measures of Key Constructs

\begin{tabular}{|c|c|c|}
\hline Constructs & Definition & Measurement items \\
\hline $\begin{array}{l}\text { Salesperson self- } \\
\text { efficacy }\end{array}$ & $\begin{array}{l}\text { Self-efficacy is the belief a } \\
\text { salesperson has about his/her } \\
\text { ability to successfully perform } \\
\text { sales related tasks such as } \\
\text { prospecting new customers, } \\
\text { generating leads, selling, etc. } \\
\text { (Wang and Netemeyer 2002) }\end{array}$ & $\begin{array}{l}\text { Adapted from Fournier et al. (2010) } \\
\text { - I know the right thing to do in } \\
\text { selling situations. } \\
\text { - Overall, I am confident of my ability } \\
\text { to perform my job well. } \\
\text { - I feel I am very capable at the task } \\
\text { of selling. } \\
\text { - I feel I have the capabilities to } \\
\text { successfully perform }\end{array}$ \\
\hline $\begin{array}{l}\text { Salesperson } \\
\text { opportunism }\end{array}$ & $\begin{array}{l}\text { Opportunism is "guileful self- } \\
\text { interest seeking behaviors that } \\
\text { benefit one party at the expense } \\
\text { of its exchange partner" } \\
\text { (Crosno and Brown } 2015, \text { p. } \\
\text { 299) }\end{array}$ & $\begin{array}{l}\text { Adapted from Anderson (1988) } \\
\text { Study } 1 \\
\text { - Sometimes, I alter the facts slightly } \\
\text { in order to get what I need } \\
\text { - I sometimes promise to do things } \\
\text { without actually doing them later } \\
\text { - Sometimes I sell things that are not a } \\
\text { customer's best interest } \\
\text { - Sometimes I withhold or choose not } \\
\text { to share important information } \\
\text { Adapted from Jap and Anderson (2003) } \\
\text { Study } 2 \text { (buyers' survey) } \\
\text { - The salesperson made hollow } \\
\text { promises } \\
\text { - The salesperson lied about the } \\
\text { product } \\
\text { The salesperson provided false } \\
\text { information } \\
\text { The salesperson withheld } \\
\text { information }\end{array}$ \\
\hline Self-control & $\begin{array}{l}\text { Self-control refers to an } \\
\text { individual's ability to regulate } \\
\text { (with effort) his/her thoughts, } \\
\text { feelings and behaviors (Vohs \& } \\
\text { Baumeister 2004). }\end{array}$ & $\begin{array}{l}\text { Adapted from Tangney et al. (2004) } \\
\text { Study } 1 \\
\text { - I sometimes say inappropriate things } \\
\text { at work } \\
\text { - Pleasure and fun sometimes keep me } \\
\text { from getting work done } \\
\text { - I have trouble concentrating at work } \\
\text { - I often act without thinking through } \\
\text { all the alternatives } \\
\text { - I wish I had more self-discipline to } \\
\text { carry out my job duties }\end{array}$ \\
\hline
\end{tabular}




\begin{tabular}{|c|c|c|}
\hline & & $\begin{array}{l}\text { I get carried away by my feelings at } \\
\text { work } \\
\text { Study } 2 \\
\text { - I said things that I should not have } \\
\text { during the sales exchange } \\
\text { - I had trouble concentrating during } \\
\text { this sales task } \\
\text { - I often responded to the buyers } \\
\text { without thinking through all the } \\
\text { alternatives }\end{array}$ \\
\hline Role Stress & $\begin{array}{l}\text { "The existence of tension and } \\
\text { pressures growing out of job } \\
\text { requirements, including } \\
\text { possible outcomes in terms of } \\
\text { feelings or physical symptoms" } \\
\text { (Chelariu and Stump 2011, p. } \\
\text { 1663). }\end{array}$ & $\begin{array}{l}\text { Adapted from Deeter-Schmelz (1997) } \\
\text { and Ramsey (1997) } \\
\text { - I feel a great deal of stress because } \\
\text { of my job } \\
\text { - Many stressful things happen to me } \\
\text { at work } \\
\text { - My job is extremely stressful } \\
\text { - I often feel stressed at work } \\
\text { - My company's sales targets stress } \\
\text { me out } \\
\text { Role Conflict (Babin and Boles } 1996 \text {, } \\
\text { Mulki et al. 2008) } \\
\text { - I sometimes have to bend a rule in } \\
\text { order to carry out an assignment } \\
\text { - I often receive incompatible requests } \\
\text { from two or more people } \\
\text { - I often receive an assignment } \\
\text { without the manpower to complete it } \\
\text { - I often receive an assignment } \\
\text { without adequate resources to } \\
\text { - I execute it } \\
\text { - I do things that are accepted by one } \\
\text { person and not accepted by others } \\
\text { Role Ambiguity (Mulki et al. 2008) } \\
\text { objectives for my job } \\
\text { has to be done } \\
\text { - }\end{array}$ \\
\hline
\end{tabular}




\begin{tabular}{|c|c|c|}
\hline & & $\begin{array}{l}\text { Role Overload (Fournier et al. 2010) } \\
\text { - I do not have enough time to do } \\
\text { what is expected of me in my job } \\
\text { - It often seems like I have too much } \\
\text { for one person to do } \\
\text { - The performance standards on my } \\
\text { job are too high } \\
\text { - I have too much work to do } \\
\text { everything well } \\
\text { - The amount of work I am asked to } \\
\text { do is unreasonable } \\
\text { - I never seem to have enough time to } \\
\text { get everything done }\end{array}$ \\
\hline Complacency & $\begin{array}{l}\text { Complacency is characterized } \\
\text { by: (1) overestimation of one's } \\
\text { accomplishment or status (2) } \\
\text { too much self-satisfaction (3) } \\
\text { lack of strong desire to improve } \\
\text { to an appropriate level of } \\
\text { accomplishment and (4) lack of } \\
\text { motivation and effort (Kawall } \\
\text { 2006) }\end{array}$ & $\begin{array}{l}\text { Adapted from Baker (2009) } \\
\text { - I do not waste time on change } \\
\text { initiatives } \\
\text { - I do not worry about the future of } \\
\text { my relationship with the company } \\
\text { - I do not usually make any changes. } \\
\text { - I am satisfied with my selling skills } \\
\text { - I would not benefit from additional } \\
\text { sales training }\end{array}$ \\
\hline Effort & $\begin{array}{l}\text { Effort is defined as "the amount } \\
\text { of time and energy allocated to } \\
\text { job tasks" (Jaramillo andMulki } \\
2008, \text { p. } 37 \text { ). }\end{array}$ & $\begin{array}{l}\text { Adapted from Brown and Peterson } \\
\text { (1994) } \\
\text { 7-point semantic differential scale } \\
\text { asking- please rate how you compare } \\
\text { with all others in the company (1= } \\
\text { "among the least in the company" and } \\
\text { 7= "among the best in the company"). } \\
\text { - Overall effort in the sales task } \\
\text { - Number of hours worked } \\
\text { - Number of sales calls made }\end{array}$ \\
\hline $\begin{array}{l}\text { Sales } \\
\text { performance }\end{array}$ & $\begin{array}{l}\text { The effectiveness of a } \\
\text { salesperson in sales related } \\
\text { tasks, such as sales quality } \\
\text { achieved, closing sales etc. } \\
\text { (Wang and Netemeyer 2002) }\end{array}$ & $\begin{array}{l}\text { Adapted from Brown and Peterson } \\
\text { (1994) } \\
\text { 7-point semantic differential scale } \\
\text { asking- please rate how you compare } \\
\text { with all others in the company (1= } \\
\text { "among the least in the company" and } \\
\text { 7= "among the best in the company"). } \\
\text { - My level of quota / goal } \\
\text { - achievement during the past year is } \\
\text { My sales manager would rate my } \\
\text { - My orformance during the past year as } \\
\text { the past year is }\end{array}$ \\
\hline
\end{tabular}




\begin{tabular}{|c|c|c|}
\hline $\begin{array}{l}\text { Perceived social } \\
\text { support (control } \\
\text { variable) }\end{array}$ & $\begin{array}{l}\text { "The degree to which } \\
\text { individuals perceive that they } \\
\text { have positive social } \\
\text { relationships with others in the } \\
\text { workplace" (Wiesenfeld et al. } \\
\text { 2001, p. 218). }\end{array}$ & $\begin{array}{l}\text { Adapted from Wiesenfeld et al. (2001) } \\
\text { Endpoints: Unsupportive (1) and } \\
\text { supportive (7) } \\
\text { How much support do you think you are } \\
\text { currently receiving from- } \\
\text { - Colleagues } \\
\text { - Direct supervisor } \\
\text { - Upper management }\end{array}$ \\
\hline $\begin{array}{l}\text { Salesforce } \\
\text { control (control } \\
\text { variable) }\end{array}$ & $\begin{array}{l}\text { A control system is "an } \\
\text { organization's set of procedures } \\
\text { for monitoring, directing, } \\
\text { evaluating, and compensating } \\
\text { its employees" (Anderson and } \\
\text { Oliver 1987, p. 76) }\end{array}$ & $\begin{array}{l}\text { Adapted from Evans et al. (2007) } \\
\text { Output control: } \\
\text { - Specific quantitative performance } \\
\text { goals are established for my job. } \\
\text { - The extent to which I attain my } \\
\text { quantitative performance goals is } \\
\text { critically evaluated. } \\
\text { - If my quantitative performance goals } \\
\text { were not met, I would be required to } \\
\text { explain why. } \\
\text { - Feedback concerning the extent to } \\
\text { which I achieve the assigned goals is } \\
\text { provided to me on a regular basis. } \\
\text { My pay increases are based upon } \\
\text { how my performance compares with } \\
\text { my goals. } \\
\text { Process control: } \\
\text { The extent to which I follow } \\
\text { established sales procedures is } \\
\text { critically monitored. } \\
\text { The procedures used to accomplish a } \\
\text { given selling task are explicitly } \\
\text { regulated. } \\
\text { My immediate boss modifies my } \\
\text { work procedures when desired } \\
\text { results are not obtained. } \\
\text { Feedback on how I accomplish my } \\
\text { performance goals is frequently } \\
\text { communicated to me. }\end{array}$ \\
\hline $\begin{array}{l}\text { Salesperson } \\
\text { ethical ideology } \\
\text { (control } \\
\text { variable) }\end{array}$ & $\begin{array}{l}\text { It is defined as the extent to } \\
\text { which a salesperson rejects } \\
\text { moral rules in favor of } \\
\text { situational and/or subjective } \\
\text { reasons (Sivadas et al. 2003). }\end{array}$ & $\begin{array}{l}\text { Adapted from Sivadas et al. (2003) } \\
\text { - Jeopardizing the well-being of } \\
\text { customers is not necessary to } \\
\text { achieve desired ends in sales. } \\
\text { - Desirable sales outcomes are most } \\
\text { frequently obtained by following an } \\
\text { ethical course of action. }\end{array}$ \\
\hline
\end{tabular}




\begin{tabular}{|c|c|c|}
\hline & & $\begin{array}{l}\text { - An ethical course of action is always } \\
\text { the best one a salesperson can take. } \\
\text { - A universal code of ethics for sales } \\
\text { can never be realized because what } \\
\text { is right or wrong is up to each } \\
\text { individual. } \\
\text { - Individuals within a company } \\
\text { should be allowed to formulate their } \\
\text { own code of ethics, because no one } \\
\text { party can say what is right for every } \\
\text { employee. } \\
\text { - Ethical standards are individualistic } \\
\text { because what one person considers } \\
\text { ethical may be judged as unethical } \\
\text { by someone else. }\end{array}$ \\
\hline $\begin{array}{l}\text { Blue attitude } \\
\text { (marker } \\
\text { variable) }\end{array}$ & $\begin{array}{l}\text { Attitude toward blue color } \\
\text { (Miller \& Chiodo, 2008). }\end{array}$ & $\begin{array}{l}\text { Adapted from Miller and Chiodo (2008) } \\
\text { - I prefer blue to other colors } \\
\text { - I like the color blue } \\
\text { - I like blue clothes }\end{array}$ \\
\hline
\end{tabular}

To ensure that the items are properly worded and easily understood, we conducted oneon-one interviews with experienced salespeople. We recruited three salespeople from different industries (e.g., pharmaceuticals, banking) and presented them with the definition and measurement items of each construct. Participants were also asked several probing, semistructured questions, such as "(1) Have you ever felt stressed in workplace? (2) What are the different opportunistic behaviors have you seen other salespeople conduct in your organization? (3) Do your get support from your supervisor and colleagues?" Based on their evaluation of the items and their answers to the open ended questions, we modified the items if necessary.

Previous research suggests that salespeople are the most reliable and appropriate judge for evaluating sales-related constructs (Wang and Netemeyer 2004). Therefore, we presented the revised items to another set of salespeople to evaluate for content validity. Content validity refers to the degree to which the measurement items adequately capture the domain of the construct (Hinkin 1998). According to Nunnally (1978, p. 93), "content validity rests mainly on appeals to 
reason regarding the adequacy with which important content has been sampled and on the adequacy with which the content has been cast in the form of test items." Specifically, this new group of salespeople (three in total and independent of one another) was provided with the definitions of the constructs (e.g., self-efficacy, role-stress, etc.) and then asked to answer to the following question for each item: Is this item (essential; useful but not essential; or not necessary) to measure this construct (Lawshe 1975)? Then we calculated content validity ratio (CVR). CVR ranges from -1.0 to 1.0, with higher values providing greater content validity for an item (Lawshe 1975). For all the constructs, CVR ranged from .90 to .99; hence, we retained all the items (Perreault and Leigh 1989).

\section{Statistical Analyses}

The purpose of this section is to provide an overview of the statistical analyses used to test the conceptual model. First, we assessed the reliability of the measurement scales. Then, we used both Exploratory Factor Analysis (EFA) and Confirmatory Factor Analysis (CFA) to evaluate the measurement scales. Next, we employed structural equation modeling (SEM) using LISREL 9.3 and Hayes's (2013) PROCESS SPSS macro to test the hypothesized relationships.

\section{Reliability Analysis}

Reliability is defined as "the extent to which results are consistent over time and an accurate representation of the total population under study and if the results of a study can be reproduced under a similar methodology, then the research instrument is considered to be reliable" (Golafshani 2003, p. 598). Reliability is considered "a necessary but insufficient condition for validity" (Cook and Beckman 2006, p. 165) ${ }^{3}$. In the current research, all the

\footnotetext{
${ }^{3}$ Validity is "the degree to which instruments truly measure the constructs which they are intended to measure" (Peter 1981, p. 165).
} 
measures are multi-item and reflective ${ }^{4}$; hence, we calculated Cronbach's coefficient alpha to assess the internal consistency reliability of the scales (Cortina 1993; DeVellis 1991). According to Hair et al. (1998), an acceptable value for Cronbach's alpha is .70 and above. Furthermore, we examined inter-item correlations and item-to-total correlations, which is the correlation between the item and the total scale score and factor loadings. Inter-items correlations should fall between .15 to .50 (Clark and Watson 1995), whereas item-to-total correlations should exceed .50 (Hair et al. 1998). Items that did not meet these criteria were removed from the scale.

Exploratory factor Analysis

EFA is used to determine the relationships between measurement items and to identify the number of factors or constructs (Hair et al. 1998). We conducted EFA using SPSS version 26. Specifically, we employed a principal component analysis (PCA) with an oblique rotation (direct oblimin). Oblique rotation is appropriate as we expected the constructs to be correlated (Rossiter 2002). EFA was performed on all the variables (e.g., self-efficacy, opportunism) in the conceptual model. High factor loadings suggest that the factor explains a higher percentage of the item's variance (Hair et al. 1998). We also examined if any item cross-loaded on more than one factor. Low-loading and/or cross-loading items were deleted from the scales.

\section{Confirmatory Factor Analysis}

We ran confirmatory factor analysis (CFA) to check for the unidimensionality of the constructs. Unidimensionality is a necessary condition for construct validity (Anderson and Gerbing 1988) and is reflected by the overall fit of the model (Bagozzi \& Yi 1988). The overall fit of the model can be evaluated based on likelihood-ratio chi-square, root mean square error approximation (RMSEA), and comparative fit index (CFI) (Hu and Bentler 1999). A non-

\footnotetext{
${ }^{4}$ In reflective measures, constructs are viewed as causes of measures. Such measures represent reflections or manifestations of a construct (Edwards and Bagozzi 2000).
} 
significant chi-square is desired for the overall model fit (Bagozzi \& Yi 1988). According to $\mathrm{Hu}$ and Bentler (1999), the recommended cut-off values for a good model fit for RMSEA and CFI are less than .06 and greater than .90 , respectively. However, it is suggested that when the sample size is smaller than 250 , researchers should use CFI to evaluate the fit of the model because for small sized sample RMSEA is more likely to over-reject the model (Hu and Bentler 1999).

When the items strongly load onto their intended latent variable, it provides evidence of convergent validity (Hair et al. 2006). We examined the item loadings from both EFA and CFA results to see if the measurements have convergent validity. Evidence of discriminant validity can be established when the average variance extracted (AVE) for each construct exceeds the squared pairwise correlation between the constructs (Fornell and Larcker 1981). For constructs that did not meet this criterion, discriminant validity was further examined using Bagozzi and Phillip's (1982) chi-square difference test method.

\section{Nonresponse Bias}

Nonresponse bias occurs when a significant number of people do not respond to survey questionnaires and their characteristics are different from people who do respond (Armstrong and Overton 1977). Because of nonresponse bias, survey results can lead to misleading information that do not generalize to entire population (Rogelberg and Stanton 2007). We strived to increase the response rate by following several recommended techniques, such as managing the survey length, providing incentives, establishing survey importance, and monitoring survey response (Rogelberg and Stanton 2007). In addition, the respondents were given the assurance of confidentiality. We also used wave analysis to compare late respondents with early respondents (Armstrong and Overton 1977, Rogelberg and Stanton 2007). For Study 1, we did not find any 
significant differences between early and late respondents on the focal variables, with the exception of role overload $(\mathrm{F}(1,224)=4.64, \mathrm{p}<.05)$.

\section{Common Method Variance}

Marketing researchers define common method variance (CMV) as the inflation or deflation in true correlations among variables (Malhotra et al. 2007). We followed several techniques a priori to control for different sources of common method bias. First, we introduced separation between the measures of independent variables and dependent variables by placing the measures in different parts of the survey questionnaire. Second, we eliminated common scale properties; the constructs were measured using different scale formats (e.g., Likert and semantic differential) (Podsakoff et al. 2012). Third, we made sure that the wordings in the measurement items were not ambiguous (Podsakoff et al. 2012). Despite these efforts, when data is collected using a single instrument (e.g., survey) and respondents' answers to the dependent and independent variables are collected all at once, it may create a common method variance (MacKenzie and Podsakoff 2012). Therefore, we used Harmon's one-factor test and the marker variable approach to assess the presence of CMV in Study 1 (Lindell and Whitney 2001; Malhotra et al. 2007).

Specifically, we ran an EFA with all the items in the study (including the control variables). If a single factor explained most of the variance then there is a high possibility of CMV. However, the EFA revealed thirteen factors for the thirteen variables included in the model. Furthermore, the first factor cumulatively accounted for approximately only $13 \%$ of the variance. Therefore, the likelihood of CMV was low (Podsakoff et al. 2003). In addition, we also used a marker-variable technique to assess CMV (Lindell and Whitney 2001). Specifically, for Study 1, we included a marker variable (i.e., blue attitude) in the survey that is theoretically 
unrelated to the variables in the survey. Because this variable is theoretically unrelated to the other variables, the correlation should be very low, providing evidence that there is low level of CMV. The results show that blue attitude is not significantly correlated to any other variables in the model except for complacency. The smallest correlation between blue attitude and the other variables was -.01; therefore, we adjusted the correlation between variables by this amount as suggested by Lindell and Whitney (2001). After this adjustment, the significance of the correlations between the variables remained the same. This suggests that CMV is not an issue for this study (Lindell and Whitney 2001).

\section{Study 2}

We conducted a laboratory experiment for Study 2. Lab experiments are less susceptible to internal validity threats and can establish causality between independent and dependent variables (Perdue and Summers 1986). Kinnear and Taylor (1996) discuss three necessary conditions for causality: (1) a cause and an effect must occur together or vary together in a way that is predicted by the hypothesis, (2) the cause must occur either before the effect or simultaneously with the effect, and (3) there must not be any other possible causal factors other than the hypothesized one. This experiment addresses all three criteria. To address the third criteria, the lab experiment will control for alternative explanations for the observed effects by measuring three control variables, namely salesperson's experience, salesperson's ethical ideology, and salesperson's conscientiousness.

\section{Design and Sample}

Study 2 is a 2 (Self-efficacy: High v. Low ) x 2 (Role Stress: High v. Low) factorial between-subjects design, where the participants were randomly assigned to one of the four 
conditions. The dependent measures are self-control, opportunism, complacency, effort, and performance.

The study was conducted in a West Virginia University computer lab. We recruited 100 undergraduate students to participate in the study via the John Chambers College of Business and Economics Subjects Pool at West Virginia University. In exchange for their participation, they were awarded up to $\$ 5$ and $2 \%$ extra credit in one of their courses. Half of the students recruited (i.e., 50 students) were assigned the role of the salesperson and the other half were assigned the role of the buyer. However, because of missing data, we deleted 4 matched dyads, making the final sample size: 46 sellers and 46 buyers. The average age of the participants was 21, and 53\% were male and $47 \%$ were female. We used "Chatplat," an online application that allows one to design, administer, record, and analyze conversations between real people online. Using this software, salespeople were engaged in negotiations with buyers. Similar to our study, previous studies also have used undergraduate students to role-play sales interactions in laboratory experiments (e.g., Kolb et al. 2012; Marshall and Mowen 1993).

While some research argues that lab experiments with college students lack external validity, it is important to "recognize that most student-based research is not conducted to generalize findings to nonstudent populations"; rather, student-based research is conducted for theory testing and to increase our understanding of the process(es) that underlie behavior in work-related contexts (Dobbins et al. 1988, p. 377). Research has demonstrated that students are acceptable subjects for this purpose (Dobbins et al. 1988). Furthermore, research has reported similar findings between student samples and non-student samples (Locke 1986). For example, Locke (1986, p. 6) reports that "Both college students and employees appear to respond similarly 
to goals, feedback, incentives, participation, and so forth, perhaps because the similarities among these subjects (such as in values) are more crucial than their differences."

\section{Procedures}

Because of the shortage of the laboratory space and unavailability of the students, we conducted the lab experiment in four sessions ${ }^{5}$. However, we took extra steps to ensure the lab settings and procedures were consistent across all four sessions (e.g., same lab, same experimenter, same script). Upon arriving at the computer lab, the salesperson participants (46 undergraduate students who were assigned the role of salesperson) were randomly assigned to one of the four conditions and were taken to an individual computer. Then the following instructions were given:

"Thank you so much for your participation. We greatly appreciate your time and help. Your participant number is written on the card taped to your desk. On the desktop, you will see a Qualtrics link. Once, you click on the link, it will take you to the survey. In the survey you will be asked to watch a short video on how to handle sales objections. After watching the video, you will take a quiz. After the quiz you will be linked up with a buyer using a software called Chatplat. It's a chatting application. You will be required to make a sale to a buyer. Information on what you will be selling is already in Qualtrics, and we will also give a printed copy of the selling scenario. You will also have to solve a set of anagrams while you are making the sale. You will solve these anagrams on pen and paper. At least three anagrams and the sale need to be completed in order to be compensated."

Next, the participants proceeded to read the consent form on the front page of the Qualtrics survey. Then the participants were directed to watch a sales training video on how to handle objections from the potential buyers and close the sales ${ }^{6}$. After viewing the video, they took a 10-question training quiz on Qualtrics (see Appendix C). While the salespeople were

\footnotetext{
${ }^{5}$ We conducted one-way ANOVA across the four sessions on focal variables to see if there are any significant differences between sessions. Results suggest that there is no significant difference across four sessions: selfefficacy $(\mathrm{F}(3,42)=.129, \mathrm{p}>.10)$, stress $(\mathrm{F}(3,42)=.864, \mathrm{p}>.10)$, self-control $(\mathrm{F}(3,42)=.526$, p >.10), effort $(\mathrm{F}(3$, $42)=.523, \mathrm{p}>.10)$, complacency $(\mathrm{F}(3,42)=.243, \mathrm{p}>.10)$, performance $(\mathrm{F}(3,42)=.199, \mathrm{p}>.10)$, and opportunism $(\mathrm{F}$ $(3,42)=1.22, \mathrm{p}>.10)$.

${ }^{6}$ The link to the video is: https://www.youtube.com/watch?v=xaY-YpePuio.
} 
watching the video and taking the sales quiz, the buyers were seated at their desk with a computer, enjoying the snacks given to them and solving anagrams with pen-and-paper. The purpose of the anagrams was to keep the buyers occupied while the salespeople were completing the training video and the follow-up quiz.

After the quiz, the salespeople were given the sales task to read (see Appendix D), and a set of anagrams to solve. Then they were given the following instructions:

"Please read the selling scenario thoroughly before entering the chat. Also, while you are engaged in the selling task, remember to solve the anagrams. You need at least three solved anagrams and a completed sales task to be compensated. You will get 12 minutes to complete both the tasks. If you finish the agreement early, please sit quietly and let everyone finish."

After reading the sales task, the salespersons entered Chatplat and were linked with a buyer. The buyers also received the buying task to read (see Appendix E) before entering the chat. Once the negotiation was complete in Chatplat, both the buyers and the salespeople handed in the anagrams and took a couple of minutes to reflect on the negotiation task they just completed. During this time the salespeople were served $30 \mathrm{M} \& \mathrm{Ms}$ in a disposable cup. After two minutes, the participants started the post-task survey. It took approximately 40 minutes for the participants to complete the whole task.

\section{Manipulations}

Self-efficacy Manipulation. To manipulate self-efficacy, we followed the process used by Vancouver et al. (2002). Participants were randomly assigned to either a high self-efficacy condition or a low self-efficacy condition. Participants in both the conditions watched the sales training video and took a 10-question, sales-training-related quiz in Qualtrics. After completing the quiz, the participants received feedback on their performance (Vancouver et al. 2002). High self-efficacy conditions received feedback that they answered 9 out of 10 question correctly 
(regardless of their actual performance). Low self-efficacy condition, in contrast, received feedback that they answered 2 out of 10 question correctly (regardless of their actual performance). Next, participants were asked to estimate from $0-10$, how many questions they think they will get correct on a similar 10-question, sales-training quiz. This measure represents self-efficacy magnitude of an individual (Bandura 1986). The participants also answered to another 3-item self-efficacy manipulation check question adapted from Jaramillo and Mulki (2008). The items were measured in a 7-point Likert scale and the items were: (1) Overall, I am confident in my ability to sell products, (2) I feel I am very capable at the task of selling, and (3) I feel I have the capability to successfully sell products. We ran a one-way ANOVA in SPSS to check if the high self-efficacy condition is statistically different from the low self-efficacy condition group.

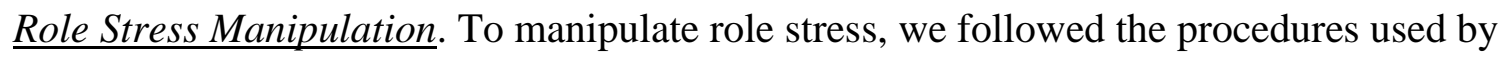
Mogg et al. (1990). In the high-stress condition, participants were asked to solve at least 3 anagrams out of 10 anagrams while they are completing the sales-related task. Out of the 10 anagrams, five were difficult but solvable (e.g., thwgie [weight]) and the remainder were unsolvable (e.g., olwgfna). In the low-stress condition, participants were asked to solve at least 3 anagrams out of 10 anagrams prepared from three-letter and four-letter words of high frequency (e.g., pehl [help]) (see Appendices H and I).

In both the high stress and low stress conditions, participants tried to solve the anagrams while they were completing the sales task. All the anagrams were given in pen-and-paper format. The reason for asking the salespeople to solve the anagrams while completing the sales task is twofold: (1) it produces role conflict, as respondents have competing demands on their time and must decide how to allocate their time and (2) this simulates role overload. To ensure 
participants are dedicating sufficient time to the anagrams, they were informed that they must complete both the sales task and solve at least three anagrams in order to get compensated.

For the manipulation check, we used 3-item stress appraisal scale (Boyes and French 2010). The items are: (1) How stressed did you feel during the anagram task? (2) To what extent did the anagram task make you feel overwhelmed? (3) How anxious did you feel during the anagram task? Items were responded on a 7-point scale ( $1=$ not at all, $7=$ extremely). We also measured role conflict and role overload, because both role conflict and role overload are recognized sources of role stress (Mulki et al. 2008). Role conflict was measured using four items: (1) It was difficult to complete both tasks, (2) I did not have adequate resources to complete both tasks, (3) I did not have enough time to complete both tasks effectively, and (4) I could not do both tasks simultaneously (Mulki et al. 2008). Role overload items were adapted from Fournier et al. (2010): (1) I was not given enough time to do the sales task, (2) It often seemed like I had too much for one person to do, (3) I had too much work to do the sales task well, and (4) The amount of work I was asked to do was unreasonable. All the items were on a 7point scale $(1=$ strongly disagree, $7=$ strongly agree $)$. One-way ANOVA was conducted to check if the high-stress condition was statistically different from the low-stress condition.

\section{Measures}

We used established measures for all the constructs in Study 2 (see Appendix F and G). However, for some constructs we used more than one measure. Furthermore, on Chatplat, all the conversations between a seller and a buyer can be monitored and coded. We measured opportunism by coding guileful tactics used by the sellers to close the sale. For example, lying about the product and other customers' satisfaction levels to close the sale, and withholding information during the Chatplat conversation (see appendix J). Salesperson opportunism was 
also measured using established scale (see Appendix G) in the buyer survey after the negotiation task was complete.

This chapter outlined the research design, sample, and the procedures for both studies. In the next chapter, we will discuss the statistical procedures used to analyze the data and we will present the results.

\section{CHAPTER 5}

\section{STUDY 1 METHOD AND RESULTS}

The purpose of this chapter is to present the methods and results of the Study 1. The chapter is organized as follows: First, we discuss the sample. Second, the psychometric properties of the measures are presented. Next, the hypotheses are tested using structural equation modeling in LISREL 9.3 and Hayes PROCESS (Study 2) in SPSS. Lastly, we present the results of Study 1.

\section{Sample}

As mentioned in the previous chapter, we employed online market research firm, Dynata, to recruit B2B salespeople in the U.S. After cleaning the data, our final sample size was 226 salespeople from multiple industries. $51.3 \%$ of the respondents were over 55 years, $27 \%$ were between $46-55$ years, $15 \%$ were between $36-45,5.8 \%$ of the respondents were between $26-35$, and only $.9 \%$ were between $18-25.66 .8 \%$ of the respondents were men and $33.2 \%$ were women. Approximately $83 \%$ of the respondents reported that they have more than 10 years of experience in sales. Respondents reported their compensation as commission (13.7\%), salary (24.4\%) and combination of commission and salary $(61.9 \%)$. Respondents also reported that they sell products $(38.1 \%)$, service $(28.3 \%)$, and both products and service $(33.6 \%)$. 


\section{Measurement Purification and Validation}

We used both Exploratory Factor Analysis (EFA) and Confirmatory Factor Analysis (CFA) to examine the psychometric properties of the scales. First, we examined inter-item correlations and item-to-total correlations. Then we ran EFA. Specifically, we employed a principal component analysis (PCA) with an oblique rotation (direct oblimin). We did not remove any items based on the EFA results, as the items strongly loading on to their intended variables (see Appendix A).

Second, we ran CFA using Lisrel 9.2 (Jöreskog and Sörbom 2015) to check the measurement model of all the constructs individually (see Table 4). We examined the modification indices which show how much the chi-square would increase if a parameter is freed (Bagozzi \& Yi 1988). Based on the modification indices and considering the theoretical relevance, we removed one item (i.e., item 2) from complacency and one item (i.e., item 5) from conscientiousness.

Third, we put all the remaining items in a measurement model to check the fit of the model. In the measurement model, the control variables (i.e., experience, process and output control, social support, ethical ideology, and conscientiousness) were set as observed variables. The indicators of the controls variable measures were averaged to make them observed variables. However, except role stress, the other focal variables were set as latent variables with their indicators. For role stress, we averaged all the 15 items of role ambiguity, role overload, and role conflict and set role stress as an observed variable. The initial measurement model fit the data poorly: Chi-square value was 1434.324 with 374 degrees of freedom ( $\mathrm{p}=0.00)$, CFI was .81 and RMSEA was 0.12 . We utilized an iterative process and examined the modification indices to further enhance the fit of the model. After several iterations, we eliminated self-efficacy items 1 
and 4, self-control items 1 and 4, opportunism item 2, performance item 2, complacency items 2, 3 and 4 , and effort item 3. The chi-square value of this measurement model was 484.078 with 169 degrees of freedom $(\mathrm{p}=.00)$. CFI and RMSEA were .90 and .09 , respectively. These two indices of fit suggest that the measurement model has an acceptable fit with the data (Hu and Bentler 1999).

We examined the item loadings from both EFA and CFA results to see if the measurements had convergent validity. All the items strongly loaded onto their intended variable and exceeded the recommended cutoff point .4 (Hinkin 1998), providing evidence of convergent validity (Hair et al. 2006). Evidence of discriminant validity can be established when the average variance extracted (AVE) for each construct exceeds the squared pairwise correlation between the constructs (Fornell and Larcker 1981). For all the constructs, AVE exceeds the suggested threshold of .5 (Fornell and Larcker 1981). Furthermore, for all the constructs, AVE exceeds the squared correlations between the corresponding constructs (see Table 5).

\section{Structural Model}

To test our hypothesized model, we employed structural equation modeling (SEM) using LISREL 9.3. SEM is more advantageous than multiple regression analysis (Hair et al., 1998) since it estimates multiple equations simultaneously and therefore examines the model as a whole. Furthermore, it accounts for measurement errors (Hair et al., 1998).

To examine interaction effects in SEM, we created the interaction terms of self-efficacy and role stress by using the residual-centered method (Little et al. 2006). According to Little et al. (2006), residual-centered method is more beneficial than the mean-centering method as it can solve the collinearity problem that mean-centering method cannot. We calculated the interaction term by multiplying each item of self-efficacy with an item from role stress measure. For 
example, with 2 items measuring self-efficacy and 15 items measuring role stress (4 items for role ambiguity, 6 items for role overload and 5 items for role conflict), a total of 30 product terms are calculated for the interaction between self-efficacy and role stress. These product terms are then regressed on all the measurement items for self-efficacy and role stress in linear equations to generate the residual terms. The residual terms then become the indicators for the interaction. In this case, there are 30 indicators for the self-efficacy-role stress interaction. However, to reduce the number of parameters, all the indicators of the interaction term are averaged to form an observed variable.

\section{Results}

For the overall structural model, the chi-square value was 515.724 with 186 degrees of freedom $(\mathrm{p}=.00)$. CFI and RMSEA were .89 and .08 , respectively (see Table 6$)$. These two indices suggest that structural model has an acceptable fit with the data (Hu and Bentler 1999).

In H1, we hypothesized that salesperson self-efficacy will be related negatively to salesperson self-control. Result suggests that although significant, it is not in the predicted direction $(\gamma=.247, \mathrm{p}<.05)$. H1, therefore, is not supported. In H2, we hypothesized that salesperson self-control will be related negatively to salesperson opportunism. Result supports this hypothesis $(\beta=-.420, \mathrm{p}<.01)$. In $\mathrm{H} 3$, we expected a positive relationship between salesperson self-efficacy and salesperson complacency. Result suggests that although significant, it is not in the predicted direction $(\gamma=-.396, \mathrm{p}<.01)$. Hence, $\mathrm{H} 3$ is not supported.

H4 is a mediation hypothesis: complacency $\rightarrow$ effort $\rightarrow$ performance. We hypothesized that salesperson complacency will be related negatively to salesperson performance and this relationship will be mediated by salesperson (reduced) effort. Result suggests that complacency is related negatively to performance $(\beta=-.197, \mathrm{p}<.05)$, and complacency is related negatively to 
effort $(\beta=-.223, p<.05)$. However, effort is not significantly related to performance $(\beta=-.02$, p>.05). Hence, H4 is not supported.

H5 posits that salesperson role stress will be related negatively to self-control. The results support this hypothesis $(\beta=-.487, \mathrm{p}<.05)$. H6 argues that as role stress increases, the negative association between self-efficacy and self-control will strengthen. The results reveal a significant interaction effect $(\gamma=.486, \mathrm{p}<.10)$, however, the interaction term is not in the hypothesized direction. Hence, H6 is not supported ${ }^{7}$. H7 suggests another moderated relationship; specifically, role stress will weaken the positive relationship between salesperson self-efficacy and complacency. The result reveals a nonsignificant interaction effect $(\gamma=.440, p>.10)$. Hence, H7 is not supported. These results, as well as the results of Study 2, will be discussed in Chapter 7.

\footnotetext{
${ }^{7}$ Using PROCESS Macro of SPSS (Model 7 with 20,000 bootstrapped samples), the Index of Moderated Mediation (IMM) for the SE x RS interaction was found to be significant $(95 \%$ CI: $-.1560<\mathrm{IMM}=-.0621<-.0083)$ for the $\mathrm{SE} \rightarrow \mathrm{SC} \rightarrow$ Opportunism path, and the IMM for the SE x RS interaction was also found to be significant (95\% CI: $.0052<\mathrm{IMM}=.0526<.1453$ ) for the $\mathrm{SE} \rightarrow \mathrm{SC} \rightarrow$ Performance path. For the interaction plots, see Appendix K.
} 
Table 4: CFA Results for the Study 1 Constructs (with all items)

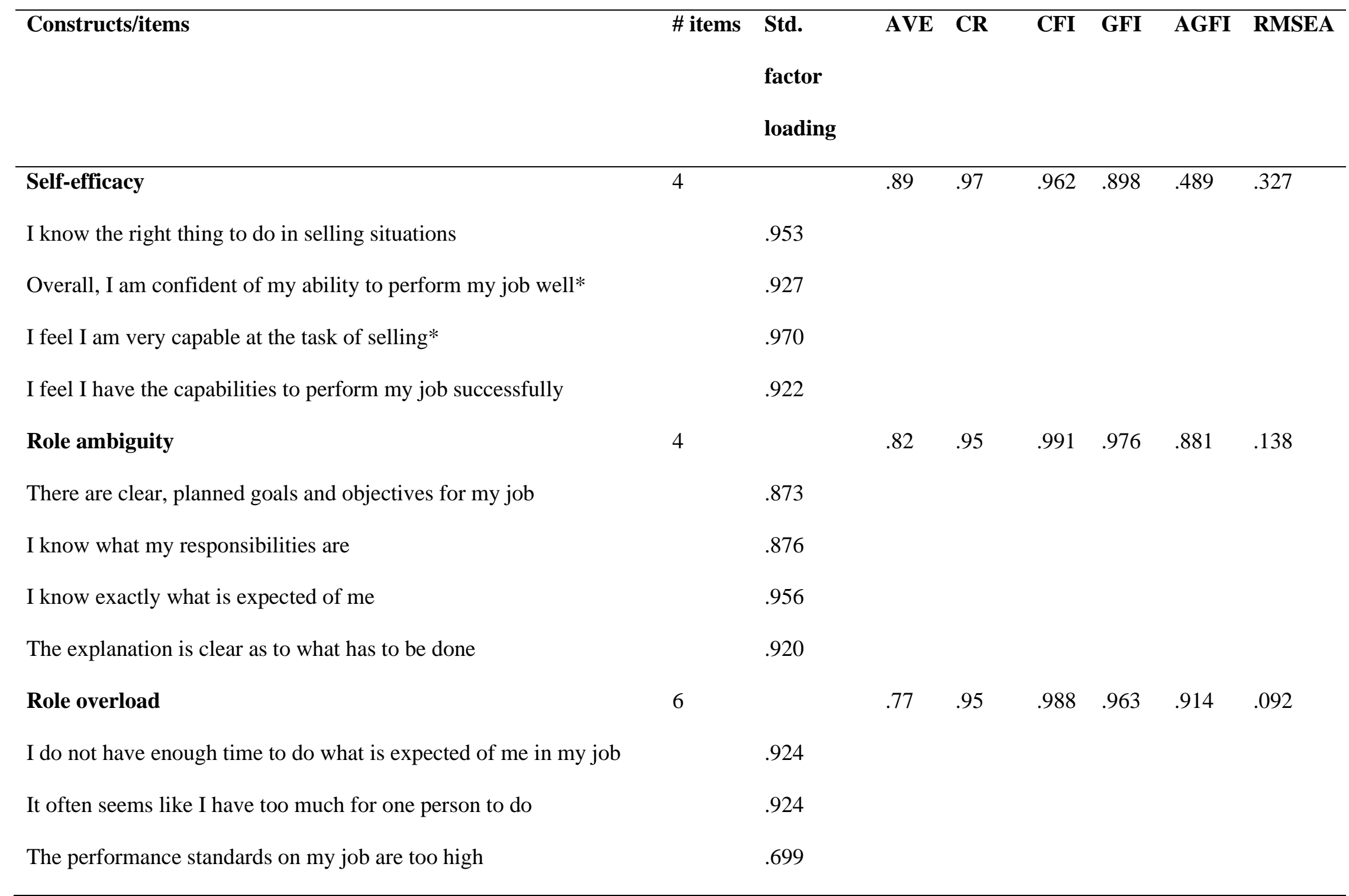




\begin{tabular}{|c|c|c|c|c|c|c|c|c|}
\hline Constructs/items & \# items & $\begin{array}{l}\text { Std. } \\
\text { factor } \\
\text { loading }\end{array}$ & AVE & $\mathbf{C R}$ & CFI & GFI & AGFI & RMSEA \\
\hline I have too much work to do everything well & & .940 & & & & & & \\
\hline The amount of work I am asked to do is unreasonable & & .887 & & & & & & \\
\hline I never seem to have enough time to get everything done & & .851 & & & & & & \\
\hline Role conflict & 5 & & .62 & .91 & .962 & .947 & .841 & .145 \\
\hline I sometimes have to bend a rule in order to carry out an assignment & & .650 & & & & & & \\
\hline I often receive incompatible requests from two or more people & & .840 & & & & & & \\
\hline I often receive an assignment without the manpower to complete it & & .819 & & & & & & \\
\hline $\begin{array}{l}\text { I often receive an assignment without adequate resources to execute } \\
\text { it }\end{array}$ & & .809 & & & & & & \\
\hline $\begin{array}{l}\text { I do things that are accepted by one person and not accepted by } \\
\text { others }\end{array}$ & & .809 & & & & & & \\
\hline Self-control & 6 & & .53 & .87 & .952 & .948 & .878 & .118 \\
\hline Pleasure and fun sometimes keep me from getting work done* & & .554 & & & & & & \\
\hline I have trouble concentrating at work & & .769 & & & & & & \\
\hline I have trouble concentrating at work & & .799 & & & & & & \\
\hline
\end{tabular}




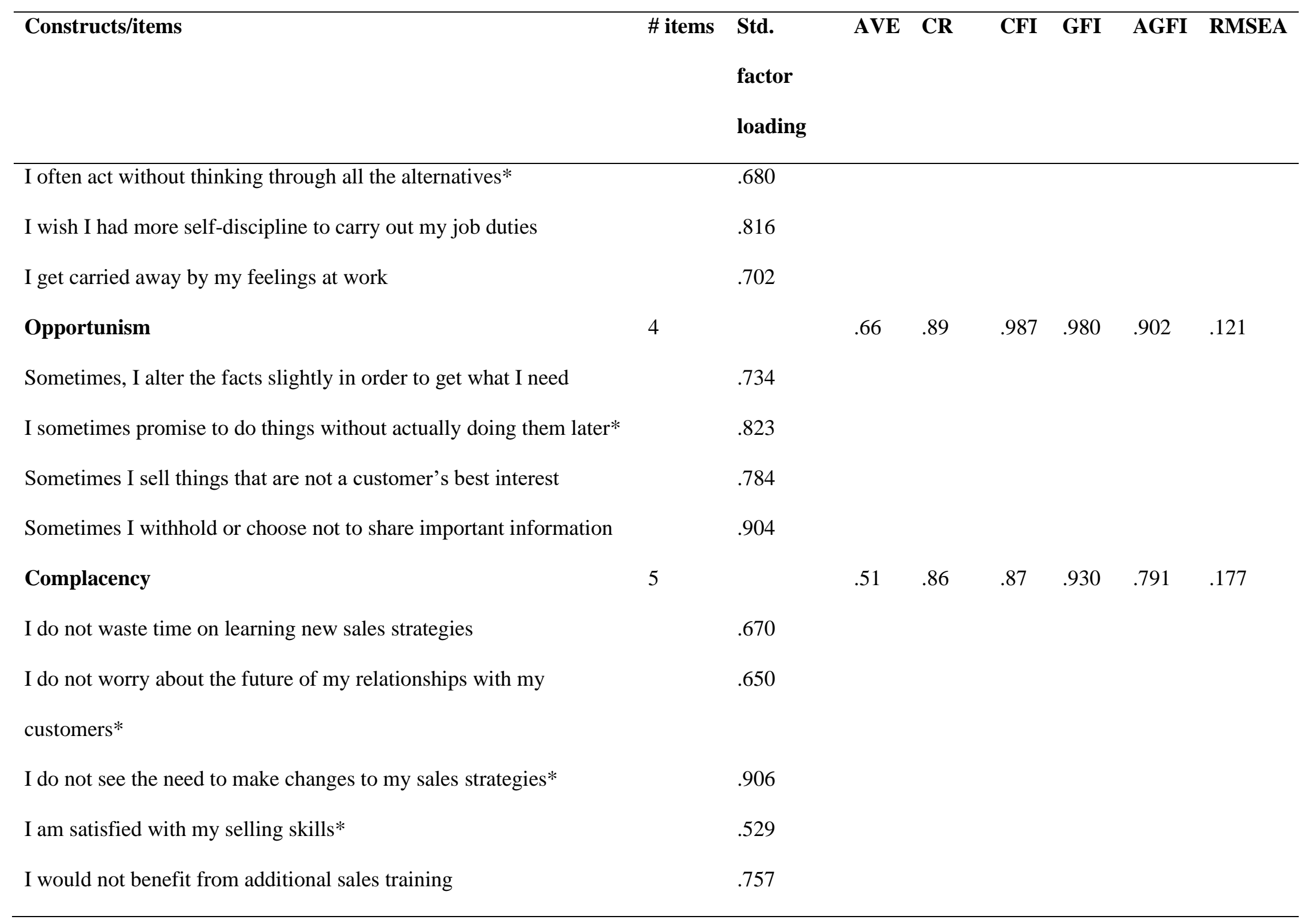




\begin{tabular}{|c|c|c|c|c|c|c|c|c|}
\hline Constructs/items & \# items & $\begin{array}{l}\text { Std. } \\
\text { factor } \\
\text { loading }\end{array}$ & AVE & $\mathbf{C R}$ & CFI & GFI & AGFI & RMSEA \\
\hline Effort & 4 & & .68 & .90 & .981 & .976 & .881 & .151 \\
\hline Overall effort in the sales task & & .861 & & & & & & \\
\hline Number of hours worked & & .801 & & & & & & \\
\hline Number of sales calls made* & & .773 & & & & & & \\
\hline Amount of time spent communicating with the customers & & .864 & & & & & & \\
\hline Performance & 3 & & .89 & .86 & - & - & - & - \\
\hline My level of quota/goal achievement during the past year is: & & .912 & & & & & & \\
\hline My sales manager would rate my performance during the past year & & .881 & & & & & & \\
\hline \multicolumn{9}{|l|}{ as*: } \\
\hline My overall sales performance during the past year is: & & 1.035 & & & & & & \\
\hline Conscientiousness (control) & 5 & & .55 & .83 & .959 & .964 & .892 & .117 \\
\hline I accomplish my work on time & & .734 & & & & & & \\
\hline I do things according to a plan & & .756 & & & & & & \\
\hline I am careful to avoid making mistakes & & .685 & & & & & & \\
\hline
\end{tabular}




\begin{tabular}{|c|c|c|c|c|c|c|c|c|}
\hline Constructs/items & \# items & $\begin{array}{l}\text { Std. } \\
\text { factor } \\
\text { loading }\end{array}$ & AVE & $\mathbf{C R}$ & CFI & GFI & AGFI & RMSEA \\
\hline I like to plan ahead & & .778 & & & & & & \\
\hline I return borrowed items* & & .490 & & & & & & \\
\hline Output control (control) & 5 & & .51 & .88 & 1.0 & .993 & .980 & 0.0 \\
\hline Specific quantitative performance goals are established for my job & & .795 & & & & & & \\
\hline $\begin{array}{l}\text { The extent to which I attain my quantitative performance goals is } \\
\text { critically evaluated }\end{array}$ & & .825 & & & & & & \\
\hline $\begin{array}{l}\text { If my quantitative performance goals are not met, I am required to } \\
\text { explain why }\end{array}$ & & .677 & & & & & & \\
\hline $\begin{array}{l}\text { Feedback concerning the extent to which I achieve the assigned } \\
\text { goals is provided to me on a regular basis }\end{array}$ & & .700 & & & & & & \\
\hline $\begin{array}{l}\text { My pay increases are based upon how my performance compares } \\
\text { with my goals }\end{array}$ & & .517 & & & & & & \\
\hline Process control (control) & & & .53 & .81 & .939 & .956 & .779 & .211 \\
\hline $\begin{array}{l}\text { The extent to which I follow established sales procedures is } \\
\text { critically monitored }\end{array}$ & & .890 & & & & & & \\
\hline
\end{tabular}




\begin{tabular}{|c|c|c|c|c|c|c|c|c|}
\hline Constructs/items & \# items & $\begin{array}{l}\text { Std. } \\
\text { factor } \\
\text { loading }\end{array}$ & AVE & $\mathbf{C R}$ & CFI & GFI & AGFI & RMSEA \\
\hline $\begin{array}{l}\text { The procedures used to accomplish a given selling task are explicitly } \\
\text { regulated }\end{array}$ & & .762 & & & & & & \\
\hline $\begin{array}{l}\text { My immediate boss modifies my work procedures when desired } \\
\text { results are not obtained }\end{array}$ & & .548 & & & & & & \\
\hline $\begin{array}{l}\text { Feedback on the process I use to accomplish my performance goals } \\
\text { is frequently communicated to me }\end{array}$ & & .673 & & & & & & \\
\hline Ethical ideology (control) & 3 & & .73 & .78 & - & - & - & - \\
\hline $\begin{array}{l}\text { Jeopardizing the well-being of customers is not necessary to achieve } \\
\text { desired ends in sales }\end{array}$ & & .804 & & & & & & \\
\hline $\begin{array}{l}\text { Desirable sales outcomes are most frequently obtained by following } \\
\text { an ethical course of action }\end{array}$ & & .851 & & & & & & \\
\hline $\begin{array}{l}\text { An ethical course of action is always the best one a salesperson can } \\
\text { take }\end{array}$ & & .901 & & & & & & \\
\hline Social support (control) & 3 & & .66 & .74 & - & - & - & - \\
\hline Colleagues & & .620 & & & & & & \\
\hline
\end{tabular}




\begin{tabular}{|c|c|c|c|c|c|c|}
\hline Constructs/items & \# items & $\begin{array}{l}\text { Std. } \\
\text { factor } \\
\text { loading }\end{array}$ & AVE CR & CFI GFI & AGFI & RMSEA \\
\hline Direct supervisor & & .922 & & & & \\
\hline Upper management & & .859 & & & & \\
\hline
\end{tabular}

Note: performance, ethical ideology, and social support have three indicators each. Hence, for these constructs, the measurement model is saturated. Items with an asterisk symbol $(*)$ were deleted in the scale purification process. 
Table 5: Descriptive Statistics and Correlations for Study 1 Variables (with trimmed items)

\begin{tabular}{|c|c|c|c|c|c|c|c|c|c|c|c|c|c|c|c|c|}
\hline & Mean & S.D. & 1 & 2 & 3 & 4 & 5 & 6 & 7 & 8 & 9 & 10 & 11 & 12 & 13 & AVE \\
\hline Self-efficacy & 6.24 & 0.96 & $(.46)$ & & & & & & & & & & & & & .90 \\
\hline Self-control & 5.21 & 1.17 & $.271^{* *}$ & $(.73)$ & & & & & & & & & & & & .60 \\
\hline Opportunism & 2.48 & 1.16 & $-.222^{* *}$ & $-.506^{* * *}$ & $(.59)$ & & & & & & & & & & & .66 \\
\hline Performance & 5.47 & 1.23 & $.286^{* *}$ & $.414^{* * *}$ & $-.251^{* *}$ & (.49) & & & & & & & & & & .98 \\
\hline Role Stress & 4.29 & 0.77 & 0.09 & $-.244^{* *}$ & $.200^{* * *}$ & -0.05 & $(-)$ & & & & & & & & & .83 \\
\hline Complacency & 3.14 & 1.24 & -0.13 & -0.09 & $.173^{* *}$ & -0.04 & 0.10 & $(.30)$ & & & & & & & & .53 \\
\hline Effort & 5.61 & 0.98 & $.261^{* * *}$ & $.328^{* *}$ & $-.275^{* *}$ & $.515^{* *}$ & 0.03 & -0.13 & $(.62)$ & & & & & & & .70 \\
\hline Experience & 3.32 & 0.69 & 0.08 & 0.13 & 0.02 & $.267^{* *}$ & -0.01 & $.156^{*}$ & $.179^{* *}$ & $(-)$ & & & & & & .98 \\
\hline Conscientious. & 5.97 & 0.70 & 0.09 & $.428^{* * *}$ & $-.265^{* *}$ & $.168^{*}$ & -0.03 & 0.00 & $.263^{* *}$ & 0.05 & $(-)$ & & & & & .53 \\
\hline Social support & 5.47 & 1.28 & 0.06 & $.202^{* *}$ & $-.196^{* *}$ & $.223^{* *}$ & $-.257^{* *}$ & -0.03 & $.205^{* *}$ & -0.02 & 0.08 & $(-)$ & & & & .66 \\
\hline Output Control & 4.68 & 1.16 & 0.03 & $.262^{* *}$ & $-.164^{*}$ & 0.08 & 0.02 & $-.139^{*}$ & 0.11 & -0.11 & $.178^{* *}$ & $.336^{* *}$ & $(-)$ & & & .51 \\
\hline Process Control & 3.81 & 1.19 & -0.01 & 0.13 & 0.01 & -0.01 & 0.12 & -0.04 & -0.02 & -0.02 & $.145^{*}$ & 0.06 & $.458^{* *}$ & $(-)$ & & .53 \\
\hline Ethics & 6.05 & 1.03 & $.254^{* * *}$ & $.163^{*}$ & $-.333^{* *}$ & $.212^{* *}$ & 0.02 & -0.03 & $.244^{* *}$ & 0.02 & $.178^{* *}$ & $.179^{* *}$ & $.178^{* *}$ & 0.05 & $(-)$ & .73 \\
\hline
\end{tabular}

Note: $* *$ Correlation is significant at the 0.01 level (2-tailed). Composite reliabilities are on the diagonal in a parenthesis. 
Table 6: Results for Structural Equation Model

\begin{tabular}{|c|c|c|c|c|c|c|c|c|c|c|c|}
\hline \multicolumn{12}{|c|}{ Overall Model Fit } \\
\hline \multicolumn{12}{|c|}{$\chi 2(186)=515.724, \mathrm{p} \leq .00 ; \mathrm{CFI}=0.89 ; \mathrm{RMSEA}=.08 ; \mathrm{GFI}=.854, \mathrm{AGFI}=.745$} \\
\hline \multirow[b]{3}{*}{ Hypothesis } & \multirow[b]{3}{*}{$\begin{array}{l}\text { Independent } \\
\text { Variables }\end{array}$} & \multicolumn{10}{|c|}{ Dependents Variables } \\
\hline & & \multicolumn{2}{|c|}{ Self-control } & \multicolumn{2}{|c|}{ Opportunism } & \multicolumn{2}{|c|}{ Complacency } & \multicolumn{2}{|c|}{ Effort } & \multicolumn{2}{|c|}{ Performance } \\
\hline & & $\begin{array}{l}\text { Unstd. } \\
\text { Est. }\end{array}$ & t-value & $\begin{array}{l}\text { Unstd. } \\
\text { Est. }\end{array}$ & t-value & $\begin{array}{l}\text { Unstd. } \\
\text { Est. }\end{array}$ & t-value & $\begin{array}{l}\text { Unstd. } \\
\text { Est. }\end{array}$ & t-value & $\begin{array}{l}\text { Unstd. } \\
\text { Est. }\end{array}$ & t-value \\
\hline $\mathrm{H} 1$ and $\mathrm{H} 3$ & $\begin{array}{l}\text { Self-efficacy } \\
\text { (SE) }\end{array}$ & 0.247 & 2.885 & - & - & -0.396 & -3.628 & - & - & - & - \\
\hline $\mathrm{H} 2$ & Self-control & - & - & -0.420 & -4.309 & - & - & - & - & - & - \\
\hline \multirow[t]{2}{*}{$\mathrm{H} 4$} & Complacency & - & - & - & - & - & - & -0.223 & -2.525 & - & - \\
\hline & Effort & - & - & - & - & - & - & - & - & -0.020 & -0.242 \\
\hline H5 & $\begin{array}{l}\text { Role stress } \\
\text { (RS) }\end{array}$ & -0.487 & -4.473 & - & - & - & - & - & - & - & - \\
\hline $\mathrm{H} 6$ and $\mathrm{H} 7$ & SExRS & 0.486 & 1.859 & - & - & 0.440 & 1.299 & - & - & - & - \\
\hline \multicolumn{12}{|c|}{ Non-Hypothesized Paths } \\
\hline & SExRS & & & -0.438 & -1.582 & & & 0.747 & 2.607 & 1.595 & 5.210 \\
\hline \multicolumn{12}{|c|}{ Control Variables } \\
\hline Conscientio & sness & 0.119 & 5.145 & -0.055 & -2.393 & 0.019 & 0.686 & 0.060 & 2.685 & 0.007 & 0.347 \\
\hline Social supp & & -0.036 & -0.447 & 0.015 & 0.180 & 0.212 & 2.122 & 0.194 & 2.400 & 0.316 & 4.280 \\
\hline Output cont & & 0.169 & 1.965 & -0.182 & -2.047 & -0.370 & -3.418 & -0.028 & -0.321 & -0.171 & -2.212 \\
\hline Process con & & -0.007 & -0.093 & 0.138 & 1.698 & 0.135 & 1.382 & -0.149 & -1.879 & -0.064 & -0.944 \\
\hline Ethical idec & & 0.025 & 1.539 & -0.073 & -4.275 & 0.009 & 0.469 & 0.035 & 2.148 & 0.041 & 2.883 \\
\hline Experience & & - & - & 0.040 & 2.723 & - & - & 0.043 & 2.874 & 0.022 & 1.722 \\
\hline
\end{tabular}




\section{CHAPTER 6}

\section{STUDY 2 METHOD AND RESULTS}

The purpose of this chapter is to present the methods and results of Study 2. The chapter is organized as follows: First, we discuss the sample. Second, the psychometric properties of the measures are presented. Next, the hypotheses are tested using Hayes PROCESS Macro in SPSS. We conclude with the results.

\section{Sample}

As mentioned in Chapter 4, the sample size is 46 matched pair of buyers and sellers who were undergraduate students at West Virginia University. The average age of the participants was 21 , and among the participants $53 \%$ were male and $47 \%$ were female.

\section{Measurement Purification and Validation}

First, we checked the inter-item and item-to-total correlations of the measurement items. Due to low item-to-total correlations, we dropped role overload item 1 (i.e., I was not given enough time to do the sales task), performance item 1 (i.e., I was effective in handling the buyer's objections), complacency item 1 (i.e., I did not waste time on learning new sales strategies), and conscientiousness items 1, 4 and 5 (i.e., I accomplish my work on time; I like to plan ahead; and I return borrowed items).

Then we ran EFA with oblimin rotation. Low-loading or cross-loading items (at .4 or above) were dropped. Based on the EFA results, we dropped role conflict items 2 and 3 (i.e., I did not have adequate resources to complete both tasks; I did not have enough time to complete both tasks effectively), self-control item 2 (i.e., I had trouble concentrating during this sales task), complacency item 4 (i.e., I did not see the need to use my knowledge provided in the sales training video) and effort items 3, 4 and 5 (i.e., I put a lot of effort in completing the tasks; I put a 
lot of time in completing the tasks; I wrote a lot of messages in my attempt to make a sale). The items for role conflict and role overload were loading on the same factor. Hence, we combined items 1 and 4 of role conflict and items 2, 3 and 4 of role overload. We refer to this combined measure as role stress. The remaining items were subjected to EFA (see Table 7) again and the analysis identified seven factors that cumulatively explained approximately $80 \%$ of the variance (see Table 8).

Table 7: EFA Results (with Oblimin Rotation) for the Study 2 Items

\begin{tabular}{lll}
\hline Constructs & Items & Factor loading \\
Self-efficacy & 1: I knew how to handle the buyer's objections & .748 \\
& 2: I felt very capable at the task of selling & .912 \\
& 3: I felt I had the skills to successfully make a sale & .839 \\
& 4: Overall, I was confident of my ability to sell & .884 \\
\hline Self-control & 1: I said things that I should not have during the sales exchange & .867 \\
& 3: I often responded to the buyers without thinking through all the & .660 \\
& alternatives & \\
\hline Role conflict & 1: It was difficult to complete both tasks & .701 \\
& 4: I could not do both tasks simultaneously & .714 \\
\hline Role & 2: It often seemed like I had too much for one person to do & .875 \\
overload & & \\
& 3: I had too much work to do the sales task well & .814 \\
& 4: The amount of work I was asked to do is unreasonable & .778 \\
\hline Opportunism & 2: The salesperson lied about the product & .849 \\
& 3: The salesperson provided false information & .875 \\
& 4: The salesperson withheld information & .624 \\
\hline Complacency & 2: I did not see the need to make changes to my sales strategies & .741 \\
& 3: I was satisfied with my selling skills & .842 \\
\hline Effort & 1: I put a lot of effort into answering the buyer's questions & .779 \\
& 2: I put a lot of effort into negotiating the sale & .831 \\
\hline Performance & 2: I communicated information about my product to the buyer \\
& effectively & .732 \\
& 3: I negotiated with the buyer effectively & .847 \\
& 4: I used my sales time efficiently & .831 \\
5: Overall, I am satisfied with my performance & .729 \\
\hline
\end{tabular}


Table 8: Variance Explained from the Exploratory Factor Analysis (With Trimmed Items)

\begin{tabular}{cccc}
\hline Component & Initial Eigenvalues & Variance Explained (\%) & $\begin{array}{c}\text { Cumulative Variance } \\
\text { Explained (\%) }\end{array}$ \\
\hline 1 & 6.741 & 28.089 & 28.089 \\
2 & 4.000 & 16.668 & 44.757 \\
3 & 2.822 & 11.759 & 56.516 \\
4 & 2.011 & 8.380 & 64.896 \\
5 & 1.459 & 6.081 & 70.977 \\
6 & 1.111 & 4.628 & 75.605 \\
7 & 1.091 & 4.547 & 80.152 \\
\hline
\end{tabular}

Convergent validity was tested by examining the loadings of the items of each variable (see Table 9). The range of factor loadings for self-efficacy was .75 to .91 . For role stress, it was .70 to .87 . For self-control it was .66 to .86 , for opportunism it was .62 to .85 , for effort it was .78 to .83 , for performance it was .72 to .84 , and for complacency it was .74 to .84 . Since all the factor loadings exceeded recommended levels, these results provide the evidence of convergent validity (Hair et al. 1998). Besides testing for the evidence of convergent validity, we also examined discriminant validity for the constructs with the trimmed items.

To examine discriminant validity, we ran a series of confirmatory factor analyses using Lisrel 9.3. Using Fornell and Larker's (1981) method, discriminant validity is established for all the pairwise constructs except for self-efficacy and complacency (see Table 9). The average variance extracted from complacency does not exceed the squared correlation between selfefficacy and complacency. Therefore, we conducted a chi-square difference test (Bagozzi and Phillips 1982) to further assess the discriminant validity of self-efficacy and complacency. Specifically, we ran a two-factor measurement model. Then, we ran a revised two-factor model keeping the factor correlation constrained to one. We found that there is a statistically significant chi-square difference between the two measurement models, which suggests that the constructs are not perfectly correlated $(\Delta \chi 2=6.42, \Delta$ d.f. $=1, \mathrm{p}<.025)$. This provides evidence of 
discriminant validity (Rokkan et al. 2003). We used this approach because the small sample size precluded us from the running the full measurement model in LISREL.

Table 9: Discriminant Validity Test (CFA Results)

\begin{tabular}{|lrrrr|}
\hline Factor1, Factor2 & \multicolumn{1}{|c}{} & $\mathbf{\Phi}^{\mathbf{2}}$ & $\mathbf{A V E}_{\mathbf{a}}$ & $\mathbf{A V E}_{\mathbf{b}}$ \\
Self-efficacy, self-control & -.472 & .220 & .86 & .58 \\
Self-efficacy, role stress & -.060 & .004 & .86 & .66 \\
Self-efficacy, opportunism & -.210 & .044 & .86 & .70 \\
(Self-efficacy, complacency) c & .892 & .790 & .87 & .73 \\
Self-efficacy, effort & -.040 & .002 & .87 & 4.18 \\
Self-efficacy, performance & .573 & .325 & .87 & .74 \\
\hline Self-control, role stress & .210 & .044 & 1.47 & .66 \\
Self-control, opportunism & .310 & .096 & .60 & .70 \\
Self-control, complacency & -.410 & .168 & .57 & .93 \\
Self-control, effort & -.020 & .000 & 5.83 & 3.47 \\
Self-control, performance & -.430 & .185 & .71 & .74 \\
\hline Role stress, opportunism & .360 & .129 & .65 & .69 \\
Role-stress, complacency & .050 & .002 & .65 & 3.34 \\
Role-stress, effort & .120 & .014 & .66 & 2.16 \\
Role stress, performance & .060 & .004 & .66 & .73 \\
\hline Opportunism, complacency &. .140 & .019 & .70 & 3.98 \\
Opportunism, effort & -.130 & .017 & .69 & 1.36 \\
Opportunism, performance & -0.07 & .005 & .70 & .73 \\
\hline Complacency, effort & -.130 & .016 & 1.31 & .91 \\
Complacency, performance & .610 & .372 & .72 & .74 \\
\hline Effort, performance & .30 & .090 & 1.14 & .72 \\
\hline
\end{tabular}

${ }^{a}$ Average variance extracted for factor one. ${ }^{b}$ Average variance extracted for factor two. ${ }^{c}$ Discriminant validity established with chi-square difference test.

\section{Manipulation Checks}

To test if our manipulation of self-efficacy was effective, we had two manipulation check questions (see the methods section in Chapter 4). Utilizing a one-way ANOVA, we found significant differences in high versus low self-efficacy conditions for both the manipulation check questions. In the first manipulation check question, participants were asked to estimate from $0-10$ how many questions they think they will get correct on a similar 10-question, salestraining quiz. Participants in the high self-efficacy condition scored higher $(M=8.47)$ than the participants in the low self-efficacy $(\mathrm{M}=4.67)$ condition. This difference was statistically 
significant $(\mathrm{F}(1,44)=43.701, \mathrm{p}<.001)$. In the second manipulation check question, the participants answered a 3-item, 7-point self-efficacy scale (Jaramillo and Mulki 2008). The ANOVA results show that participants in the high self-efficacy condition scored $(\mathrm{M}=5.67)$ higher than the participants in the low self-efficacy $(\mathrm{M}=4.22)$ condition. This difference was also statistically significant $(\mathrm{F}(1,44)=15.35, \mathrm{p}<.001)$.

For the stress manipulation check, we used a 3-item stress appraisal scale (Boyes and French 2010), 4-item role conflict scale (Mulki et al. 2008), and 4-item role overload scale (Fournier et al. 2010). All the scales were 7-point, Likert scales ( $1=$ strongly disagree, $7=$ strongly agree). With the stress appraisal scale, the ANOVA results revealed that the high stress condition scored higher $(\mathrm{M}=4.41)$ than the low stress condition $(\mathrm{M}=2.58)$ and this difference was statistically significant $(\mathrm{F}(1,44)=12.03, \mathrm{p}<.001)$. With the role conflict scale, the high stress condition scored higher $(M=5.37)$ than the low stress condition $(M=3.80)$ and this difference was also statistically significant $(\mathrm{F}(1,44)=23.02, \mathrm{p}<.001)$. With the role overload scale, the high stress condition scored higher $(M=4.88)$ than the low stress condition $(M=3.75)$ and this difference was statistically significant $(F(1,44)=8.41, p<.05)$. Cumulatively, these results suggest that the self-efficacy and role stress manipulations were effective.

\section{Results}

Table 10 presents the correlation matrix and descriptive statistics for Study 2. Two control variables had significant effects. Respondent age had a significant and negative relationship with self-control $(\mathrm{b}=-.3486 ; \mathrm{CI}=-.6643$ to $-.0330 ; \mathrm{p}<.05)$. Also, students' experience in a sales-related courses was related positively to effort $($ coefficient $=.8623 ; \mathrm{CI}=$ .0376 to $1.6870 ; \mathrm{p}<.05)$. 
Table 10: Descriptive Statistics and Correlations for Study 2 Variables (with trimmed items)

\begin{tabular}{|c|c|c|c|c|c|c|c|c|c|c|c|}
\hline & Mean & S.D. & 1 & 2 & 3 & 4 & 5 & 6 & 7 & 8 & 9 \\
\hline Self-efficacy & 4.89 & 1.36 & $(.91)$ & & & & & & & & \\
\hline Self-control & 3.52 & 1.50 & $-.402^{* *}$ & $(.45)$ & & & & & & & \\
\hline Opportunism & 2.91 & 1.15 & -0.210 & 0.228 & $(.72)$ & & & & & & \\
\hline Role Stress & 4.01 & 1.52 & -0.001 & 0.197 & $.299^{*}$ & $(.91)$ & & & & & \\
\hline Complacency & 4.02 & 1.51 & $.799^{* *}$ & $-.296^{*}$ & $-.306^{*}$ & -0.015 & $(.48)$ & & & & \\
\hline Effort & 5.03 & 1.38 & 0.043 & 0.110 & $.444^{* * *}$ & 0.249 & -0.117 & (.49) & & & \\
\hline Performance & 4.73 & 1.22 & $.578^{* *}$ & $-.410^{* *}$ & -0.067 & -0.009 & $.514^{* *}$ & 0.225 & (.86) & & \\
\hline Ethics & 5.41 & 1.23 & 0.016 & 0.065 & 0.253 & 0.022 & -0.063 & $.348^{*}$ & 0.078 & $(.78)$ & \\
\hline Conscientiousness & 5.53 & 1.07 & 0.167 & -0.014 & 0.063 & 0.110 & 0.072 & 0.112 & 0.062 & $.366^{*}$ & $(.87)$ \\
\hline
\end{tabular}

**. Correlation is significant at the 0.01 level (2-tailed). * Correlation is significant at the 0.05 level (2-tailed). CR is on the diagonal. 
To test our hypotheses, we employed Hayes’s (2013) PROCESS Macro (Model 7) with 20,000 bootstrapped samples with a $95 \%$ confidence interval. The results suggest that selfefficacy is related negatively to self-control $(b=-.465 ; \mathrm{CI}=-.7612$ to $-.1683 ; \mathrm{p}<.05)$. Hence, $\mathrm{H} 1$ is supported. The results also indicate that self-control is not significantly related to salesperson opportunism $(b=.0246 ; C I=-.1802$ to $.2294 ; p>.10)$. Hence, $\mathrm{H} 2$ is not supported.

Supporting H3, self-efficacy is related positively to complacency $(b=.8599 ; \mathrm{CI}=.6318$ to $1.0879 ; \mathrm{p}<.05)$. H4 is a mediation hypothesis: complacency $\rightarrow$ effort $\rightarrow$ performance. The indirect effect is not significant (indirect effect [IE] $=-.0272 ; \mathrm{CI}=-.1347$ to .0926). More elaborately, complacency is not significantly related to effort $(b=-.0909 ; \mathrm{CI}=-.3602$ to .1783 ; $\mathrm{p}>.10)$, but effort is significantly and positively related to performance $(\mathrm{b}=.2994 ; \mathrm{CI}=.0504$ to $.5485 ; \mathrm{p}<.05)$. Therefore, $\mathrm{H} 4$ is not supported. H5 argues that the relationship between role stress and self-control is negative. The relationship between role stress and self-control is not significant $(b=.2443 ; \mathrm{CI}=-.0152$ to $.5038 ; \mathrm{p}>.10)$. Hence, hypothesis 5 is not supported.

Hypothesis 6 posits that role stress will strengthen the negative relationship between selfefficacy and self-control. The result reveals a significant negative interaction $(b=-.2981 ; \mathrm{CI}=-$ .4934 to $-.1028 ; \mathrm{p}<.05$ ), supporting H6 (see figure 2). Hypothesis 7 argues that role stress will weaken the positive relationship between salesperson self-efficacy and complacency. Although the results reveal a nonsignificant interaction $(b=-.0254 ; C I=-.1757$ to $.1248 ; \mathrm{p}>.10)$, the interaction effect is in the hypothesized direction. In summary, the results support the presence of bad stress, but fail to show the presence of good stress, even though the direction of H7 suggests that this could be a possibility. Table 11 summarizes the results from Study 1 and Study 2 . The results will be discussed in the next chapter. 
Figure 2: Moderation Result (Hypothesis 6)

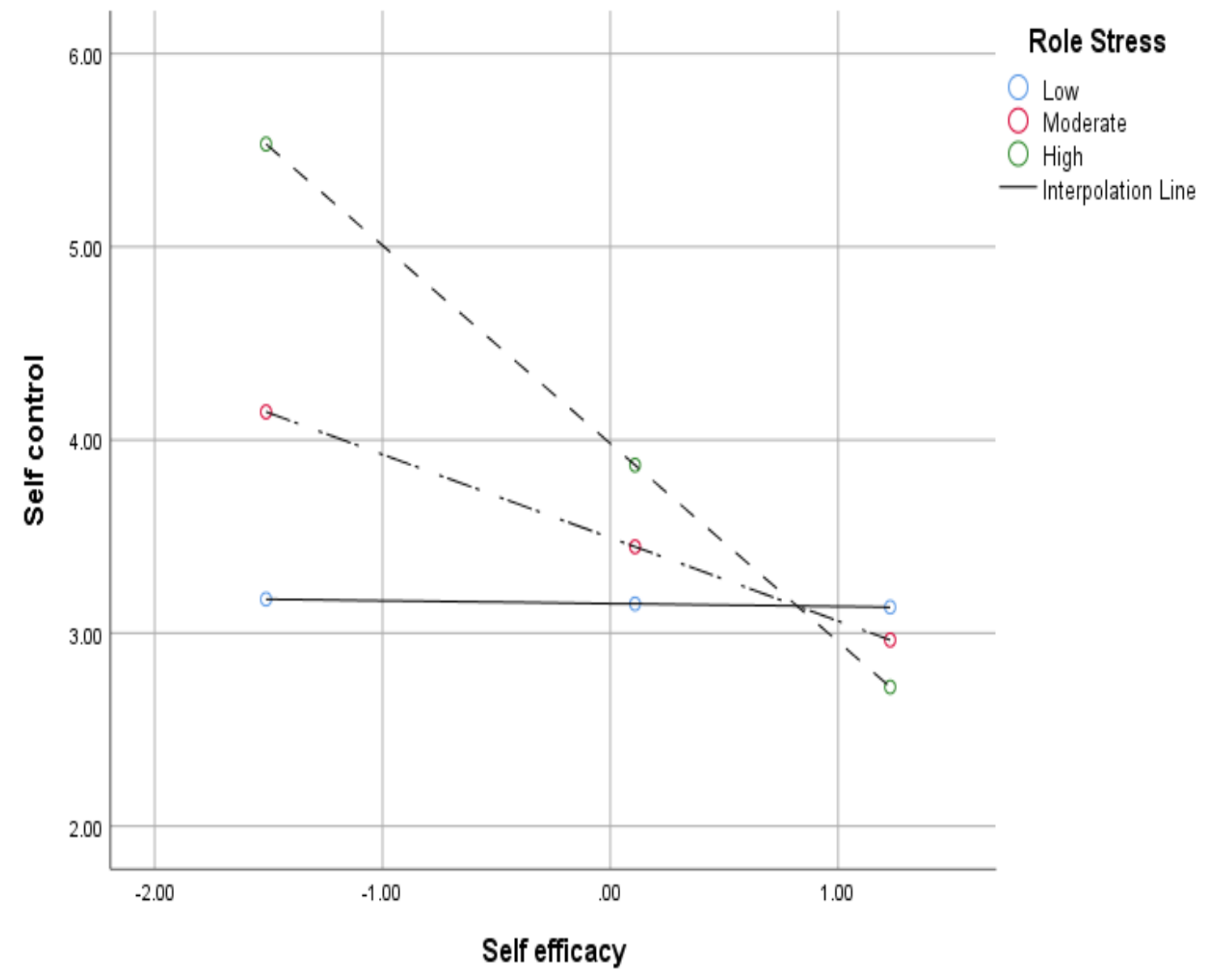


Table 11: Summary of the Results

\begin{tabular}{|l|c|c|}
\hline Hypotheses & Study 1 & Study 2 \\
\hline $\begin{array}{l}\mathbf{H}_{1}: \text { Salesperson self-efficacy is related negatively to salesperson } \\
\text { self-control }\end{array}$ & $\mathrm{NS}$ & $\mathrm{S}$ \\
\hline $\begin{array}{l}\mathbf{H}_{2}: \text { Salesperson self-control is related negatively to salesperson } \\
\text { opportunism }\end{array}$ & $\mathrm{S}$ & $\mathrm{NS}$ \\
\hline $\begin{array}{l}\mathbf{H}_{3}: \text { Salesperson self-efficacy is related positively to salesperson } \\
\text { complacency }\end{array}$ & $\mathrm{NS}$ & $\mathrm{S}$ \\
\hline $\begin{array}{l}\mathbf{H}_{4}: \text { Salesperson complacency is related negatively to salesperson } \\
\text { performance and this relationship is mediated by salesperson } \\
\text { (reduced) effort }\end{array}$ & $\mathrm{NS}$ & $\mathrm{NS}$ \\
\hline $\mathbf{H}_{5}:$ Salesperson role stress is related negatively to self-control & $\mathrm{S}$ & $\mathrm{NS}$ \\
\hline $\begin{array}{l}\mathbf{H}_{6}: \text { Role stress will strengthen the negative relationship between } \\
\text { salesperson self-efficacy and self-control }\end{array}$ & $\mathrm{NS}$ & $\mathrm{S}$ \\
\hline $\begin{array}{l}\mathbf{H}_{7}: \text { Role stress will weaken the positive relationship between } \\
\text { salesperson self-efficacy and complacency }\end{array}$ & $\mathrm{NS}$ & $\mathrm{NS}$ \\
\hline
\end{tabular}

Note: $\mathrm{S}=$ Supported, NS = Not supported 


\section{CHAPTER 7}

\section{DISCUSSION}

The purpose of this chapter is to discuss the research results and implications. Following a discussion of theoretical and managerial implications, the chapter concludes with limitations and future research directions.

\section{Summary of Results}

The current research empirically examines two possible dark side effects (i.e., opportunism and complacency) of salesperson self-efficacy. The current research also examines the potential good versus bad effects of role stress. Our results indicate mixed findings on the relationship between self-efficacy and self-control. Our experimental findings suggest that salesperson self-efficacy is related negatively to self-control, yet our survey research uncovered a positive relationship. In both studies, self-control related negatively to salesperson opportunism although it did not achieve significance in the experimental study. In the experimental study, we also find that self-efficacy is related positively to complacency, which further strengthens our argument that self-efficacy may have undesirable effects. These findings have implications in both theory and practice, as this is the first empirical study in sales that provides evidence that self-efficacy is not always a good thing.

Furthermore, the experimental study uncovered that role stress strengthens the negative relationship between salesperson self-efficacy and self-control. As such, at higher levels of stress, salespeople are more resource depleted and thus lose self-control. Although we did not find any significant result for the effect of good stress, the direction of the results in Study 2 (H7) provides some credence to this argument. Next, we will discuss the managerial and theoretical implications of these research findings. 


\section{Theoretical Contributions}

Largely, we contribute to theory by integrating social cognitive theory (Bandura 1997), ego depletion theory (Baumeister 2002), and perceptual control theory (Powers 1973). Utilizing the concept of resources, we tie these three theories together and explain a previously unexplained phenomenon in a sales context. Specifically, we suggest that resources, such as objects, personal characteristics, conditions, and energies that people value and strive to protect (Hobfoll 1989), can help build a person's self-efficacy. Yet resources can also engender a dark side of self-efficacy, namely decreased effort and/or increased opportunism.

The current research offers three primary theoretical contributions to the literature. First, to the best of our knowledge, all the self-efficacy research in sales report a positive correlation between self-efficacy and performance (e.g., Ahearne et al. 2005; Barling and Beattie 1983; Frayne and Geringer 2000). However, research in psychology, using the lens of perceptual control theory, suggests that there can be a downside of self-efficacy (e.g., Stirin Tzur et al. 2016; Vancouver et al. 2002). Our research provides support for perceptual control theory in a sales context by showing that high self-efficacy can engender complacency (Study 2), and complacency can hinder performance (Study 1).

Second, we argue that along with complacency, another undesirable effect of high selfefficacy may be opportunism. We also examine the mechanism behind this undesirable effect. We suggest that highly efficacious salespeople may engage in opportunism because of their lack of self-control. Drawing on ego-depletion theory, we argue that highly self-efficacious individuals are more resource depleted; therefore, they have limited will power or self-regulatory power left at their disposal. Moreover, the awareness of the social acceptability and/or the morality of many opportunistic behaviors is an attention consuming process that requires 
cognitive/mental resources. Therefore, highly efficacious salespeople (because of their reduced cognitive resources) may be more prone to give in to opportunism. Study 2 results suggest that salesperson self-efficacy is related negatively to salesperson self-control. Furthermore, Study 1 sugests that salesperson self-control is related negatively to salesperson opportunism. These results demonstrate that ego depletion theory can explain salesperson's opportunistic behavior. Third, we introduce the concept of "good stress" and "bad stress," which may affect a salesperson in different ways. Bad stress may impair the salesperson's capacity to engage in selfcontrol and thus, it contributes to opportunism. On the other hand, good stress may reduce complacency by compelling the salesperson to put forth more effort. The current research (Study 2) provides support for the existence of bad stress. Our research also reveals that there is possibility that good stress might also be there ${ }^{8}$. By exploring both positive and negative effects of stress, we believe the current research creates an opportunity for theory-building in the area of self-efficacy.

\section{Managerial Contributions}

As this is the first study to examine the potential negative effects of self-efficacy in a sales context, there are multiple managerial implications that arise from this study. Specifically, our research has managerial implications in at least four key areas: motivation, sales training, performance, and organizational culture. While it has long been suggested that highly selfefficacious salespeople perform better because of their increased effort (e.g., Sujan, Weitz, and Kumar 1994; Wang and Natameyer 2002), we provide managers with a new insight. In particular, we provide evidence that high self-efficacy can engender complacency, which may create a lack

\footnotetext{
${ }^{8}$ Although Study 2 results reveal a nonsignificant interaction, the direction of the interaction is in the hypothesized direction. We believe small numbers may have masked this effect in Study 2.
} 
of motivation toward performing a task. To avoid pitfall, managers could induce stress (i.e., good stress). Salespeople with a high level of self-efficacy would attribute stress to internal factors (e.g., lack of effort) and hence, would be less likely to fall into a complacency trap.

Managers should be cognizant that sales training may enhance self-efficacy, but training could also have deleterious effects on highly efficacious salespeople. By utilizing cognitive resources to develop and maintain self-efficacy, high self-efficacious salespeople have fewer cognitive resources to devote to controlling their actions. Their diminished self-control could lead to opportunism. Additional managerial controls (behavioral or output monitoring) may need to be put into place for high self-efficacious salespeople. Related to this, managers may reconsider the need for additional training for salespeople who exhibit high self-efficacy. High self-efficacious salespeople may not glean as much from training, yet it places additional demands on their cognitive load, which could exacerbate the potential dark side effects of self-efficacy.

In addition, this research has implications for salesperson performance. First, high selfefficacy may hinder performance because of complacency. Second, high self-efficacy may also hurt performance because of opportunism. Even though stress may reduce complacency, stress may engender opportunism by lowering self-control. Hence, managers should be cognizant about the fact that stress can be a double-edged sword.

Finally, our research provides insight regarding managerial and social support. Highly efficacious salespeople may think they don't need social support (e.g., support from coworkers or managers) because they consider themselves very knowledgeable and capable. Even when these salespeople are resource depleted due to their higher utilization of cognitive resources, they may be more reluctant to ask for support. As a result, highly efficacious salespeople are less likely to gain additional resources via external managerial and social support to replenish their resource 
loss. Managers could change this by creating an organizational culture that promotes managerial and peer support. A resource depleted salesperson (although highly efficacious) may seek support from coworkers and supervisors if he/she believes that the organizational culture is such that promotes care, empathy, and willingness to help.

\section{Limitations and Future Research}

The limitations of this research should be addressed. First, self-reported measures of selfefficacy, stress, self-control, and opportunism are used in Study 1. Extant research suggests that self-reported measures could create social desirability bias which may influence the results (Podsakoff and Organ 1986). We tried to mitigate this concern by conducting a lab experiment as our second study. In Study 2, self-efficacy and stress are manipulated, and opportunism is not self-reported. Second, the methodology in Study 1 is cross sectional in nature. Even though we designed an experiment to establish causality, future research may benefit from longitudinal studies that can provide further evidence of causality and/or explore how the effects of selfefficacy evolve over time.

Third, this research examines salesperson opportunism as a global construct without differentiating different types of opportunism. Past research suggests that "different forms of opportunism are capable of producing different outcomes" (Wathne and Heide 2000, p. 42). Seggie et al. (2013) provide empirical evidence that active opportunism (e.g., lying, breaching agreements, etc.) and passive opportunism (e.g., hiding information, not doing as promised, etc.) have different effects on performance. Future research should examine the effects of selfefficacy on both active and passive opportunism. It seems plausible that highly self-efficacious salespeople know how to engage in opportunism covertly to prevent being caught; hence, they may engage in passive opportunism more so than active opportunism. 
Finally, the experiment we conducted also has a limitation. We asked undergraduate students to role-play as salespeople. This may have elicited a lower level of respondent involvement than what would have happened if real salespeople were used. Also, the sample size was not sufficient in our lab experiment. This may have contributed to the lack of significant results. Future research should build off our research and conduct a larger scale experiment and/or longitudinal studies using salespeople in a field setting.

\section{Conclusion}

This dissertation is the first empirical exploration of the potential dark side effects of selfefficacy in a sales context. Using data from an online survey of salespeople and a lab experiment, the current research examines undesirable consequences (i.e., opportunism and complacency) of self-efficacy. This research provides important theoretical and managerial implications, yet additional research is needed to increase the generalizability of our findings and to build on extant theory. 


\section{REFERENCES}

Ahearne, M., Mathieu, J., \& Rapp, A. (2005). To empower or not to empower your sales force? An empirical examination of the influence of leadership empowerment behavior on customer satisfaction and performance. Journal of Applied psychology, 90(5), 945.

Ahearne, M., Rapp, A., Hughes, D. E., \& Jindal, R. (2010). Managing Sales Force Product Perceptions and Control Systemsinthe Success of New Product Introductions. Journal of Marketing Research, 47(4), 764-776.

Anaza, N. A., \& Nowlin, E. L. (2017). What's mine is mine: A study of salesperson knowledge withholding \& hoarding behavior. Industrial Marketing Management, 64, 14-24.

Anderson, E. (1988). Transaction costs as determinants of opportunism in integrated and independent sales forces. Journal of Economic Behavior \& Organization, 9(3), 247-264.

Anderson, J. C., \& Gerbing, D. W. (1988). Structural equation modeling in practice: A review and recommended two-step approach. Psychological bulletin, 103(3), 411.

Anderson, E., \& Oliver, R. L. (1987). Perspectives on behavior-based versus outcome-based salesforce control systems. Journal of Marketing, 51(4), 76-88.

Armstrong, J. S., \& Overton, T. S. (1977). Estimating nonresponse bias in mail surveys. Journal of marketing research, 14(3), 396-402.

Austin, Jon R. (1991), "An Exploratory Examination of the Development of Marketing Research Service Relationships: An Assessment of Exchange Evaluation dimensions," in AMA Summer Educators' Conferen (ce Proceedings. Chicago: American Marketing Association.

Avlonitis, G. J., \& Panagopoulos, N. G. (2006). Role stress, attitudes, and job outcomes in business-to-business selling: does the type of selling situation matter?. Journal of Personal Selling \& Sales Management, 26(1), 67-77.

Babin, B. J., \& Boles, J. S. (1996). The effects of perceived co-worker involvement and supervisor support on service provider role stress, performance and job satisfaction. Journal of retailing, 72(1), 57-75.

Bagozzi, R. P., \& Yi, Y. (1988). On the evaluation of structural equation models. Journal of the academy of marketing science, 16(1), 74-94.

Bagozzi, R. P., \& Yi, Y. (2012). Specification, evaluation, and interpretation of structural equation models. Journal of the academy of marketing science, 40(1), 8-34.

Bagozzi, R. P., \& Phillips, L. W. (1982). Representing and testing organizational theories: A holistic construal. Administrative science quarterly, 459-489.

Bandura (1986). The explanatory and predictive scope of self-efficacy theory. Journal of social and clinical psychology, 4(3), 359-373. 
Bandura (1989). Human agency in social cognitive theory. American psychologist, 44(9), 1175. Bandura (1997). Self-efficacy: The exercise of control: Macmillan.

Bandura and Jourden, F. J. (1991). Self-regulatory mechanisms governing the impact of social comparison on complex decision making. Journal of personality and social psychology, 60(6), 941.

Bandura and Locke, E. A. (2003). Negative self-efficacy and goal effects revisited. Journal of applied psychology, 88(1), 87.

Bandura, A. (1977). Self-efficacy: toward a unifying theory of behavioral change. Psychological review, 84(2), 191.

Bandura, A. (1999). Social cognitive theory of personality. Handbook of personality, 2, 154-196.

Barling, J., \& Beattie, R. (1983). Self-efficacy beliefs and sales performance. Journal of Organizational Behavior Management, 5(1), 41-51.

Baron, R. A., Mueller, B. A., \& Wolfe, M. T. (2016). Self-efficacy and entrepreneurs' adoption of unattainable goals: The restraining effects of self-control. Journal of business venturing, 31(1), $55-71$.

Barrick, M. R., Mount, M. K., \& Strauss, J. P. (1993). Conscientiousness and performance of sales representatives: Test of the mediating effects of goal setting. Journal of applied psychology, 78(5), 715.

Baumeister, R. F. (2002). Ego depletion and self-control failure: An energy model of the self's executive function. Self and identity, 1(2), 129-136.

Baumeister, R. F., Bratslavsky, E., \& Muraven, M. (1998). Ego depletion: Is the active self a limited resource?. In Self-Regulation and Self-Control (pp. 24-52). Routledge.

Baumeister, R. F., Vohs, K. D., \& Tice, D. M. (2007). The strength model of self-control. Current directions in psychological science, 16(6), 351-355.

Behrman, D. N., \& Perreault Jr, W. D. (1984). A role stress model of the performance and satisfaction of industrial salespersons. Journal of marketing, 48(4), 9-21.

Benight, C. C., \& Bandura, A. (2004). Social cognitive theory of posttraumatic recovery: The role of perceived self-efficacy. Behaviour research and therapy, 42(10), 1129-1148.

Berger, L., Klassen, K. J., Libby, T., \& Webb, A. (2013). Complacency and giving up across repeated tournaments: Evidence from the field. Journal of Management Accounting Research, 25(1), 143-167.

Bolander, W., Satornino, C. B., Hughes, D. E., \& Ferris, G. R. (2015). Social networks within sales organizations: Their development and importance for salesperson performance. Journal of Marketing, 79(6), 1-16. 
Boyer, D. A., Zollo, J. S., Thompson, C. M., Vancouver, J. B., Shewring, K., \& Sims, E. (2000). A quantitative review of the effects of manipulated self-efficacy on performance. In Poster session presented at the annual meeting of the American Psychological Society, Miami, FL.

Boyes, M. E., \& French, D. J. (2010). Neuroticism, stress, and coping in the context of an anagram-solving task. Personality and Individual Differences, 49(5), 380-385.

Brown, S. P., \& Peterson, R. A. (1994). The effect of effort on sales performance and job satisfaction. Journal of marketing, 58(2), 70-80.

Brown, S. P., Cron, W. L., \& Slocum Jr, J. W. (1998). Effects of trait competitiveness and perceived intraorganizational competition on salesperson goal setting and performance. Journal of Marketing, 62(4), 88-98.

Brown, S. P., Ganesan, S., \& Challagalla, G. (2001). Self-efficacy as a moderator of informationseeking effectiveness. Journal of applied psychology, 86(5), 1043.

Brown, S. P., Jones, E., \& Leigh, T. W. (2005). The attenuating effect of role overload on relationships linking self-efficacy and goal level to work performance. Journal of Applied Psychology, 90(5), 972.

Brownell, K. D., Marlatt, G. A., Lichtenstein, E., \& Wilson, G. T. (1986). Understanding and preventing relapse. American psychologist, 41(7), 765.

Bureau of Labor Statistics (2018). Sales occupations. Retrieved November 15, 2018 from https://www.bls.gov/ooh/sales/home.htm

Burns, T. R., \& Dietz, T. (2000). Human agency and evolutionary processes: Institutional dynamics and social revolution. Agency in social theory. Thousand Oaks, CA: Sage.

Cameron Montgomery, D., Blodgett, J. G., \& Barnes, J. H. (1996). A model of financial securities salespersons' job stress. Journal of Services Marketing, 10(3), 21-38.

Chelariu, C., \& Stump, R. (2011). A study of work-family conflict, family-work conflict and the contingent effect of self-efficacy of retail salespeople in a transitional economy. European Journal of Marketing, 45(11/12), 1660-1679.

Chemers, M. M. (1993). An integrative theory of leadership.

Chen, G., Gully, S. M., \& Eden, D. (2004). General self-efficacy and self-esteem: Toward theoretical and empirical distinction between correlated self-evaluations. Journal of Organizational Behavior: The International Journal of Industrial, Occupational and Organizational Psychology and Behavior, 25(3), 375-395.

Choi, N. (2005). Self-efficacy and self-concept as predictors of college students' academic performance. Psychology in the Schools, 42(2), 197-205.

Cholbi, M. (1996). The implications of ego depletion for the ethics and politics of manipulation. Philosophical Quarterly, 33(1), 44. 
Chowdhury, S. D., \& Lang, J. R. (1996). The decline of small firms: a preliminary investigation into the concept of complacency. Canadian Journal of Administrative Sciences/Revue Canadienne des Sciences de l'Administration, 13(4), 321-331.

Churchill Jr, G. A. (1979). A paradigm for developing better measures of marketing constructs. Journal of marketing research, 16(1), 64-73.

Clark, L. A., \& Watson, D. (1995). Constructing validity: Basic issues in objective scale development. Psychological assessment, 7(3), 309.

Cook, D., \& Beckman, T. (2006). Current concepts in validity and reliability for psychometric instruments: Theory and application. The American Journal of Medicine, 119(2), 7-16.

Cooper, C. L., Cooper, C. P., Dewe, P. J., O'Driscoll, M. P., \& O'Driscoll, M. P. (2001). Organizational stress: A review and critique of theory, research, and applications. Sage.

Cortina, J. M. (1993). What is coefficient alpha? An examination of theory and applications. Journal of applied psychology, 78(1), 98.

Crosno, J. L., \& Brown, J. R. (2015). A meta-analytic review of the effects of organizational control in marketing exchange relationships. Journal of the Academy of Marketing Science, 43(3), 297-314.

Dant, R. P., \& Gleiberman, A. (2011). Preventing and combating the onset of dark-side symptoms. Journal of Marketing Management, 27(13-14), 1426-1443.

Deadrick, D. L., \& Madigan, R. M. (1990). Dynamic criteria revisited: A longitudinal study of performance stability and predictive validity. Personnel Psychology, 43(4), 717-744.

Deci, E. L., \& Ryan, R. M. (2002). Overview of self-determination theory: An organismic dialectical perspective. Handbook of self-determination research, 3-33.

Deeter-Schmelz, D. R., \& Ramsey, R. P. (1997). Considering sources and types of social support: A psychometric evaluation of the House and Wells (1978) instrument. The Journal of personal selling and sales management, 49-61.

DeSimone, J. A., Harms, P. D., \& DeSimone, A. J. (2015). Best practice recommendations for data screening. Journal of Organizational Behavior, 36(2), 171-181.

DeVellis, R. F. (1991). Guidelines in scale development. Scale Development: Theory and Applications. Newbury Park, Calif: Sage, 5191.

Dixon, A. L., \& Schertzer, S. M. (2005). Bouncing back: How salesperson optimism and selfefficacy influence attributions and behaviors following failure. Journal of Personal Selling \& Sales Management, 25(4), 361-369.

Dobbins, G. H., Lane, I. M., \& Steiner, D. D. (1988). A note on the role of laboratory methodologies in applied behavioural research: Don't throw out the baby with the bath water. Journal of Organizational Behavior, 9(3), 281-286. 
Edwards, J. R., \& Bagozzi, R. P. (2000). On the nature and direction of relationships between constructs and measures. Psychological methods, 5(2), 155.

Evans, K. R., Landry, T. D., Li, P. C., \& Zou, S. (2007). How sales controls affect job-related outcomes: the role of organizational sales-related psychological climate perceptions. Journal of the Academy of Marketing Science, 35(3), 445-459.

Faber, R. J. (1992). Money changes everything: Compulsive buying from a biopsychosocial perspective. American Behavioral Scientist, 35(6), 809-819.

Fang, E., Palmatier, R. W., \& Evans, K. R. (2004). Goal-setting paradoxes? Trade-offs between working hard and working smart: The United States versus China. Journal of the Academy of Marketing Science, 32(2), 188-202.

Feltz, D. L. (2007). Self-confidence and sports performance. studies, 33(41), 50-66.

Field, A. (2009). Discovering statistics using SPSS. Sage publications.

Fornell, C., \& Larcker, D. F. (1981). Structural equation models with unobservable variables and measurement error: Algebra and statistics.

Fournier, C., Tanner Jr, J. F., Chonko, L. B., \& Manolis, C. (2010). The moderating role of ethical climate on salesperson propensity to leave. Journal of Personal Selling \& Sales Management, 30(1), 7-22.

Franke, G. R., \& Park, J. E. (2006). Salesperson adaptive selling behavior and customer orientation: a meta-analysis. Journal of marketing Research, 43(4), 693-702.

Frayne, C. A., \& Geringer, J. M. (2000). Self-management training for improving job performance: A field experiment involving salespeople. Journal of Applied Psychology, 85(3), 361.

Freeman, N., \& Muraven, M. (2010). Self-control depletion leads to increased risk taking. Social Psychological and Personality Science, 1(2), 175-181.

Friend, S. B., \& Johnson, J. S. (2017). Familiarity breeds contempt: perceived service and sales complacency in business-to-business relationships. Journal of Personal Selling \& Sales Management, 37(1), 42-60.

Frone, M. R., Russell, M., \& Cooper, M. L. (1995). Job stressors, job involvement and employee health: A test of identity theory. Journal of Occupational and Organizational Psychology, 68(1), 1-11.

Fu, F. Q. (2009). Effects of salesperson experience, age, and goal setting on new product performance trajectory: A growth curve modeling approach. Journal of Marketing Theory and Practice, 17(1), 7-20.

Fu, F. Q., Elliott, M. T., Mano, H., \& Galloway, C. (2017). The Role of Affective Brand Commitment on Sales Effort. Journal of Marketing Theory and Practice, 25(3), 257-273. 
Fu, F. Q., Richards, K. A., Hughes, D. E., \& Jones, E. (2010). Motivating salespeople to sell new products: The relative influence of attitudes, subjective norms, and self-efficacy. Journal of Marketing, 74(6), 61-76.

Gailliot, M. T., \& Baumeister, R. F. (2007). The physiology of willpower: Linking blood glucose to self-control. Personality and social psychology review, 11(4), 303-327.

Ganster, D. C., Fusilier, M. R., \& Mayes, B. T. (1986). Role of social support in the experience of stress at work. Journal of applied psychology, 71(1), 102.

Gardner, D. G., \& Pierce, J. L. (1998). Self-esteem and self-efficacy within the organizational context: An empirical examination. Group \& Organization Management, 23(1), 48-70.

Gino, F., Schweitzer, M. E., Mead, N. L., \& Ariely, D. (2011). Unable to resist temptation: How self-control depletion promotes unethical behavior. Organizational Behavior and Human Decision Processes, 115(2), 191-203.

Gist, M. E., \& Mitchell, T. R. (1992). Self-efficacy: A theoretical analysis of its determinants and malleability. Academy of Management review, 17(2), 183-211.

Golafshani, N. (2003). Understanding reliability and validity in qualitative research. The qualitative report, 8(4), 597-606.

Groza, M. D., \& Groza, M. P. (2018). Salesperson regulatory knowledge and sales performance. Journal of Business Research, 89, 37-46.

Hadi, A. S. (1992). Identifying multiple outliers in multivariate data. Journal of the Royal Statistical Society: Series B (Methodological), 54(3), 761-771.

Hagger, M. S., Wood, C., Stiff, C., \& Chatzisarantis, N. L. (2010). Ego depletion and the strength model of self-control: a meta-analysis. Psychological bulletin, 136(4), 495.

Hair, J. F., Anderson, R. E., Tatham, R. L., \& Black, W. C. (1998). Multivariate data analysis.

Hair, J. F., Black, W. C., Babin, B. J., Anderson, R. E., \& Tatham, R. L. (2006). Multivariate data analysis. Uppersaddle River.

Halbesleben, J. R. (2006). Sources of social support and burnout: a meta-analytic test of the conservation of resources model. Journal of applied Psychology, 91(5), 1134.

Hartmann, N. N., \& Rutherford, B. N. (2015). Psychological contract breach's antecedents and outcomes in salespeople: The roles of psychological climate, job attitudes, and turnover intention. Industrial Marketing Management, 51, 158-170.

Hayes, A. F. (2013). Methodology in the social sciences. Introduction to mediation, moderation, and conditional process analysis: A regression-based approach.

Heide, J. B., Wathne, K. H., \& Rokkan, A. I. (2007). Interfirm monitoring, social contracts, and relationship outcomes. Journal of marketing Research, 44(3), 425-433. 
Heider, F. (1958). The psychology of interpersonal relations. New York: John Wiley.

Hinkin, T. R. (1998). A brief tutorial on the development of measures for use in survey questionnaires. Organizational research methods, 1(1), 104-121.

Hobfoll, S. E. (1989). Conservation of resources: A new attempt at conceptualizing stress. American psychologist, 44(3), 513.

Holden, G. (1992). The relationship of self-efficacy appraisals to subsequent health related outcomes: A meta-analysis. Social work in health care, 16(1), 53-93.

Holden, G., Moncher, M. S., Schinke, S. P., \& Barker, K. M. (1990). Self-efficacy of children and adolescents: A meta-analysis. Psychological Reports, 66(3), 1044-1046.

Hsu, M. H., Ju, T. L., Yen, C. H., \& Chang, C. M. (2007). Knowledge sharing behavior in virtual communities: The relationship between trust, self-efficacy, and outcome expectations.

International journal of human-computer studies, 65(2), 153-169.

Hu, L. T., \& Bentler, P. M. (1999). Cutoff criteria for fit indexes in covariance structure analysis: Conventional criteria versus new alternatives. Structural equation modeling: a multidisciplinary journal, 6(1), 1-55.

Husted, B. W., \& Folger, R. (2004). Fairness and transaction costs: The contribution of organizational justice theory to an integrative model of economic organization. Organization Science, 15(6), 719-729.

Ingene, C. A., Brown, J. R., \& Dant, R. P. (Eds.). (2019). Handbook of Research on Distribution Channels. Cheltenham, UK: Edward Elgar Publishing.

Jap, S. D., \& Anderson, E. (2003). Safeguarding interorganizational performance and continuity under ex post opportunism. Management science, 49(12), 1684-1701.

Jaramillo, F., \& Mulki, J. P. (2008). Sales effort: The intertwined roles of the leader, customers, and the salesperson. Journal of Personal Selling \& Sales Management, 28(1), 37-51.

Jaramillo, F., Mulki, J. P., \& Solomon, P. (2006). The role of ethical climate on salesperson's role stress, job attitudes, turnover intention, and job performance. Journal of Personal Selling \& Sales Management, 26(3), 271-282.

John, G. (1984). An empirical investigation of some antecedents of opportunism in a marketing channel. Journal of marketing Research, 21(3), 278-289.

Johnson, J. S., \& Sohi, R. S. (2014). The curvilinear and conditional effects of product line breadth on salesperson performance, role stress, and job satisfaction. Journal of the Academy of Marketing Science, 42(1), 71-89.

Joosten, A., Van Dijke, M., Van Hiel, A., \& De Cremer, D. (2014). Being "in control" may make you lose control: The role of self-regulation in unethical leadership behavior. Journal of business ethics, 121(1), 1-14. 
Jöreskog, K., \& Sörbom, D. (2015). LISREL (Version 9.2).

Karatepe, O. M., \& Uludag, O. (2008). Role stress, burnout and their effects on frontline hotel employees' job performance: evidence from Northern Cyprus. International Journal of Tourism Research, 10(2), 111-126.

Kawall, J. (2006). On complacency. American Philosophical Quarterly, 43(4), 343-355.

Kinnear, T. C., \& Taylor, J. R. (1996). Marketing research: an applied approach. McGraw-Hill Companies.

Kohli, A. K. (1985). Some unexplored supervisory behaviors and their influence on salespeople's role clarity, specific self-esteem, job satisfaction, and motivation. Journal of Marketing Research, 22(4), 424-433.

Kolb, P., Gockel, C., \& Werth, L. (2012). The effects of temperature on service employees' customer orientation: An experimental approach. Ergonomics, 55(6), 621-635.

Krishnan, B. C., Netemeyer, R. G., \& Boles, J. S. (2002). Self-efficacy, competitiveness, and effort as antecedents of salesperson performance. Journal of Personal Selling \& Sales Management, 22(4), 285-295.

Kutner, M. H., Nachtsheim, C. J., Neter, J., \& Li, W. (2005). Applied linear statistical models (Vol. 5). New York: McGraw-Hill Irwin.

Lawshe, C. H. (1975). A quantitative approach to content validity 1. Personnel psychology, 28(4), 563-575.

Lee, C., \& Gillen, D. J. (1989). Relationship of Type A behavior pattern, self-efficacy perceptions on sales performance. Journal of organizational Behavior, 75-81.

Lent, R. W., \& Maddux, J. E. (1997). Self-efficacy: Building a sociocognitive bridge between social and counseling psychology. The Counseling Psychologist, 25(2), 240-255.

Lindell, M. K., \& Whitney, D. J. (2001). Accounting for common method variance in crosssectional research designs. Journal of applied psychology, 86(1), 114.

Little, T. D., Bovaird, J. A., \& Widaman, K. F. (2006). On the merits of orthogonalizing powered and product terms: Implications for modeling interactions among latent variables. Structural Equation Modeling, 13(4), 497-519.

Locke, E. A. (1986). Generalizing from laboratory to field settings: Research findings from industrial-organizational psychology, organizational behavior, and human resource management. Free Press.

Lunenburg, F. C. (2011). Self-efficacy in the workplace: Implications for motivation and performance. International journal of management, business, and administration, 14(1), 1-6.

MacKenzie, S. B., \& Podsakoff, P. M. (2012). Common method bias in marketing: causes, mechanisms, and procedural remedies. Journal of retailing, 88(4), 542-555. 
Maddux, J. E. (2016). Self-efficacy. In Interpersonal and Intrapersonal Expectancies (pp. 55-60). Routledge.

Maignan, I., \& Ferrell, O. C. (2001). Antecedents and benefits of corporate citizenship: An investigation of French businesses. Journal of Business Research, 51(1), 37-51.

Malhotra, N. K., Patil, A., \& Kim, S. S. (2007). Bias breakdown. Marketing Research, 19(1).

Mallin, M. L., \& Mayo, M. (2006). Why did I lose? A conservation of resources view of salesperson failure attributions. Journal of Personal Selling \& Sales Management, 26(4), 345357.

Marshall, G. W., \& Mowen, J. C. (1993). An experimental investigation of the outcome bias in salesperson performance evaluations. Journal of Personal Selling \& Sales Management, 13(3), 31-47.

Mathieu, J., Ahearne, M., \& Taylor, S. R. (2007). A longitudinal cross-level model of leader and salesperson influences on sales force technology use and performance. Journal of Applied Psychology, 92(2), 528.

Mayo, M., \& Mallin, M. L. (2010). The impact of sales failure on attributions made by" resource-challenged" and" resource-secure" salespeople. Journal of Marketing Theory and Practice, 18(3), 233-248.

McCormick, M. J. (2001). Self-efficacy and leadership effectiveness: Applying social cognitive theory to leadership. Journal of Leadership Studies, 8(1), 22-33.

Menguc, B., Auh, S., Yeniaras, V., \& Katsikeas, C. S. (2017). The role of climate: implications for service employee engagement and customer service performance. Journal of the Academy of Marketing Science, 45(3), 428-451.

Mogg, K., Mathews, A., Bird, C., \& Macgregor-Morris, R. (1990). Effects of stress and anxiety on the processing of threat stimuli. Journal of Personality and Social Psychology, 59(6), 1230.

Moritz, S. E., Feltz, D. L., Fahrbach, K. R., \& Mack, D. E. (2000). The relation of self-efficacy measures to sport performance: A meta-analytic review. Research quarterly for exercise and sport, 71(3), 280-294.

Mulki, J. P., \& Jaramillo, F. (2011). Workplace isolation: salespeople and supervisors in USA. The International Journal of Human Resource Management, 22(04), 902-923.

Mulki, J. P., Lassk, F. G., \& Jaramillo, F. (2008). The effect of self-efficacy on salesperson work overload and pay satisfaction. Journal of Personal Selling \& Sales Management, 28(3), 285-297.

Mullins, R. R., Ahearne, M., Lam, S. K., Hall, Z. R., \& Boichuk, J. P. (2014). Know your customer: How salesperson perceptions of customer relationship quality form and influence account profitability. Journal of Marketing, 78(6), 38-58.

Multon, K. D., Brown, S. D., \& Lent, R. W. (1991). Relation of self-efficacy beliefs to academic outcomes: A meta-analytic investigation. Journal of counseling psychology, 38(1), 30. 
Muraven, M., Tice, D., \& Baumeister, R. (1998). Self-control as limited resource: Regulatory depletion patterns. Journal of Personality and Social Psychology, 74(3), 774-789.

doi:10.1037/0022-3514.74.3.774

Nunnally, J. C. (1978). Psychometric Theory: 2d Ed. McGraw-Hill.

Nygaard, A., \& Dahlstrom, R. (2002). Role stress and effectiveness in horizontal alliances. Journal of Marketing, 66(2), 61-82.

Oaten, M., \& Cheng, K. (2005). Academic examination stress impairs self-control. Journal of social and clinical psychology, 24(2), 254-279.

Oster, G. (2018). Death by Complacency. Effective Executive, 21(1), 52-56.

Panagopoulos, N. G., \& Ogilvie, J. (2015). Can salespeople lead themselves? Thought selfleadership strategies and their influence on sales performance. Industrial Marketing Management, 47, 190-203.

Parasuraman, R., Molloy, R., \& Singh, I. L. (1993). Performance consequences of automationinduced'complacency'. The International Journal of Aviation Psychology, 3(1), 1-23.

Perdue, B. C., \& Summers, J. O. (1986). Checking the success of manipulations in marketing experiments. Journal of marketing research, 23(4), 317-326.

Peter, J. P. (1981). Construct validity: a review of basic issues and marketing practices. Journal of marketing research, 18(2), 133-145.

Podsakoff, P. M., \& Organ, D. W. (1986). Self-reports in organizational research: Problems and prospects. Journal of management, 12(4), 531-544.

Podsakoff, P. M., MacKenzie, S. B., \& Podsakoff, N. P. (2012). Sources of method bias in social science research and recommendations on how to control it. Annual review of psychology, 63, 539-569.

Podsakoff, P. M., MacKenzie, S. B., Lee, J. Y., \& Podsakoff, N. P. (2003). Common method biases in behavioral research: a critical review of the literature and recommended remedies. Journal of applied psychology, 88(5), 879.

Porter, L. W., Bigley, G. A., \& Steers, R. M. (2003). Motivation and work behavior.

Powers, W. T. (1991). Commentary on Bandura's" human agency.".

Powers, W. T. (1973). Behavior: The control of perception. New York: Hawthorne

Ramsey, R. P., \& Sohi, R. S. (1997). Listening to your customers: The impact of perceived salesperson listening behavior on relationship outcomes. Journal of the Academy of marketing Science, 25(2), 127. 
Rapp, A., Baker, T. L., Bachrach, D. G., Ogilvie, J., \& Beitelspacher, L. S. (2015). Perceived customer showrooming behavior and the effect on retail salesperson self-efficacy and performance. Journal of Retailing, 91(2), 358-369.

Reynolds, W. M. (1982). Development of reliable and valid short forms of the Marlowe-Crowne Social Desirability Scale. Journal of clinical psychology, 38(1), 119-125.

Rodgers, W. M., Markland, D., Selzler, A. M., Murray, T. C., \& Wilson, P. M. (2014). Distinguishing perceived competence and self-efficacy: An example from exercise. Research quarterly for exercise and sport, 85(4), 527-539.

Rogelberg, S. G., Stanton, J. M., \& Stanton, J. M. (2007). Understanding and dealing with organizational survey nonresponse-Introduction.

Rokkan, A. I., Heide, J. B., \& Wathne, K. H. (2003). Specific investments in marketing relationships: Expropriation and bonding effects. Journal of marketing research, 40(2), 210-224.

Rossiter, J. R. (2002). The C-OAR-SE procedure for scale development in marketing. International journal of research in marketing, 19(4), 305-335.

Sadri, G., \& Robertson, I. T. (1993). Self-efficacy and work-related behaviour: a review and meta-analysis. Applied Psychology, 42(2), 139-152.

Sager, J. K. (1994). A structural model depicting salespeople's job stress. Journal of the Academy of Marketing Science, 22(1), 74-84.

Sager, J. K., \& Wilson, P. H. (1995). Clarification of the meaning of job stress in the context of sales force research. Journal of Personal Selling \& Sales Management, 15(3), 51-63.

Schaefer, A. D., \& Burnett, M. S. (2014). Salesperson performance: exploring the roles of role ambiguity, autonomy and self-efficacy. EDITORIAL BOARD MEMBERS, 18(1), 99.

Schmeichel, B. J., Vohs, K. D., \& Baumeister, R. F. (2003). Ego depletion and intelligent performance: Role of the self in logical reasoning and other information processing. Journal of Personality and Social Psychology, 85, 33-46.

Schmidt, A. M., \& DeShon, R. P. (2010). The moderating effects of performance ambiguity on the relationship between self-efficacy and performance. Journal of applied psychology, 95(3), 572 .

Schrock, Wyatt (2016), "Sales-Oriented Competitiveness: Implications for Sales Managers", Doctoral Dissertation, Department of Marketing, Michigan State University.

Schunk, D. H. (1991). Self-efficacy and academic motivation. Educational psychologist, 26(3-4), 207-231.

Schwab, C. (1999). P-and Hp-Finite Element Methods: Theory and Applications in Solid and Fluid Mechanics (Numerical Mathematics and Scientific Computation). Clarendon Press, 21, 83. 
Schwepker Jr, C. H., \& Good, M. C. (2017). Reducing salesperson job stress and unethical intent: The influence of leader-member exchange relationship, socialization and ethical ambiguity. Industrial Marketing Management, 66, 205-218.

Schwepker, C. H., \& Good, D. J. (2011). Moral judgment and its impact on business-to-business sales performance and customer relationships. Journal of Business Ethics, 98(4), 609-625.

Schwepker, C. H., \& Ingram, T. N. (1996). Improving sales performance through ethics: The relationship between salesperson moral judgment and job performance. Journal of Business Ethics, 15(11), 1151-1160.

Seggie, S. H., Griffith, D. A., \& Jap, S. D. (2013). Passive and active opportunism in interorganizational exchange. Journal of Marketing, 77(6), 73-90.

Shadish, W. R., Cook, T. D., \& Campbell, D. T. (2002). Experimental and quasi-experimental designs for generalized causal inference.

Shipley, D. (1994). Achieving cross-functional co-ordination for marketing implementation. Management decision, 32(8), 17-20.

Shortridge-Baggett, L. M. (2002). The theory and measurement of the self-efficacy construct. Self-efficacy in nursing: Research and measurement perspectives, 9.

Singh, J. (1998). Striking a balance in boundary-spanning positions: An investigation of some unconventional influences of role stressors and job characteristics on job outcomes of salespeople. Journal of marketing, 62(3), 69-86.

Singh, J., Verbeke, W., \& Rhoads, G. K. (1996). Do organizational practices matter in role stress processes? A study of direct and moderating effects for marketing-oriented boundary spanners. Journal of marketing, 60(3), 69-86.

Singh, R., Kumar, N., \& Puri, S. (2017). Thought self-leadership strategies and sales performance: integrating selling skills and adaptive selling behavior as missing links. Journal of Business \& Industrial Marketing.

Sitzmann, T., \& Yeo, G. (2013). A meta-analytic investigation of the within-person selfefficacy domain: Is self-efficacy a product of past performance or a driver of future performance?. Personnel Psychology, 66(3), 531-568.

Sivadas, E., Bardi Kleiser, S., Kellaris, J., \& Dahlstrom, R. (2003). Moral philosophy, ethical evaluations, and sales manager hiring intentions. Journal of Personal Selling \& Sales Management, 23(1), 7-21.

Slochower, J., \& Kaplan, S. P. (1980). Anxiety, perceived control, and eating in obese and normal weight persons. Appetite, 1(1), 75-83.

Spector, P. E. (2019). Do Not Cross Me: Optimizing the Use of Cross-Sectional Designs. Journal of Business and Psychology, 34(2), 125-137. 
Stajkovic, A. D., \& Luthans, F. (1998). Self-efficacy and work-related performance: A metaanalysis. Psychological bulletin, 124(2), 240.

Stirin Tzur, K., Ganzach, Y., \& Pazy, A. (2016). On the positive and negative effects of selfefficacy on performance: Reward as a moderator. Human Performance, 29(5), 362-377.

Stone, D. N. (1994). Overconfidence in initial self-efficacy judgments: Effects on decision processes and performance. Organizational Behavior and Human Decision Processes, 59(3), $452-474$.

Sujan, H. (1986). Smarter versus harder: An exploratory attributional analysis of salespeople's motivation. Journal of Marketing Research, 23(1), 41-49.

Sujan, H., Weitz, B. A., \& Kumar, N. (1994). Learning orientation, working smart, and effective selling. Journal of marketing, 58(3), 39-52.

Sunder, S., Kumar, V., Goreczny, A., \& Maurer, T. (2017). Why do salespeople quit? An empirical examination of own and peer effects on salesperson turnover behavior. Journal of Marketing Research, 54(3), 381-397.

Tangney, J. P., Baumeister, R. F., \& Boone, A. L. (2004). High self-control predicts good adjustment, less pathology, better grades, and interpersonal success. Journal of personality, 72(2), 271-324.

Teas, R. K. (1983). Supervisory behavior, role stress, and the job satisfaction of industrial salespeople. Journal of marketing research, 20(1), 84-91.

Tice, D. M., Bratslavsky, E., \& Baumeister, R. F. (2001). Emotional distress regulation takes precedence over impulse control: If you feel bad, do it!. Journal of personality and social psychology, 80(1), 53.

Twenge, J. M., Tice, D. M., \& Baumeister, R. F. (2000). Decision fatigue: Making multiple personal decisions depletes the self's resources. Manuscript submitted for publication.

Vancouver, J. B., \& Kendall, L. N. (2006). When self-efficacy negatively relates to motivation and performance in a learning context. Journal of Applied Psychology, 91(5), 1146.

Vancouver, J. B., \& Purl, J. D. (2017). A computational model of self-efficacy's various effects on performance: Moving the debate forward. Journal of Applied Psychology, 102(4), 599.

Vancouver, J. B., Thompson, C. M., \& Williams, A. A. (2001). The changing signs in the relationships among self-efficacy, personal goals, and performance. Journal of applied psychology, 86(4), 605.

Vancouver, J. B., Thompson, C. M., Tischner, E. C., \& Putka, D. J. (2002). Two studies examining the negative effect of self-efficacy on performance. Journal of applied psychology, 87(3), 506. 
Vieira, V. A., Perin, M. G., \& Sampaio, C. H. (2018). The moderating effect of managers' leadership behavior on salespeople's self-efficacy. Journal of Retailing and Consumer Services, 40, 150-162.

Vohs, K. D., Baumeister, R. F., Schmeichel, B. J., Twenge, J. M., Nelson, N. M., \& Tice, D. M. (2014). Making choices impairs subsequent self-control: a limited-resource account of decision making, self-regulation, and active initiative.

Vroom V.H. (1995), Work and motivation. San Francisco : Jossey-Bass Publishers.

Vroom, V. H. (1964). Work and motivation (Vol. 54). New York: Wiley.

Walker Jr, O. C., Churchill Jr, G. A., \& Ford, N. M. (1975). Organizational Determinants of the Industrial Salesman's Role Conflict and Ambiguity: The right organizational structure and supervisory style can help salesmen understand their jobs, but they don't reduce the conflicts experienced by salesmen. Journal of Marketing, 39(1), 32-39.

Wang, G., \& Netemeyer, R. G. (2002). The effects of job autonomy, customer demandingness, and trait competitiveness on salesperson learning, self-efficacy, and performance. Journal of the Academy of Marketing Science, 30(3), 217-228.

Wang, G., \& Netemeyer, R. G. (2004). Salesperson creative performance: conceptualization, measurement, and nomological validity. Journal of Business Research, 57(8), 805-812.

Wathne, K. H., \& Heide, J. B. (2000). Opportunism in interfirm relationships: Forms, outcomes, and solutions. Journal of marketing, 64(4), 36-51.

Watt Adrienne (2019), Chapter 3 Characteristics and Benefits of a Database. Retrieved on July 19, 2019 from: https://opentextbc.ca/dbdesign01/chapter/chapter-3-characteristics-and-benefitsof-a-database/

Weiner, B. (1985). An attributional theory of achievement motivation and emotion. Psychological review, 92(4), 548.

Weiss, H. M. (1990). Learning theory and industrial and organizational psychology.

White, R. W. (1959). Motivation reconsidered: The concept of competence. Psychological review, 66(5), 297.

Wiesenfeld, B. M., Raghuram, S., \& Garud, R. (2001). Organizational identification among virtual workers: The role of need for affiliation and perceived work-based social support. Journal of management, 27(2), 213-229.

Williamson, O. E. (1975). Markets and hierarchies. New York, 2630.

Williamson, O. E. (1981). The economics of organization: The transaction cost approach. American journal of sociology, 87(3), 548-577.

Wilson, P. H., Strutton, D., \& Farris, M. T. (2002). Investigating the perceptual aspect of sales training. Journal of Personal Selling \& Sales Management, 22(2), 77-86. 
Wood, R., \& Bandura, A. (1989). Social cognitive theory of organizational management. Academy of management Review, 14(3), 361-384.

Wright, T. A., \& Hobfoll, S. E. (2004). Commitment, psychological well-being and job performance: An examination of conservation of resources (COR) theory and job burnout. Journal of Business \& Management, 9(4).

Yang, B., Kim, Y., \& McFarland, R. G. (2011). Individual differences and sales performance: A distal-proximal mediation model of self-efficacy, conscientiousness, and extraversion. Journal of Personal Selling \& Sales Management, 31(4), 371-381.

Zablah, A. R., Franke, G. R., Brown, T. J., \& Bartholomew, D. E. (2012). How and when does customer orientation influence frontline employee job outcomes? A meta-analytic evaluation. Journal of Marketing, 76(3), 21-40. 


\section{APPENDIX A}

\section{EFA Results for Study 1 (with all items)}

\begin{tabular}{|c|c|}
\hline Items & Factor Loadings \\
\hline \multicolumn{2}{|l|}{ Self-efficacy } \\
\hline I know the right thing to do in selling situations & .916 \\
\hline Overall, I am confident of my ability to perform my job well & .874 \\
\hline I feel I am very capable at the task of selling & .933 \\
\hline I feel I have the capabilities to perform my job successfully & .887 \\
\hline \multicolumn{2}{|l|}{ Role ambiguity } \\
\hline There are clear, planned goals and objectives for my job & .873 \\
\hline I know what my responsibilities are & .765 \\
\hline I know exactly what is expected of me & .891 \\
\hline The explanation is clear as to what has to be done & .872 \\
\hline \multicolumn{2}{|l|}{ Role overload } \\
\hline I do not have enough time to do what is expected of me in my job & .905 \\
\hline It often seems like I have too much for one person to do & .932 \\
\hline The performance standards on my job are too high & .595 \\
\hline I have too much work to do everything well & .905 \\
\hline The amount of work I am asked to do is unreasonable & .821 \\
\hline I never seem to have enough time to get everything done & .879 \\
\hline \multicolumn{2}{|l|}{ Role conflict } \\
\hline I sometimes have to bend a rule in order to carry out an assignment & .803 \\
\hline I often receive incompatible requests from two or more people & .766 \\
\hline I often receive an assignment without the manpower to complete it & .694 \\
\hline I often receive an assignment without adequate resources to execute it & .703 \\
\hline I do things that are accepted by one person and not accepted by others & .781 \\
\hline \multicolumn{2}{|l|}{ Self-control } \\
\hline Pleasure and fun sometimes keep me from getting work done & .697 \\
\hline I have trouble concentrating at work & .576 \\
\hline I have trouble concentrating at work & .531 \\
\hline I often act without thinking through all the alternatives & .615 \\
\hline I wish I had more self-discipline to carry out my job duties & .674 \\
\hline I get carried away by my feelings at work & .678 \\
\hline \multicolumn{2}{|l|}{ Opportunism } \\
\hline Sometimes, I alter the facts slightly in order to get what I need & .752 \\
\hline I sometimes promise to do things without actually doing them later & .761 \\
\hline Sometimes I sell things that are not a customer's best interest & .783 \\
\hline Sometimes I withhold or choose not to share important information & .823 \\
\hline \multicolumn{2}{|l|}{ Complacency } \\
\hline I do not waste time on learning new sales strategies & .694 \\
\hline I do not worry about the future of my relationships with my customers & .535 \\
\hline I do not see the need to make changes to my sales strategies & .831 \\
\hline I am satisfied with my selling skills & .501 \\
\hline I would not benefit from additional sales training & .784 \\
\hline Effort & \\
\hline
\end{tabular}




\begin{tabular}{|c|c|}
\hline Overall effort in the sales task & .732 \\
\hline Number of hours worked & .798 \\
\hline Number of sales calls made & .673 \\
\hline Amount of time spent communicating with the customers & .847 \\
\hline \multicolumn{2}{|l|}{ Performance } \\
\hline My level of quota/goal achievement during the past year is: & .846 \\
\hline My sales manager would rate my performance during the past year as*: & .770 \\
\hline My overall sales performance during the past year is: & .891 \\
\hline \multicolumn{2}{|l|}{ Conscientiousness (control) } \\
\hline I accomplish my work on time & .664 \\
\hline I do things according to a plan & .668 \\
\hline I am careful to avoid making mistakes & .616 \\
\hline I like to plan ahead & .730 \\
\hline I return borrowed items & .547 \\
\hline \multicolumn{2}{|l|}{ Output control (control) } \\
\hline Specific quantitative performance goals are established for my job & .661 \\
\hline $\begin{array}{l}\text { The extent to which I attain my quantitative performance goals is critically } \\
\text { evaluated }\end{array}$ & .733 \\
\hline If my quantitative performance goals are not met, I am required to explain why & .700 \\
\hline $\begin{array}{l}\text { Feedback concerning the extent to which I achieve the assigned goals is provided } \\
\text { to me on a regular basis }\end{array}$ & .530 \\
\hline My pay increases are based upon how my performance compares with my goals & .669 \\
\hline \multicolumn{2}{|l|}{ Process control (control) } \\
\hline The extent to which I follow established sales procedures is critically monitored & .759 \\
\hline The procedures used to accomplish a given selling task are explicitly regulated & .697 \\
\hline $\begin{array}{l}\text { My immediate boss modifies my work procedures when desired results are not } \\
\text { obtained }\end{array}$ & .749 \\
\hline $\begin{array}{l}\text { Feedback on the process I use to accomplish my performance goals is frequently } \\
\text { communicated to me }\end{array}$ & .746 \\
\hline \multicolumn{2}{|l|}{ Ethical ideology (control) } \\
\hline $\begin{array}{l}\text { Jeopardizing the well-being of customers is not necessary to achieve desired ends } \\
\text { in sales }\end{array}$ & .814 \\
\hline $\begin{array}{l}\text { Desirable sales outcomes are most frequently obtained by following an ethical } \\
\text { course of action }\end{array}$ & .811 \\
\hline An ethical course of action is always the best one a salesperson can take & .798 \\
\hline \multicolumn{2}{|l|}{ Social support (control) } \\
\hline Colleagues & .642 \\
\hline Direct supervisor & .855 \\
\hline Upper management & .862 \\
\hline
\end{tabular}




\section{APPENDIX B}

\section{Salesperson Survey - Study 1}

Self-efficacy (source: Fournier et al. 2010)

1. To what extent do you agree with the following statements ( $1=$ strongly disagree and $7=$ strongly agree):

- I know the right thing to do in selling situations.

- Overall, I am confident of my ability to perform my job well.

- I feel I am very capable at the task of selling.

- I feel I have the capabilities to successfully perform my job.

Role Conflict (source: Babin and Boles 1996, Mulki et al. 2008)

2. To what extent do you agree with the following statements (1=strongly disagree and $7=$ strongly agree):

- I sometimes have to bend a rule in order to carry out an assignment.

- I often receive incompatible requests from two or more people.

- I often receive an assignment without the manpower to complete it.

- I often receive an assignment without adequate resources to execute it.

- I do things that are accepted by one person and not accepted by others.

Role Ambiguity (source: Mulki et al. 2008)

3. To what extent do you agree with the following statements ( $1=$ strongly disagree and $7=$ strongly agree):

- There are clear, planned goals and objectives for my job.

- I know what my responsibilities are.

- I know exactly what is expected of me.

- The explanation is clear as to what has to be done.

Role Overload (Fournier et al. 2010)

4. To what extent do you agree with the following statements (1=strongly disagree and $7=$ strongly agree):

- I am given enough time to do what is expected of me in my job.

- It often seems like I have too much for one person to do.

- The performance standards on my job are too high.

- I have too much work to do everything well.

- The amount of work I am asked to do is reasonable. 
- I never seem to have enough time to get everything done.

Stress (source: Deeter-Schmelz and Ramsey 1997)

5. To what extent do you agree with the following statements ( $1=$ strongly disagree and $7=$ strongly agree):

- I feel a great deal of stress because of my job.

- Very few stressful things happen to me at work.

- My job is extremely stressful.

- I almost never feel stressed at work. (R)

Effort (source: Brown and Peterson 1994)

6. Please rate how you compare with all others in the company ( $1=$ "among the least in the company" and $7=$ "among the best in the company").

- Overall effort in the sales task.

- Number of hours worked.

- Number of sales calls made.

- Amount of time spent communicating with the customers.

Self-control (source: Tangney et al. 2004)

7. To what extent do you agree with the following statements (1=strongly disagree and $7=$ strongly agree):

- I sometimes say inappropriate things at work

- Pleasure and fun sometimes keep me from getting work done

- I have trouble concentrating at work

- I often act without thinking through all the alternatives

- I wish I had more self-discipline to carry out my job duties

- I get carried away by my feelings at work

Complacency (adapted from: Baker 2009)

8. To what extent do you agree with the following statements (1=strongly disagree and $7=$ strongly agree):

- I do not waste time on change initiatives

- I do not worry about the future of my relationship with the company

- I do not usually make any changes.

- I am satisfied with my selling skills

- I would not benefit from additional sales training 
Sales Performance (source: Brown and Peterson 1994)

9. Please rate how you compare with all others in the company ( $1=$ "among the least in the company" and $7=$ "among the best in the company").

- My level of quota / goal achievement during the past year is

- My sales manager would rate my performance during the past year as

- My overall sales performance during the past year is

Social Desirability (source: Reynolds 1982)

10. To what extent do you agree with the following statements ( $1=$ strongly disagree and $7=$ strongly agree):

- It is sometimes hard for me to go on with my work if I am not encouraged.

- I sometimes feel resentful when I don't get my way.

- On a few occasions, I have given up doing something because I thought too little of my ability.

- There have been times when I felt like rebelling against people in authority even though I knew they were right.

- No matter who I'm talking to, I'm always a good listener.

- There have been occasions when I took advantage of someone.

- I'm always willing to admit it when I make a mistake.

- I sometimes try to get even rather than forgive and forget.

- I am always courteous, even to people who are disagreeable.

- I never resent being asked to return a favor. 26. I have never been irked when people.

- There have been times when I was quite jealous of the good fortunes of others.

- I am sometimes irritated by people who ask favors of me.

- I have never deliberately said something that someone's feelings.

\section{Control variables}

Perceived Social Support (source: Wiesenfeld et al. 2001)

11. How much support do you think you are currently receiving from- Unsupportive (1) and supportive (7)

- Colleagues

- Direct supervisor

- Upper management 
Output Control (source: Evans et al. 2007)

12. To what extent do you agree with the following statements ( $1=$ strongly disagree and $7=$ strongly agree):

- Specific quantitative performance goals are established for my job.

- The extent to which I attain my quantitative performance goals is critically evaluated.

- If my quantitative performance goals were not met, I would be required to explain why.

- Feedback concerning the extent to which I achieve the assigned goals is provided to me on a regular basis.

- My pay increases are based upon how my performance compares with my goals.

Process Control (source: Evans et al. 2007)

13. To what extent do you agree with the following statements (1=strongly disagree and $7=$ strongly agree):

- The extent to which I follow established sales procedures is critically monitored.

- The procedures used to accomplish a given selling task are explicitly regulated.

- My immediate boss modifies my work procedures when desired results are not obtained.

- Feedback on how I accomplish my performance goals is frequently communicated to me.

Ethical Ideology (source: Sivadas et al. 2003)

14. To what extent do you agree with the following statements ( $1=$ strongly disagree and $7=$ strongly agree):

- Jeopardizing the well-being of customers is not necessary to achieve desired ends in sales.

- Desirable sales outcomes are most frequently obtained by following an ethical course of action.

- An ethical course of action is always the best one a salesperson can take.

- A universal code of ethics for sales can never be realized because what is right or wrong is up to each individual.

- Individuals within a company should be allowed to formulate their own code of ethics, because no one party can say what is right for every employee. 


\section{Marker Variable}

Blue Attitude (Miller \& Chiodo, 2008)

15. Please answer the following questions ( $1=$ not at all, $7=$ very $)$

- I prefer blue to other colors

- I like the color blue

- I like blue clothes

\section{Demographics}

16. What do you sell?

- Product

- Service

- Combination of product and service

17. How many different product lines and/or services do you sell?

18. How often do you receive mandatory sales training from your company?

- Not at all

- Rarely

- Sometimes

- Very often

19. How long have you been working in a sales?

20. How long have been with your current company?

21 . What is your job title?

22. Are you in Business-to-Business (B2B) or in Business-to-consumer (B2C) industry?

23. On average, how long (in days) does it take for you to close a sale (from initial customer contact to close)?

24. Please briefly write about your work responsibilities.

25 . What is your age.

26. Gender?

- Male

- Female

- Prefer not to answer 


\section{APPENDIX C}

\section{Sales Quiz}

1. Good customer discovery always focuses on asking
A. The customers about themselves
B. Open ended questions
C. Inquisitive questions
D. Yes or no questions

2. Brien is a salesperson for a payroll processing company. Brien has found that a few of his prospects provide objections even when they are confident the solution Brien is presenting will work and is worth the price. Which of the following best explains why these prospects object?
A. The prospects are resistant to change
B. The prospects want to slowdown the buying process
C. The prospects are awaiting better offers from competitors
D. All of the above

3. Objections mean that.

A. The customer wants to make your life harder

B. The customer is actually listening and wants to buy the product

C. Your presentation was not clear enough for the customer to understand

D. The customer is interested in relating how the product can work for his/her business

4. When the buyer says, "the price you want for your system is just too high," how should you respond?
A. Offer a discount if he/she buys the system today
B. Show him/her a lower-priced system
C. Tell him/her it is not high compared to competitors
D. Ask him/her why he/she thinks that and prove him/her wrong

5. When the buyer says, "I like this system, but it's got too many whistles and bells," how should you respond?
A. Ask what features he/she likes
B. Offer a discount if he/she buys the system today and offer a gift
C. Show him/her a lower price system
D. Explain that the manufacturer only offers accessories that market research shows that customers want

6. When the buyer says, "a customer objects that the system is not reliable, citing a friend's opinion," how should you respond?

A. Tell her that it is not a problem anymore and give her examples of how satisfied the current customers are (make it up if necessary)

B. Tell her the opinion does not affect the system she is buying 
C. Offer a discount if she buys the system today

D. Show understanding of her concern and show her current reliability data

7. What should you do when a customer puts an objection in front of you?
A. Try to change the subject
B. Try to prove the customer wrong
C. Tell the customer that this objection is applicable for anyone who is selling this product
D. None of the above

8. Managing objections
A. Can be mastered without practice
B. Does not require much patience
C. Is easy to learn
D. Is necessary to close a sale
E. None of the above

9. What is the most common reason for an objection?
A. Because there are doubts or unanswered questions in the mind of the prospect
B. Because the prospect wants to buy or is interested in buying, but needs clarification, wants a better deal, or must have a third-party approval
C. Because the prospect does not want to buy
D. You did a poor job in the presentation

10. Which objection is the most difficult to handle? When a prospect says:
A. We already work with a competitor
B. We don't have the budget
C. I have never heard of your company
D. I am not interested 


\section{APPENDIX D}

\section{Sales Task}

You are a sales representative of a software development company, Intrepid Tech. Your company wants to sell a database management software to an elementary school that has close to 300 students. This software will help the school administrators manage data better. This software will also allow a teacher to share a student's records with parents very efficiently. This software has other benefits as well, such as:

(1) minimizing data redundancy and data inconsistency,

(2) improving decision making by granting a quick access to information,

(3) generating customized reports for students,

(4) allowing many users to access the same database at the same time, and thus, maintaining data integrity, and

(5) accessing privileges. For example, a user might have read-only privilege (i.e., the ability to read a file but not edit it), while another might have read and write privileges, which is the ability to both read and edit a file (adapted from Watt 2019).

For this reason, a database management system should provide a security system to control different types of user accounts and restrict unauthorized access.

Your job is to sell this database management software to Sunshine Elementary School. You have done your research, and this school is a good prospect. However, this is a new product that your company developed, and this school is your first client. You will be negotiating with the procurement manager (i.e., the buyer), and you know that this person has the purchasing authority.

You might face objections from the buyer, but in order to get compensated you have to overcome the objection(s), convince the buyer, and finally, make the sale. Please remember that your compensation depends on your performance, specifically on "sealing the deal" and solving the anagrams.

You might face an objection that you did not anticipate. In that case, use your knowledge from the sales video to try to overcome the challenge. At times, thinking out-of-the-box helps. Use your judgement. Also, remember that this sale is very important to you because you want to show your manager your selling ability.

The price tag on this software is $\$ 6,000$, so at first ask for $\$ 6,000$. You can offer $5 \%$ discount if pushed (which would be $\$ 5,700$ ). However, there are two features (i.e., 24/7 tech support and enhanced data security) in the software that can be removed. If these two features are removed from the package, the price can be lowered (you could offer 10\% discount, which would be $\$ 5,400)$. The buyer does not know about these features. You cannot sell below this price. Remember, you must sell to be compensated. 


\section{APPENDIX E}

\section{Buying Task}

You are the procurement manager of Sunshine elementary School. Your school has close to 300 students and the number is increasing. You are in the market to buy a database management software that will help you systematically store and manage student information. You have heard good things about database management software in general. You know that you can easily share student records with parents, create customized reports and lower data inconsistency using a database management software.

However, your biggest concern is about data security and the protection of data. Specifically, you want to know from the seller what are the backup and recovery methods that would allow you to protect your data from loss.

You also have a limited budget, but you have the authority to make a decision.

You will be negotiating with a salesperson from Intrepid Tech, a software company that is offering you a customized database management software for your school. You have never heard of this company before, but you are ready to know all there is to know about this product.

Your task is to buy the software, but under certain conditions. You must ask the following:

- You must ask about the backup and recovery method to protect the loss of data

- You must ask about the company's other clients who bought database management software and their experience.

The maximum you can spend on this software is $\$ 5,400$. The less you spend the more you are compensated.

Please remember, you will be compensated only if you buy. 


\section{APPENDIX F}

\section{Salesperson Survey - Study 2}

Stress Appraisal (source: Boyes and French 2010)

1. You were asked to complete a set of anagrams while selling your product to the buyer. Please answer the following questions about the anagrams ( $1=$ not at all, $7=$ extremely)

- How stressed did you feel during the anagram task?

- To what extent did the anagram task make you feel overwhelmed?

- How anxious did you feel during the anagram task?

Role Conflict (adapted from: Mulki et al. 2008)

2. You were asked to complete a set of anagrams while selling your product to a customer. Now, please answer the following questions ( $1=$ strongly disagree, $7=$ strongly agree)

- It was difficult to complete both tasks.

- I did not have adequate resources to complete both tasks.

- I did not have enough time to complete both tasks effectively.

- I could not do both tasks simultaneously.

Role Overload (Fournier et al. 2010)

3. You were asked to complete a set of anagrams while selling your product to a customer. Now, please answer the following questions ( $1=$ strongly disagree, $7=$ strongly agree)

- I was NOT given enough time to do the sales task

- It often seemed like I had too much for one person to do

- I had too much work to do the sales task well

- The amount of work I was asked to do is unreasonable

Self-control in sales task (adapted from: Tangney et al. 2004)

4. Please answer the following questions ( $1=$ strongly disagree, $7=$ strongly agree)

- I said things that I should not have during the sales exchange (R)

- I had trouble concentrating during this sales task. (R)

- I often responded to the buyers without thinking through all the alternatives. (R)

Over all Self-control (adapted from: Tangney et al. 2004)

5. Please answer the following questions ( $1=$ strongly disagree, $7=$ strongly agree)

- I sometimes say inappropriate things at school

- Pleasure and fun sometimes keep me from getting schoolwork done

- I have trouble concentrating at school

- I often act without thinking through all the alternatives

- I wish I had more self-discipline to carry out my studies 
- I get carried away by my feelings at school

Effort (adapted from Brown and Peterson 1994)

6. You were asked to complete a set of anagrams while selling your product to a customer.

Now, please answer the following questions $(1=$ strongly disagree, $7=$ strongly agree $)$

- I put a lot of effort into answering the buyer's questions.

- I put a lot of effort into negotiating the sale.

- I put a lot of effort in completing the tasks.

- I put a lot of time in completing the tasks.

- I wrote a lot of messages in my attempt to make a sale.

Self-efficacy (source: Fournier et al. 2010)

7. Please answer the following questions $(1=$ strongly disagree, $7=$ strongly agree $)$

- I knew how to handle the buyer's objections.

- I felt very capable at the task of selling.

- I felt I had the skills to successfully make a sale.

- Overall, I was confident of my ability to sell.

Complacency (adapted from Baker 2009)

8. Please answer the following questions $(1=$ strongly disagree, $7=$ strongly agree $)$

- I did not waste time on learning new sales strategies.

- I did not see the need to make changes to my sales strategies.

- I was satisfied with my selling skills.

- I did not see the need to use my knowledge provided in the sales training video.

Performance (adapted from Schwepker and Good 2011)

9. Please answer the following questions ( $1=$ strongly disagree, $7=$ strongly agree $)$

- I was effective in handling the buyer's objections.

- I communicated information about my product to the buyer effectively.

- I negotiated with the buyer effectively.

- I used my sales time efficiently.

- Overall, I am satisfied with my performance.

Ethical Ideology (source: Sivadas et al. 2003)

10. To what extent do you agree with the following statements ( $1=$ strongly disagree and $7=$ strongly agree):

- Jeopardizing the well-being of buyers is not necessary to achieve desired ends in sales

- Desirable sales outcomes are most frequently obtained by following an ethical course of action

- An ethical course of action is always the best one a salesperson can take

11. What is your age? 
12. What is your gender?

- Male

- Female

- Prefer not to answer

13. Do you have a professional experience in sales?

- Full-time professional experience

- Part-time professional experience

- No experience

14. If you have a professional experience, please briefly describe your duties in the box below. 15. Have you taken any sales-related course?

- Yes

- No

16. If yes, which course:

- MKTG 320: Personal Selling I

- MKTG 321: Personal Selling II

- MKTG 345: Selling with Digital Media

- MKTG 420: Sales Management

- Other 


\section{APPENDIX G}

\section{Buyer Survey - Study 2}

Buyer Evaluation of the Salesperson performance (adapted from: Marshall and Mowen 1993)

1. Please rate the salesperson on the following: $(1=$ very unfavorable evaluation, $7=$ very favorable evaluation)

- Please rate the salesperson's sales ability.

- Rate the salesperson's overall job performance.

- Rate the salesperson's skill level.

Buyer Evaluation of the Salesperson effort (adapted from: Marshall and Mowen 1993)

2. Please rate the salesperson on the following: $(1=$ very unfavorable evaluation, $7=$ very favorable evaluation)

- The salesperson put a lot of effort into answering my questions.

- The salesperson put a lot of time into responding to my questions.

- The salesperson was trying hard to make a sale.

- Overall, the salesperson put a lot of effort into negotiating the sale.

Buyer Satisfaction with Salesperson (source: Ramsey and Sohi 1997)

3. Please answer the following questions ( $1=$ strongly disagree, $7=$ strongly agree).

- The amount of contact I have had with this salesperson was adequate.

- I am satisfied with the level of information this salesperson has provided.

- In general, I am pretty satisfied with my dealings with this salesperson.

Buyer Perception of Salesperson Opportunism (adapted from Jap and Anderson 2003)

Please indicate the degree to which you agree with the following statements: (1= Strongly Disagree, $7=$ Strongly Agree)

- The salesperson made hollow promises.

- The salesperson lied about the product.

- The salesperson provided false information.

- The salesperson withheld information.

Buyer Trust in Salesperson (source: Ramsey and Sohi 1997)

4. Please answer the following questions ( $1=$ strongly disagree, $7=$ strongly agree $)$.

- This salesperson was friendly.

- This salesperson was sincere.

- This salesperson was honest.

- I felt very little risk was involved when dealing with this salesperson.

5. Do you think that the salesperson was using some guileful techniques (e.g., lying, promising something that cannot be kept, etc.) to sell you the product? Please write your comments in the box below- 
6. What is your age?

7. What is your gender?

- Male

- Female

- Prefer not to answer

8. Do you have a professional experience in sales?

- Full-time professional experience

- Part-time professional experience

- No experience

9. If you have a professional experience, please briefly describe your duties in the box below.

10. Have you taken any sales-related course?

- Yes

- No

11. If yes, please indicate which course

- MKTG 320: Personal Selling I

- MKTG 321: Personal Selling II

- MKTG 345: Selling with Digital Media

- MKTG 420: Sales Management

- Other 


\section{Appendix H}

\section{High Stress Condition Anagrams}

Please remember that you need to complete at least three anagrams while performing the sales task in order to get compensated. Please use the pencil provided to you to solve the anagrams on this paper. You can also use the other side of the paper if you need more space. You have $\underline{12}$ minutes to solve the anagrams and complete the sales task.

\section{Participant Number:}

\begin{tabular}{|l|l|}
\hline 1. THWGIE & 2. VDAOCO \\
& \\
\hline 3. CATHERROS & 4. OLWGFNA \\
\hline 5. ORRYOMTDI & 6. GASLEVINET \\
& 9. KDNITE \\
\hline 9. GEITEWSRS & 10. ALLRGON \\
\hline
\end{tabular}




\section{Appendix I}

\section{Low Stress Condition Anagrams}

Please remember that you need to complete at least three (3) anagrams while performing the sales task in order to get compensated. Please use the pencil provided to you to solve the anagrams on this paper. You can also use the other side of the paper if you need more space. You have 12 minutes to solve the anagrams and complete the sales task.

\section{Participant Number:}

\begin{tabular}{|l|l|}
\hline 1. PJUM & 2. PEHL \\
\hline 3. IMWS & \\
\hline 5. WHOS & 4. AECK \\
\hline 7. INCE & 6. NGOS \\
\hline & 8. MILA \\
\hline & \\
\hline
\end{tabular}




\section{Appendix J}

\section{Example of Buyer-Seller Conversation in Chatplat}

\begin{tabular}{|c|c|c|}
\hline Time & User & Message \\
\hline $2 / 21 / 202017: 54$ & User 1 & $\mathrm{Hi}, \mathrm{I}$ am S-10 \\
\hline 2/21/2020 17:54 & User 2 & I am B-1 \\
\hline 2/21/2020 17:54 & User 2 & I am looking to buy new software for my school \\
\hline 2/21/2020 17:55 & User 1 & $\begin{array}{l}\text { Well I am glad to hear that B1, our software is premiere in offering } \\
\text { school administrations the best quality data management systems on } \\
\text { the market }\end{array}$ \\
\hline 2/21/2020 17:56 & User 1 & $\begin{array}{l}\text { We offer features to have teacher's share student records seamlessly } \\
\text { with the student's parents }\end{array}$ \\
\hline 2/21/2020 17:56 & User 1 & $\begin{array}{l}\text { as well as minimizing data redundancy and inconsistencies } \\
\text { That's good to hear, can you tell me more about your method for }\end{array}$ \\
\hline 2/21/2020 17:56 & User 2 & backup and recovery to protect the loss of data \\
\hline 2/21/2020 17:57 & User 1 & That's a great question B1 \\
\hline $2 / 21 / 202017: 57$ & User 1 & $\begin{array}{l}\text { I am always glad to hear my customers making good points } \\
\text { We have a } 24 / 7 \text { tech support as well as advanced data security }\end{array}$ \\
\hline 2/21/2020 17:58 & User 1 & $\begin{array}{l}\text { algorithms to ensure that your data is always safe } \\
\text { great! that is very important to us, since we have a lot of students }\end{array}$ \\
\hline 2/21/2020 17:59 & User 2 & information to keep secure and to transfer while they age. \\
\hline 2/21/2020 18:00 & User 2 & $\begin{array}{l}\text { How does the tech support work security-wise with information share } \\
\text { over the phone }\end{array}$ \\
\hline 2/21/2020 18:01 & User 1 & $\begin{array}{l}\text { We will be able to help you with any problems which may arise with } \\
\text { your system }\end{array}$ \\
\hline 2/21/2020 18:01 & User 1 & All information shared is confidential and safe \\
\hline 2/21/2020 18:01 & User 1 & so there is no need to worry about that \\
\hline 2/21/2020 18:02 & User 2 & $\begin{array}{l}\text { sounds good, that is a great thing to have! } \\
\text { What other clients have you worked with? How does it differ from an }\end{array}$ \\
\hline 2/21/2020 18:02 & User 2 & $\begin{array}{l}\text { Elementary school? } \\
\text { >> This chat has } 180 \text { seconds remaining before expiring. Please start }\end{array}$ \\
\hline 2/21/2020 18:02 & System & \\
\hline 2/21/2020 18:03 & User 2 & $\begin{array}{l}\text { Did they enjoy the experience, and do you still work with them now? } \\
\text { Our program works to seamlessly transfer data as students move up }\end{array}$ \\
\hline 2/21/2020 18:03 & User 1 & \\
\hline 2/21/2020 18:04 & User 1 & We foster long standing relationships with ou \\
\hline 2/21/2020 18:04 & User 2 & That is good to hear, what is your pricing for the software? \\
\hline 2/21/2020 18:04 & User 1 & Now \\
\hline 2/21/2020 18:04 & User 1 & starting price is at $\$ 6000$ \\
\hline $2 / 21 / 202018: 04$ & User 1 & ompetition \\
\hline 2/21/2020 18:05 & User 2 & $\begin{array}{l}\text { Oh, well that is a little steep for our budget right now, the other } \\
\text { company offered a lower price so not sure we could do the full } \$ 6000 \\
\text { *Chat Expired* }\end{array}$ \\
\hline
\end{tabular}




\section{Appendix K}

\section{Interaction Plots}
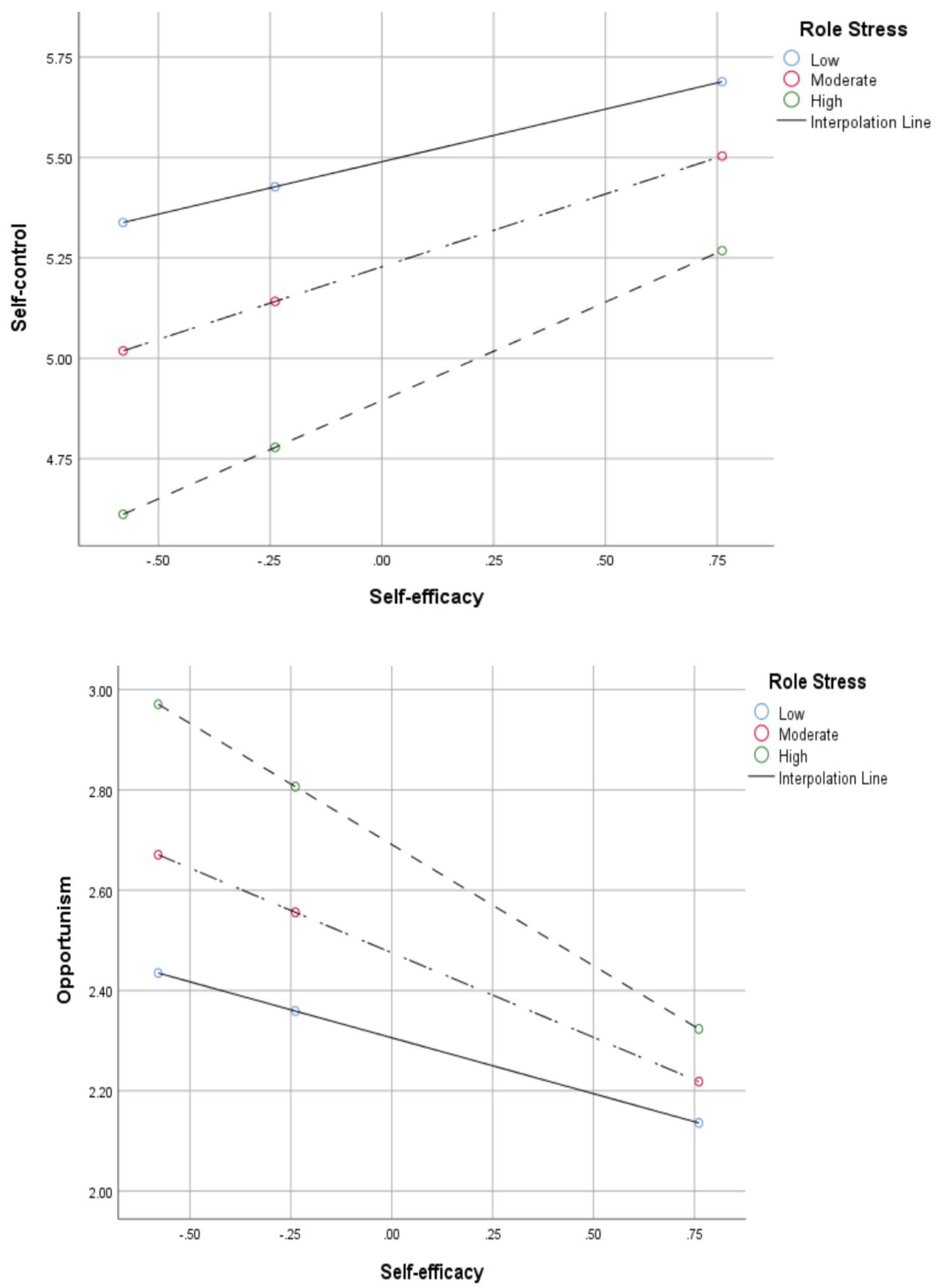